Portland State University

PDXScholar

12-14-1977

\title{
An Experimental Investigation of the Hole-drilling Technique for Measuring Residual Stresses in Welded Fabricated Steel Tubes
}

Chau Mong Tran

Portland State University

Follow this and additional works at: https://pdxscholar.library.pdx.edu/open_access_etds

Part of the Engineering Commons

Let us know how access to this document benefits you.

Recommended Citation

Tran, Chau Mong, "An Experimental Investigation of the Hole-drilling Technique for Measuring Residual Stresses in Welded Fabricated Steel Tubes" (1977). Dissertations and Theses. Paper 2574.

https://doi.org/10.15760/etd.2571

This Thesis is brought to you for free and open access. It has been accepted for inclusion in Dissertations and Theses by an authorized administrator of PDXScholar. Please contact us if we can make this document more accessible: pdxscholar@pdx.edu. 
AN ABSTRACT OF THE THESIS OF Chau Mong Tran for the Master of Science presented December 14, 1977.

Title: An Experimental Investigation of the Hole-drilling Technique for Measuring Residual Stresses in Welded Fabrlcated Steel Tubes.

APPROVED BY MEMBERS OF THE THESIS COMMITTEE:

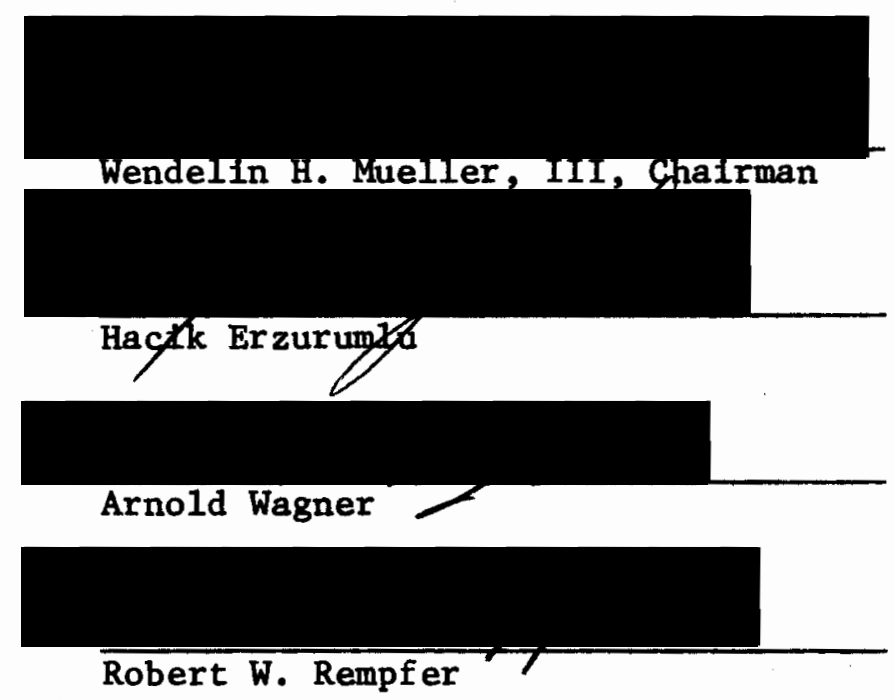

Among semi-destructive methods of measuring residual stresses in elastic materials, the blind hole-drilling strain-gage method is one of the best because it is simple, economical and accurate. It is based on the measurement of strains disturbed by machining a small diameter shallow hole in the test piece. The strains measured in three known directions permit the determination of the direction and magnitude of principal stresses and subsequently of any stress in any direction. This thesis presents the investigation of residual stresses in the longltudinal direction of a welded fabricated steel tube of 22 inch diameter, relating to a series of holes drilled In one half of a 
circular section of the tube. An initial assumption, substantiated later, was the existence of a uniform field of residual stresses through the thickness of the tube. Several methods for determining calibration coefficients are documented. The values of longitudinal stresses once computed are presented in a smooth curve. A straight line approximation is recommended for use in further studies of the effects of residual stresses on fallure loads. 
AN EXPERIMENTAL INVESTIGATION OF THE HOLE-DRILLING TECHNIQUE FOR MEASURING RESIDUAL STRESSES IN WELDED FABRICATED STEEL TUBES

$$
\text { by }
$$

CHAU MONG TRAN
A thesis submitted in partial fulfillment of the requirements for the degree of

\author{
MASTER OF SCIENCE \\ in \\ APPLIED SCIENCE
}

\author{
Portland State University \\ 1977
}


TO THE OFFICE OF GRADUATE STUDIES AND RESEARCH:

The members of the Committee approve the thesis of Chau Mong Tran presented December 14, 1977.

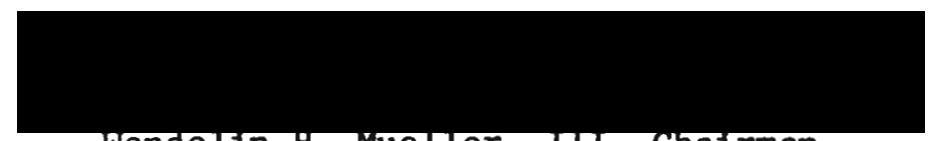

Wendelin H. Mueller, II, Chalrman
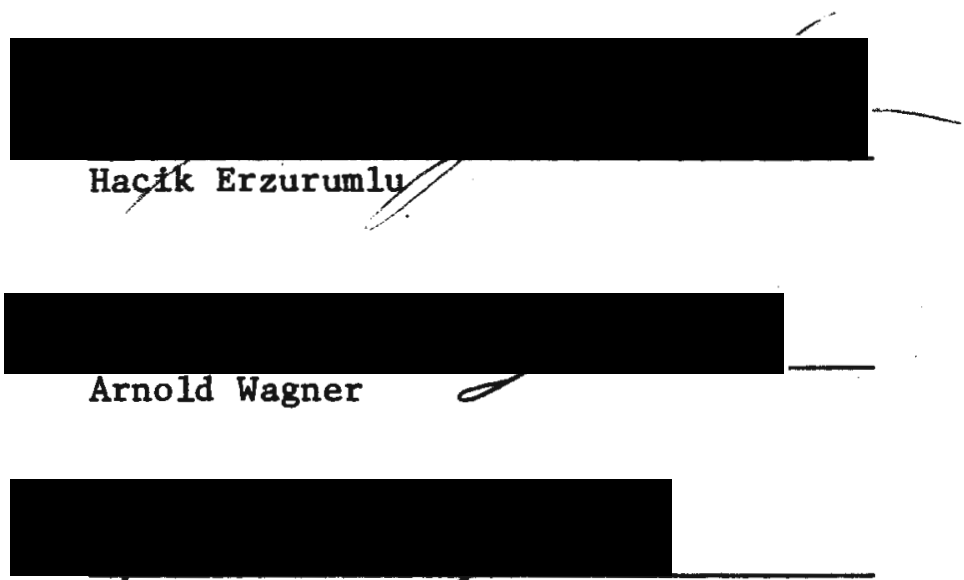

Robert W. Rempfer

APPROVED:

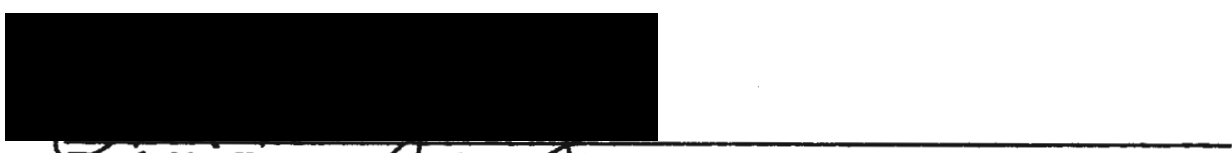

Tred M. Young, 䀚价, Engineering and Applied Science

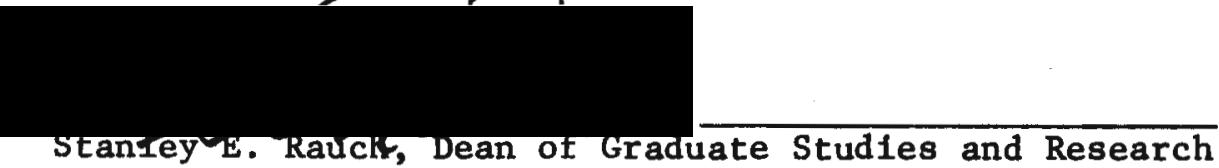




\section{IN LOVING MEMORY OF MY PARENTS, \\ OF MY PARENTS-IN-LAW, AND OF \\ MY FOSTER FATHER.}

TO MY FOSTER MOTHER,

TO MY BROTHER,

TO MY WIFE,

TO MY CHILDREN,

IO MY CHILDREN-IN-LAW. 


\section{ACKNOWLEDGMENTS}

This investigation was carrled out under the supervision of Dr. Wendelin H. Mueller. The author is deeply indebted to Dr. Mueller for his continued help, leadership and guldance throughout the course of this study. The author also wishes to express his grateful appreclation to the Englneering and Applied Sclence Department, especially the Civil-Structural Engineering Section.

The author would like to convey his warmest thanks to the other members of his thesis commlttee: Dr. Haclk Erzurumlu, Dr. Robert Rempfer and Mr. Arnold Wagner for thelr helpful comments and valuable suggestions.

Also, much apprectation is due to Dr. Franz N. Rad for his advice and suggestions. Special thanks are due to Mrs. Marjorle Terdal for help and encouragement.

The author would like to extend his appreclation to Mr. Thomas Gavin for his advice and encouragement and to Mr. Steve Barrett for his help in computer programming.

The help of Mr. Steve Speer throughout the physical testing is also acknowledged and appreciated. Thanks are also due to Mrs. Donna Mikulic for typing this thesis.

Finally, the author would like to thank his wife, Mrs. Tran Th1 Ngo for her Interest and encouragement throughout the author's graduate work, his children and children-in-law for their encouragement. 
TABLE OF CONTENTS

PAGE

ACKNOWLEDGEMENTS $\ldots \ldots \ldots \ldots \ldots \ldots \ldots \ldots \ldots \ldots \ldots \ldots \ldots \ldots \ldots \ldots \ldots \ldots \ldots$ Iv

LIST of TABLES $\ldots \ldots \ldots \ldots \ldots \ldots \ldots \ldots \ldots \ldots \ldots \ldots \ldots \ldots \ldots \ldots \ldots \ldots \ldots$

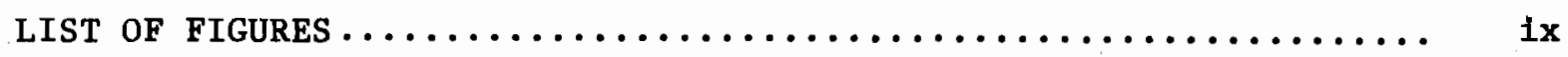

LIST OF SYMBOLS $\ldots \ldots \ldots \ldots \ldots \ldots \ldots \ldots \ldots \ldots \ldots \ldots \ldots \ldots \ldots \ldots \ldots \ldots$

CHAPTER

I INTRODUCTION $\ldots \ldots \ldots \ldots \ldots \ldots \ldots \ldots \ldots \ldots \ldots \ldots \ldots \ldots \ldots$

1.1 Review of Literature..................... 1

1.2 Objective of This Investigation............. 4

1.3 Organization of the Report................ 5

II ANALYTICAL APPROACH..................... 7

2.1 General Considerations................... 7

2.2 Hole-drılling Method................... 8

2.2.1 Presentation of the Method

2.2.2 Terminology of Stresses and Mathematica1

Expressions

2.2.3 Measuring strains using the strain gage rosette

2.2 .4 Limft of strains for $D / D_{0}=1.0$

2.2.5 Variation in residual stress field

2.3 Determination of calibration coefficients by experimental method.....................

2.3.1 Determination of calibration coefficients by the method of strain relaxation due to drilling

2.3.2 Determination of calibration coefficients by method of strain separation 
2.3.3 Experiment of tensioning a steel plate specimen for callbration

2.4 Computer Programs.

2.4.1 Calculation of $\sigma_{1}$ and $\sigma_{2}$ When Strains

in 3 Directions are Known

2.4.2 Calculation of $\sigma_{\mathrm{L}}$ and $\sigma_{\mathrm{T}}$ When Strains

in 3 Directions are Known

2.4.3 Calculation of $\varepsilon_{\mathrm{L}}$ and $\varepsilon_{\mathrm{T}}$ When Strains

in 3 Directions are known

III EXPERIMENTAL PROGRAM ...................... 23

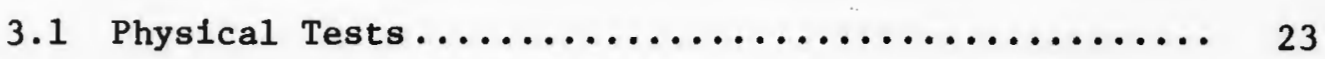

3.1.1 Drilling Outside Holes

a) Material and Gages

b) Apparatus

c) Experimental set Up

d) Validity of Results and Remarks

3.1.2 Drilling Inside Holes

3.1.3 Experiment of Tensioning and Drilling Holes on a Steel Plate Specimen

a) Material and Gages

b) Apparatus

c) Experimental Set Up

3.2 Test Results..........................

3.2.1 Results From Hole Drilling Experiment Evaluation of Results

a) Remarks

b) Varlation in stress field

3.2.2 Tensioning and Calibration Experiment

a) Results of the Test

b) Computation of the Modulus of elasticity

c) Results from Method of Strain-Relaxation

d) Results from Method of Strain Separation

e) Summary of results

f) Application of Calibration Coefficients to Tube Data

VI BALANCE OF FORCES AND MOMENTS .................

4.1 Balancing Forces and Moments of results using

analytically derived calibration coefficients.......

4.1.1 Analytica1 Approach

a) Pattern of longitudinal Residual

Stress Distribution 
b) Area and Center of Gravity

c) Application to Tube Data

d) Dimensions and Values for Summation of Forces and Moments

\subsubsection{Flow Diagram \\ 4.1.3 Computer Program \\ 4.1.4 Results of the computer program}

4.2 Evaluation of results

V SUMMARY, CONCLUSIONS AND RECOMMENDATIONS ........... 107

5.1 Summary of Results.................... 107

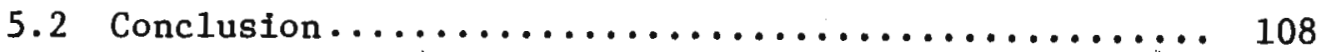

5.3 Recommendations........................ 110

REFERENCES $\ldots \ldots \ldots \ldots \ldots \ldots \ldots \ldots \ldots \ldots \ldots \ldots \ldots \ldots \ldots \ldots \ldots \ldots \ldots \ldots \ldots$

APPENDIX I $\ldots \ldots \ldots \ldots \ldots \ldots \ldots \ldots \ldots \ldots \ldots \ldots \ldots \ldots \ldots \ldots \ldots \ldots \ldots \ldots \ldots$

APPENDIX II ................................... 119

APPENDIX III.................................. 121

APPENDIX IV $\ldots \ldots \ldots \ldots \ldots \ldots \ldots \ldots \ldots \ldots \ldots \ldots \ldots \ldots \ldots \ldots \ldots \ldots \ldots \ldots \ldots$

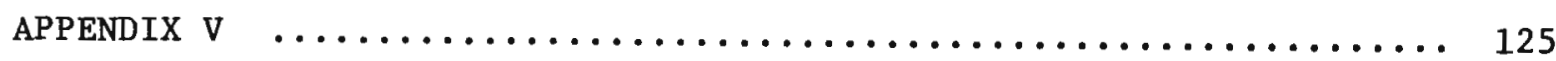

APPENDTX VI $\ldots \ldots \ldots \ldots \ldots \ldots \ldots \ldots \ldots \ldots \ldots \ldots \ldots \ldots \ldots \ldots \ldots \ldots \ldots \ldots \ldots$

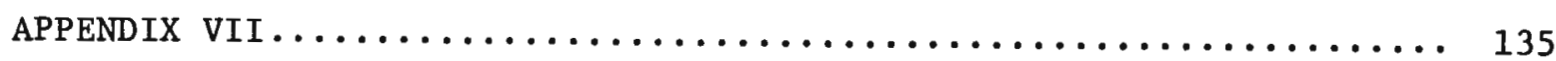

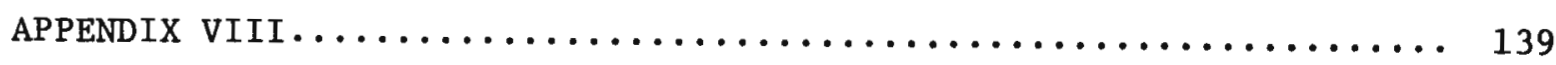

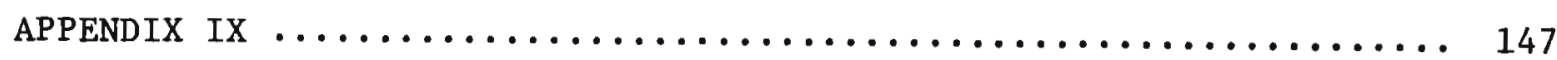

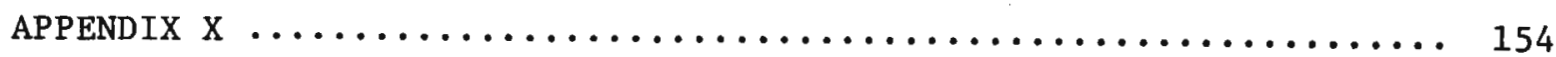

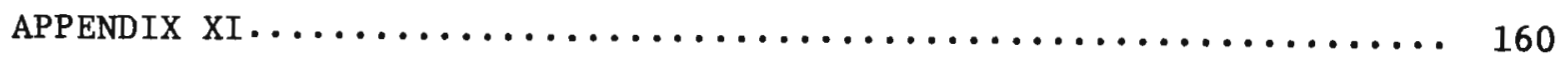


LIST OF TABLES

TABLE

PAGE

3.1 Experiment of Outside Hole Drilling

Results for Hole 1 .

3.2 Experiment of Outside Hole Drilling (continued)

3.3 Experiment of Outside Hole Drilling Data and Results for 11 Holes.

3.4 Experiment of Inside Hole Drilling Results for Four Holes $\quad 58$

3.5 Values of factors of proportionality $\quad 62$

3.6 Data from a non-uniform stress field 64

$\begin{array}{lll}3.7 & \text { Results of application to tube data } & 67\end{array}$

3.8 Experiment of Tensioning and Calibration Data from Strain-Relaxation Method 68

3.9 Experiment of Tensioning and Calibration Data from Method of strain separation

3.10 Values of $4 \mathrm{~A}$ and $4 \mathrm{~B}$ computed by curves from Figure 2.3

3.11 Recapitulation of $4 \mathrm{~A}$ and $4 \mathrm{~B}$ Values

3.12 Results with Computed Data Reduction Coefficients

3.13 Results from Method of Strain-Relaxation Due to Drilling

3.14 Results from Method of Strain separation

4.1 Results of Force and Moment Balance 
LIST OF FIGURES

FIGURE

PAGE

2.1 Radial and tangential strains 9

2.2 Position of gage with respect to principal stress 9

2.3 Data reduction coefficients $4 \mathrm{~A}$ and $4 \mathrm{~B}$

2.4 Strain-relaxation due to drilling 19

2.5 Strain separation 19

$\begin{array}{lll}3.1 & \text { Steel tube } & 25\end{array}$

$\begin{array}{lll}3.2 & \text { Strain gage rosette } & 25\end{array}$

$\begin{array}{lll}3.3 & \text { Milling gulde } & 28\end{array}$

$\begin{array}{lll}3.4 & \text { Strain indicator } & 28\end{array}$

3.5 Strain Indicator, rear view 29

3.6 Location of hole section 31

3.7 Position of drilled holes 31

$3.8 \quad$ Rosette pattern enlarged 33

3.9 Orientation or rosette gages 33

3.10 Adjustable swivel feet 35

3.11 Milling bar $\quad 35$

3.12 Drilling set up 36

3.13 Drilling under action 36

3.14 Set up for drilling inside hole 39

$\begin{array}{lll}3.15 & \text { Cementing swivel feet } & 39\end{array}$

3.16 Alignment set up before drilling $\quad 40$

3.17 Inside hole drilling under action 41

3.18 Shape of the steel plate specimen and
position of gages

3.19 Material Testing System (MTS) 44 
$\begin{array}{lll}3.20 & \text { M T S with load cell } & 44\end{array}$

3.21 Gage A for a residual stress check 45

3.22 Hole in gage A under drilling 45

3.23 Setting test piece in the jaws of the MTS 47

3.24 Hole in gage B under drilling 49

3.25 Reference gage at left hand side $\quad 49$

3.26 Strain separation for Direction 1 with numerical application

3.27 Strain relieved vs depth 59

3.28 Curve of inftial values of measured longitudinal residual stresses

3.29 Curve of longitudinal residual stresses recalculated with new data reduction coefficients

3.30 Curve of longitudinal residual stresses computed from strain-relaxation method

3.31 Curve of longitudinal residual stresses computed from the method of strain separation

4.1 Pattern of distribution of longitudinal residual stresses

4.2 Segmental division for preparing data for the computer program

4.3 Area and center of gravity. Case 1.

$4.4 \quad$ Case 2

4.5 Case 3

4.6 Case 4

4.7 Case 5

4.8 Case 6

4.9 Sketch of a three dimensional representation of the tube and an element of area of forces 
4.11 Sketch of a volume of forces 95

4.12 Flow diagram

5.1 Curve of residual stresses by hole-drilling method (solid line) and curve by method of sectioning (dashed line)

5.2 Ross and Chen simplified curve by sectioning method and simplified curve by hole drilling method

A.6.1 Stress Mohr's circle

A.7.1 Strain Mohr's circle 136

A.11.1 Polygonal line and smooth continuous curve representing residual stresses, Table 3.11 , Case 1

A.11.2 Polygonal line inscribed in continuous curve to define elementary areas of forces

A.11.3 Conversion of tube data to input for the computer program 


\section{LIST OF SYMBOLS}

4A Data reduction coefficient or calibration coefficient

4B Data reduction coefficient or calibration coefficient (for minimum principal stress)

D Difference of strains, $\varepsilon_{a}-\varepsilon_{c}$

d Outside diameter of the steel tube

$d_{1} \quad$ Inside diameter of the steel tube

E Modulus of elasticity

I Moment of inertia

$M_{y} \quad$ Bending moment at first yield

P Axial load

Py Axial load caustng complete yielding of the cross-section

R Distance of the gage to hole center

$R_{0} \quad$ Radius of the drilled hole

$r \quad R / R_{0}$, ratio of $R$ to $R_{0}$

S Sum of strains, $\varepsilon_{a}+\varepsilon_{c}$

s Section modulus

t Thickness

$\alpha \quad$ Angle of longitudinal stress to principal stress $\sigma_{1}$

$\beta \quad$ Angle of direction (gage) a to principal stress $\sigma_{1}$

E Strain measured by gage a

$E_{b} \quad$ Strain measured by gage $b$

$E_{c} \quad$ Strain measured by gage $c$

$\varepsilon_{L} \quad$ Longitudinal strain

$\varepsilon_{\mathrm{T}} \quad$ Transverse strain

$\sigma_{1} \quad$ Principal stress, maximum 
xiii

$\begin{array}{ll}\sigma_{2} & \text { Principal stress, minimum } \\ \sigma_{\mathrm{L}} & \text { Longitudinal residual stress } \\ \sigma_{\mathrm{T}} & \text { Circumferential or transverse residual stress } \\ \sigma_{\mathrm{y}} & \text { Yield stress }\end{array}$


CHAPTER I

\section{INTRODUCTION}

\subsection{REVIEW OF LITERATURE}

In many occurrences, one of the predominant factors contributing to structural failures and fatigue in welded parts, pipes, rolled structural shapes and finfshed structures, is the residual stresses which existed in the part before being put into service. These stresses are introduced either by the Initial imperfections in fabrication or during the manufacturing processes due to the operations of casting, molding, laminating, heat treating, cold or hot rolling, machining or welding. In other instances, residual stresses can appear due to installation procedures or the dead weight of the structure. In general, residual stresses tend to reduce the strength In stability, fatigue and fracture $(7,13,14)$; In some situations, however, their existence might improve the strength $(13,14)$. Consequently, knowledge of the distributions and magnitude of the residual stresses is a necessary prelude to any analytical investigation of the effects of these stresses on the behavior of the structure.

The directions and magnitudes of these stresses can be determined by several methods:

- Methods termed "destructive" consist of removing metal by machining, slicing $(5,7)$ grinding or etching and measuring elastic strains of the remaining section.

In 1888, Lalakoutsky (7) reported on a "sectioning method" to determine longitudinal stresses in steel bars by slicing longitu- 
dinal strips from the bar and measuring their change in length. The other methods are based on similar principles. That is the internal stresses are relleved or changed when the specimen is reduced to strips or pieces of smaller cross-section. The test piece submitted to the experiment of one of these methods, is unusable in its original configuration and thus the method is termed destructive.

Non-destructive or $x$-ray methods are based on the princlple of modification of the texture of metal grains revealed by $x$-rays. The results are correlated to the texture of the same metal under known stress conditions. Internal stresses present in the metal piece are finally determined.

Semi-destructive methods consist of machining a shallow hole in a test piece by means of a rotating cutter or an abrasive jet, and of measuring the strains disturbed in three directions by a strain-gage rosette: the stresses present in the test plece, for any direction around the hole, are computed from these strains.

Because of the complexity of their use, the slicing techniques have become less acceptable.

Using $x$-ray does not lend itself to field conditions and stresses can be detected only in the surface layer to a depth of one thousandth of an inch.

The two hole-drilling methods attempt to minimize the disadvantages of the previous discussed methods.

The "Abrasive Jet Machining" method consists of directing a controlled stream of gas containing fine abrasive particles against a workpiece to chip away tiny particles of material making a small hole. 
The strains relieved are measured by means of a strain-gage and internal stresses relaxed around the drilled hole can be calculated. However, because the "Abrasive Jet Machining" method (2) requires costly equipmentthe hole-drilling or hole-relaxation method, consisting of drilling a hole In the test piece by means of a rotating cutter and of measuring the strains relleved with a strain-gage, was used in this study. Both are termed "semi-destructive", because the amount of metal removed is sma11. The part itself once drilled for the disturbed strains can be repaired by means of a rivet or a plug and recovers the integrity of its strength and properties.

The drilling method was first concelved by G. Sachs (6) who, In 1927, worked with specially shaped pieces (e.g., those with round or rectangular cross-sections). In 1932, Josef Mathar In Germany $(1,3)$ developed the technique and measured the deformations around the drilled hole by means of a mechanical extensometer. HIs apparatus has been subject to criticlsm, because the vibrations during drilling cause the strain readings to be unsteady and irregular. The use of the method developed by Mathar is restricted to cases where the stresses are considered to be uniform through the thickness.

In 1948, Soete in Belgium (1) improved the technique and extended its use to cases of non-uniform stress field.

During the evolution of the hole-drilling technique the strains relieved were at first measured by an extensometer (1) then by some photoelastic materials bonded to the specimen surface or by a brittle lacquer sprayed on 1ts surface $(2,10)$. Finally, in the present time, bonded resistance wire strain gages constitute the most widely used 
process of strain measurement $(2,10,12)$. The combined method - hole drilling and strain gage - finds its use in most work, because of its simplicity, ease of strain measurement and stress calculation and its higher precision. In fact, it has been proven in a specific job that the hole-drilling method needs only 10 man hours, where as the layer removal method requires about 70 to 80 man hours (1), the former saves at least 85 per cent of labor and time.

In spite of its numerous advantages, the hole-drilling method shows two relatively unfavorable conditions:

a) Difficulty of obtaining a perfect alignment of the drilled hole with respect to the strain gages (problem of centering the drill bit in a gage rosette).

b) Spot residual stresses introduced during drilling.

The first disadvantage can be avolded by using a commercial fixture: a precision milling guide capable of centering the hole to the center of the rosette within \pm 0.001 inch.

A method of determining the effect of the spot residual stresses caused by drilling, described in detail in paragraph 2.3 .1 overcomes the second shortcoming. The spot residual stresses introduced during drilling, although measured at the same time by the strain gage, are separated from the stresses of interest by the use of calibration coefficients.

\subsection{OBJECTIVE OF THIS INVESTIGATION}

The purpose of this investigation is to study longitudinal residual stresses present in a welded fabricated steel tube, to 
determine their magnitudes and distributions along a semi-circular cross-section and to check the correctness of measurements by a test of statical equilibrium of the stress distribution. The tube chosen was 5/16 inch thick, 22 inches in diameter and 6 feet long.

The following outlines the two major steps in determining residual stresses:

1) Drilling holes on the outside and inside surfaces, in one half of a circular section of the tube, two feet from the edge, then measuring the strains by means of strain gage rosettes, calculating the corresponding longltudinal stresses using the calibration coefficients determined in Step 2, and plotting these stresses in a curve.

2) Performing experiments of calibration. The first one is conducted according to a calibration process of strain-relaxation due to drilling: a plate specimen is submitted to a known applied tension, then a hole is drilled in the plate. The strain due to the applied stress and the strain induced by the drilling are measured. This calibration yields the first pair of calibration coefficients.

The second experiment is carried out according to a calibration process of separating strains and consequently the induced stresses and applied stresses. This experiment gives the second pair of calibration constants.

In the calibration study, a steel plate was used having the same general characteristics as the steel tube.

\subsection{ORGANIZATION OF THE REPORT}

The following is a documentation of longitudinal residual 
stresses present in a welded fabricated steel tube.

The hole-drilling method was used in the experiment of drilling outside and Inside of a semi-circular section of a full steel tube. Calibration coefficients were determined through experiments of preloading a steel plate specimen.

A procedure is presented which separates stresses introduced by the drilling process.

The results are shown as a stress distribution around the circumference of the tube. An independent check of translational and rotational equilibrium is presented. A stress distribution is recommended for use in a study of the effect of residual stresses on failure loads of fabricated steel tubes. 
CHAPTER II

ANALYTICAL APPROACH

\subsection{GENERAL CONSIDERATIONS}

As the investigation is carried out on a welded cylindrical steel tube, it is appropriate here to describe the process by which welded fabricated steel tubes are commonly made. Usua11y, before welding, several cycles of cold-rolling of a flat plate are repeated until the two opposite edges come together to form a cylinder or "can". A can is then completed by welding along the longitudinal seam. The length of the can is usually limited to 10 feet by this manufacturing process, but several cans can be welded together end-to-end to yield the desired length.

A possibility of longitudinal weld tearing in a finished member when loaded, is avoided by staggering the weld between cylinders making the weld in one can 180 degrees out-of-phase to the weld in the next can.

This manufacturing process genera11y introduces:

a) Initial residual stresses from the flat plate before forming the "can" $(5,14)$.

b) Circumferential residual stresses by repeated cold-rolling (5).

c) Longitudinal residual stresses due to longitudinal welding (5) (Shrinkage during cooling).

d) A bending moment on the cross-section of the wall of the 
(3) because it is possible that the edges of the rolled plate do not meet exactly, thus requiring some "pulling together" of the edges prior to or during the welding operation (incomplete "spring back")(5). Among these stresses, measurement of longitudinal residual stresses is the main objective of this analysis.

\subsection{HOLE-DRILLING METHOD}

2.2.1 Presentation of the method. The measurement of residual stresses cannot be performed by conventional surface techniques such as photoelastic coatings or strain gages, because the measuring device ignores the past story of the parts. It measures strain after it is bonded to the part.

For this investigation, the hole-drilling method was chosen for use in determining the "locked-in" stresses. The stress field being disturbed by drilling, stresses are relaxed around the hole and relieved strains are measured.

\subsubsection{Terminology of stresses and mathematical expresgions. When a} hole of smaller diameter $\left(d=2 R_{0}\right)$ is drilled in a part subjected to residual stresses, a strain relaxation occurs. If there is only one stress $\sigma_{1}$, the strains relieved at a point $P$ from a distance $R$ of the center $A$ of the hole are called radial strain $\varepsilon_{r}$ and tangential strain $\varepsilon_{t}(10)$, in Figure 2.1.

$$
\begin{aligned}
& \varepsilon_{r}=-\sigma_{1}(1+\mu) / 2 E\left(1 / r^{2}-3 \cos 2 \alpha / r^{4}+4 \cos 2 \alpha /\left((1+\mu) r^{2}\right)\right) \\
& \varepsilon_{t}=-\sigma_{1}(1+\mu) / 2 E\left(-1 / r^{2}+3 \cos 2 \alpha / r^{4}-4 \cos 2 \alpha /\left((1+\mu) r^{2}\right)\right) \\
&
\end{aligned}
$$




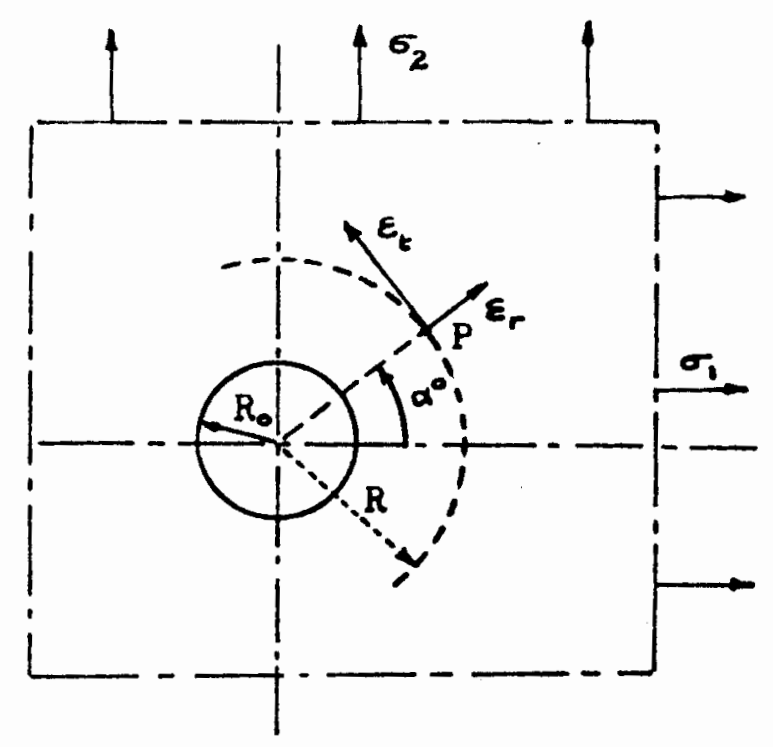

Digure 2.1 Radial and tengential strains

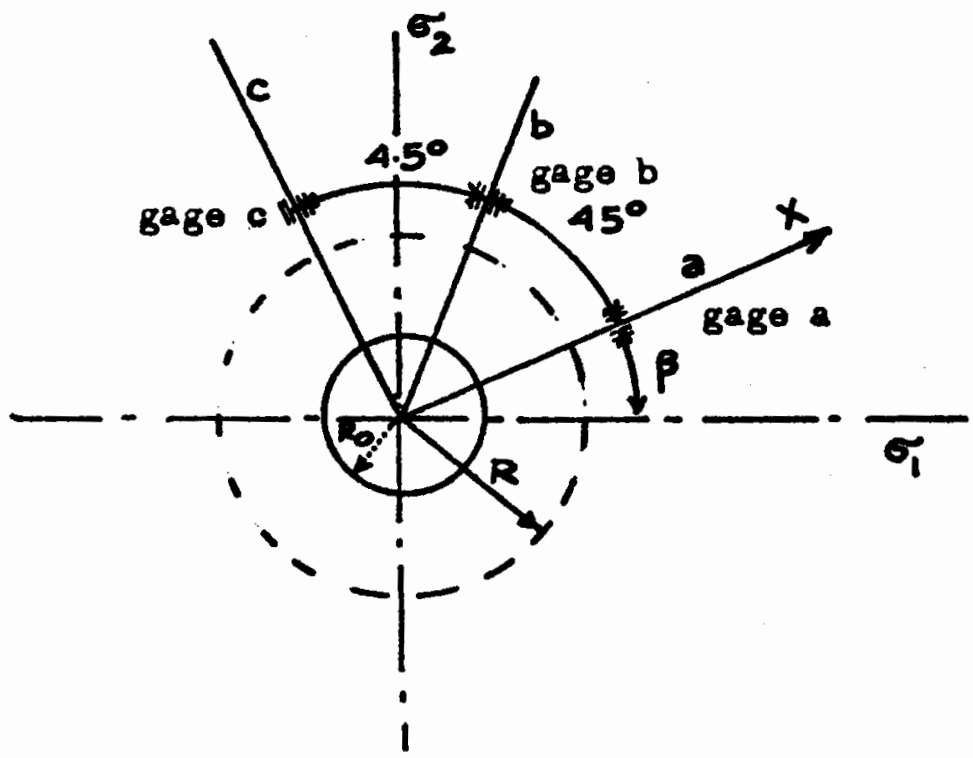

Pigure 2.2 Postion of gages uith respect to principal stress $\sigma_{1}$. 
where $\alpha=$ angle of radial strain to direction of stress $\sigma_{1}$.

$\mathbf{r}=\mathrm{R} / \mathrm{R}_{\mathrm{o}}$

$\mu=$ Poisson's ratio.

The equation (1) is used by Redner (10)

$E=$ Modulus of elasticity.

The above expressions show that the radial and tangential strains vary sinusioda11y along a circle of radius $R$ and can be expressed as:

$$
\begin{aligned}
& \varepsilon_{r}=(A+B \cos 2 \alpha) \sigma_{1} \\
& \varepsilon_{t}=(C+D \cos 2 \alpha) \sigma_{1}
\end{aligned}
$$

If both stresses $\sigma_{1}$ and $\sigma_{2}$ are present at the same time $\sigma_{1}$ and $\sigma_{2}$ orthogonal to each other), the expression becomes:

$$
\varepsilon_{\mathbf{r}}=(A+B \cos 2 \alpha) \sigma_{1}+(A+B \cos 2(\alpha+90)) \sigma_{2}
$$

Only the radial strain expression is retained here because each gage of the rosette $125 \mathrm{RE}$ used in the main experiment is unidirectional and measure the radial strain for each of the directions $a, b, c$.

Coefficlents $A$ and $B$ in expression (2) can be calculated from equations (1) for any given material and at any specified radius of measruements. They can also be determined experimentally.

\subsubsection{Measuring strains using the strain gage rosette. In order to} measure residual stresses $\sigma_{1}$ and $\sigma_{2}$ and their direction $B$ (see Figure 2.2) to a selected reference $X$, three strain measurements are required. These three measurements will provide three equations from which the three unknown, $\sigma_{1}$ and $\sigma_{2}$ stresses and $\beta$ direction, can be calculated. As shown in Figure 2.2, the strain gage rosette comprises three 
separate gages in directions a,b,c spaced 45 degrees apart, on a radius $R$. The stralns can be established from equation (2) by letting the angles:

$$
\alpha_{a}=\beta \quad \alpha_{b}=\beta \quad \alpha_{c}=\beta+90^{\circ}
$$

Solving for stresses, one obtains (Derivation of equations (3) Is given In Appendix I):

$$
\begin{aligned}
& \sigma_{1}=\left((A+B \cos 2 B) \varepsilon_{a}-(A-B \cos 2 B) \varepsilon_{c}\right) / 4 A B \cdot \cos 2 B \\
& \sigma_{2}=\left((A+B \cos 2 B) \varepsilon_{c}-(A-B \cos 2 B) \varepsilon_{a}\right) / 4 A B \cos 2 B \\
& \operatorname{Tan} 2 B=\left(\varepsilon_{a}-2 \varepsilon_{b}+\varepsilon_{c}\right) /\left(\varepsilon_{a}-\varepsilon_{c}\right)
\end{aligned}
$$

The equations are for a hole drilled in a macroscoplcally homogeneous, isotropic material subjected to a blaxial stress.

Equations (3) provide good results when gages a and $c$ are approximately positioned along princlpal stresses (10). But if the directions are grossly misjudged and gages a and $c$ give the largest spread, the following equations (4) provide better results (Derivation of equations (4) given in Appendix II):

$$
\begin{aligned}
& \sigma_{1}=\frac{(A+B \sin 2 \beta) \varepsilon_{a}-(A-B \cos 2 \beta) \varepsilon_{b}}{2 A B(\sin 2 \beta+\cos 2 \beta)} \\
& \sigma_{2}=\frac{(A+B \cos 2 B) \varepsilon_{b}-(A-B \sin 2 \beta) \varepsilon_{a}}{2 A B(\sin 2 \beta+\cos 2 B)}
\end{aligned}
$$

Equations (3) can be rewritten in the following form to simplify the numerical calculations (10) (Derivation of equations ( $3 a$ ) is given in Appendix III) 


$$
\begin{aligned}
& \sigma_{1}=\mathrm{S} / 4 \mathrm{~A}+\mathrm{D} / 4 \mathrm{~B} \cos 2 \beta \\
& \sigma_{2}=\mathrm{S} / 4 \mathrm{~A}-\mathrm{D} / 4 \mathrm{~B} \cos 2 \beta
\end{aligned}
$$

with $\operatorname{Tan} 2 \beta=\left(S-2 \varepsilon_{b}\right) / D$

where $\quad S=\varepsilon_{a}+\varepsilon_{c}$

$$
D=\varepsilon_{a}-\varepsilon_{c}
$$

The coefficients $4 \mathrm{~A}$ and $4 \mathrm{~B}$ can be computed from equation (1) or obtained from curves in Figure 2.3; these curves established by S. Redner (10) yleld one palr of values of $4 \mathrm{~A}$ and $4 \mathrm{~B}$ for one value of $r=R / R_{0}$. In this study, they were also determined experimentally. Each system of equations (3), (3a) and (4) can be used to compute the magnitudes and directions of the princtpal stresses. However, for the case of this investigation, the system of equations ( $3 a$ ) is most often applied because of their simplicity.

A computer program using equations (3a) to calculate the directions and magnitudes of the principal stresses, when the strains $\varepsilon_{a}, \varepsilon_{b}$ and $\varepsilon_{c}$ are known, is given in Appendix IV.

Generally the directions of the principal residual stresses calculated do not coinclde with the longitudinal and circumferential directions of the tube. A graphical method using a stress Mohr's circle (11) permits the orfentation of the longitudinal and circumferential residual stresses.

When the strains in the directions of gages $a, b$ and $c$ are known, a graphical solution using a strain Mohr's circle (11) allows the calculation of the longitudinal and circumferential strains 


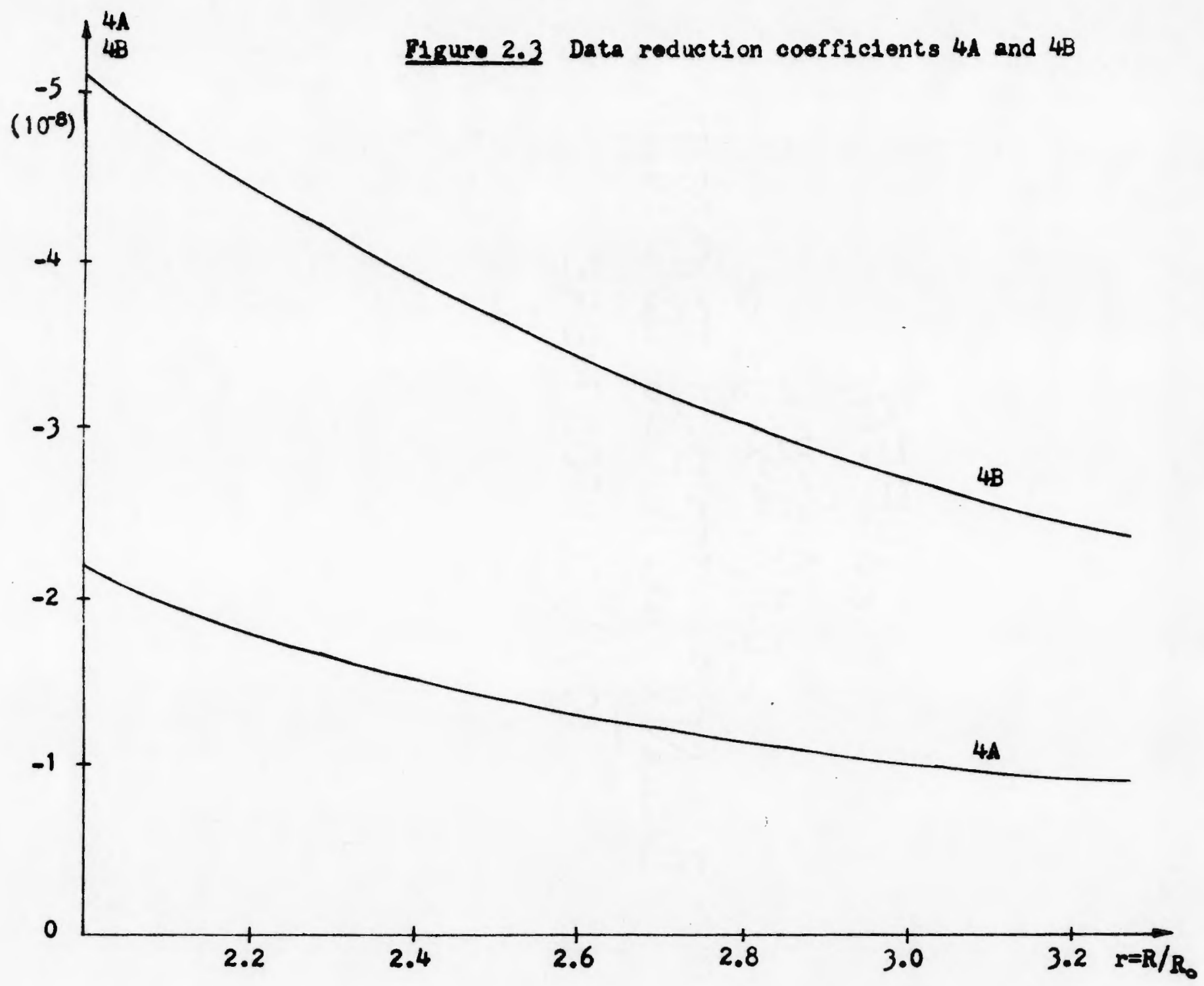

$\varpi$ 
(see Appendix VII).

A series of computer program presented in section 2.4 constitutes a second method for solving the above mentioned problems (see Appendices VI and VIII).

2.2 .4 Limit of strains for $B / D_{0}=1.0$. As mentioned previously, the hole-drilling method is based on the fact that drilling a hole in a stress field disturbs the equilibrium of the stresses, thus causing measurable strains at the surface of the part, adjacent to the hole. Previous Investigators have found that the deformations of the surface in a thick test plece, approach a limiting value. This is because the stresses relleved from the removal of the metal, at some distance below the surface will have no effects on the deformations at the surface. It has been found that this limiting value occurs at a hole depth varying from one to two times the hole diameter (1). Mathar (6) found this limit to be 1.5 to 2, while Bush, Kromer (2) and Redner (10) suggested 1.0 .

In this investigation, it was found that 11ttle change in the strains occurs after a hole depth to dlameter ratio of 1.018 reached. For convenience, it w111 be shown in Chapter III.

2.2.5 Varlation in residual stress field. An assumption has been made that the residual stresses existing in the tube are unfform through its thickness. This assumption will be numerically substantiated in section $3.2 \cdot 1 . b$.

At this time, the following observation about the distribution of residual stress is noted. 
According to S. Redner (10), the criterion of a uniform stress field is:

When the residual stresses are uniform in depth, the strains in the immediate vicinity of the hole are fully relieved (the curve reaches an asymptotical value) when the depth equals approximately one diameter of the hole.

In this study, it was found that strains relieved were small

for the first layers of material, but increased with depth. When the hole depth reached the value of hole diameter, strains attained their maximum and when plotted remained parallel to the horizontal axis.

The quasi-stationary values of the stresses computed for several depth values close to the constant diameter value will be shown in Chapter III a substantiation of the above assumption.

\subsection{DETERMINATION OF CALIBRATION COEFFICIENTS BY EXPERIMENTAL METHOD}

The hole-drilling or hole-relaxation method of measuring residual stresses is based on the measurement of strains distributed by machining a small hole in the test piece. A theoretical solution for the strain at any point on the surface of a drilled hole is not known and furthermore the relaxed strain is not unfform across the surface of the part. A strain gage at best can measure the average strain across the area it covers. Because of these limitations, most investigators belfeve that a calibration procedure is necessary. Calibration operations consist of applying known stresses to a test plece and measuring corresponding strains. These known stresses and strains permit the establishment of calibration coefficients which can be used in similar experiments to calculate stresses when the strains relleved are known. In this investigation, results are presented using calibration coefficients obtained 
by: a) theoretical calculations, b) published literature, c) experimental work performed as part of this research.

\subsubsection{Determination of calibration coeffictents by the method of} strain relaxation due to driling. This method consists of computing the strain relaxed when a hole is drilled in a steel plate subjected to a known state of stress. In this method no account is made for stresses induced by drilling.

The test set up is simple. A steel plate having a shape shown in Figure 3.18 is installed in a testing system capable of applying a tension force.

The following presents the major steps in this method:

1) A known tension (for example a tension giving a stress $\sigma_{1}=0.50 \mathrm{~F}_{\mathrm{y}}$ ) is applied to the plate and strain $\varepsilon_{a}$ is measured by a strain gage rosette $B ; \varepsilon_{a}$ is the strain due to the known force. Plot point a in Figure 2.4. (Note: no hole has been drilled as yet.)

2) The tension is released. The strain reading comes back to zero. A hole is drilled to a depth equal to the hole diameter. There is another strain reading, but it is reset to zero. The same tension is reapplied to the plate and a new $\operatorname{strain} \varepsilon_{b}$ is read and recorded; $\varepsilon_{b}$ is the total strain due to the application of the force and the existence of the drilled hole. Plot point $b\left(\right.$ strain $\varepsilon_{b}$, stress $\left.\sigma_{1}\right)$ in Figure 2.4.

3) The strain-relaxation $\Delta \varepsilon$ is the difference between the two measured strains $\varepsilon_{\text {- }}$ and $\varepsilon_{h}$. 
As all strain readings have been zeroed before and after drilling, the influence of any unknown residual stresses in the test plate is eliminated. Their effect has been eliminated by using the experimental procedure outlined above. All readings were zeroed before the force was applied. As the known force is applied before and after drilling, only the effects of the applied load and any stresses induced by drilling are recorded.

This calibration method yields a pair of calibration coefficients 4A and 4B, their computation w111 be shown in Chapter III.

\subsubsection{Determination of calibration coefficients by the method of}

strain-separation. The second method of determining the calibration coefficients separates the unknown stresses induced during the drilling process.

It has been found that, during the drilling operation, significant stresses are introduced in a general specimen by drill bits or rotating cutters. According to Bush and Kromer (2), their magnitude can be of the order of $\pm 10000 \mathrm{psi}$. Now the change in strain introduced by drilling a hole In any test plece when the latter is under load, is a function of initlal residual stresses, spot stresses induced by drilling and applied stresses. Therefore, for an accurate calibration, It is necessary to 1solate the values of existing unknown residual stresses in our test plate from stresses induced by drilling and from those caused by our applied loads.

The test set-up is similar to the previous method but there are some differences In making readings and computing strains. The same test plate is installed in a testing system capable of applying a 
tension force. The experimental procedure is as follows:

1) Before drilling, zero strain indicator. Apply a known load $\left(\sigma_{1}=0.40 \mathrm{~F}_{\mathrm{y}}\right)$ to the specimen. Record the strain $\varepsilon_{a}$ from the strain indicator. P1ot point a of Figure 2.5.

2) Maintaining the stress $\sigma_{1}$. A hole is drilled to the desired depth. Record the corresponding strain $\varepsilon_{b}$. Plot in the same graph point $b\left(\varepsilon_{b}, \sigma_{1}\right)$.

3) Reduce the magnitude of stress to $\sigma_{2}\left(\sigma_{2}=0.10 \mathrm{Fy}\right)$ and record the corresponding strain $\varepsilon_{d}$. Plot point $d\left(\varepsilon_{d}, \sigma_{2}\right)$. Locate point $c$, which is the intersection of line oa and a line through d parallel to the strain axis (see Figure 2.5).

4) Extend line bd cutting the strain axis at point e (graphical interpolation). $\varepsilon_{e}$ is the strain with no load on the plate. As there is no load applied, the segment oe represents the strain due to Initial residual stresses and spot stresses introduced by the drilling operation.

5) Referring to ordinate $\sigma_{1}$, the segment ab represents the difference of two strains $\varepsilon_{a}-\varepsilon_{b}=\Delta \varepsilon_{T}$ which is the strainrelaxation due to drilling under applied stress $\sigma_{1} \cdot \Delta \varepsilon_{\mathrm{T}}$ is the sum of two strains: 1) strains due to drilling effects and unknown residual stresses existing in the plate and 2) strains due to applied stress. From 0, a parallel ine to eb is drawn cutting $a b$ at $b^{\prime}$. The segment $b^{\prime}$ parallel and equal to eo represents the strain due to drilling effects and unknown residual stresses in the plate $\left(\Delta \varepsilon_{R}\right)$. The segment b'a represents the strain due to the applied stress $\sigma_{1}\left(\Delta \varepsilon_{1}\right)$. 


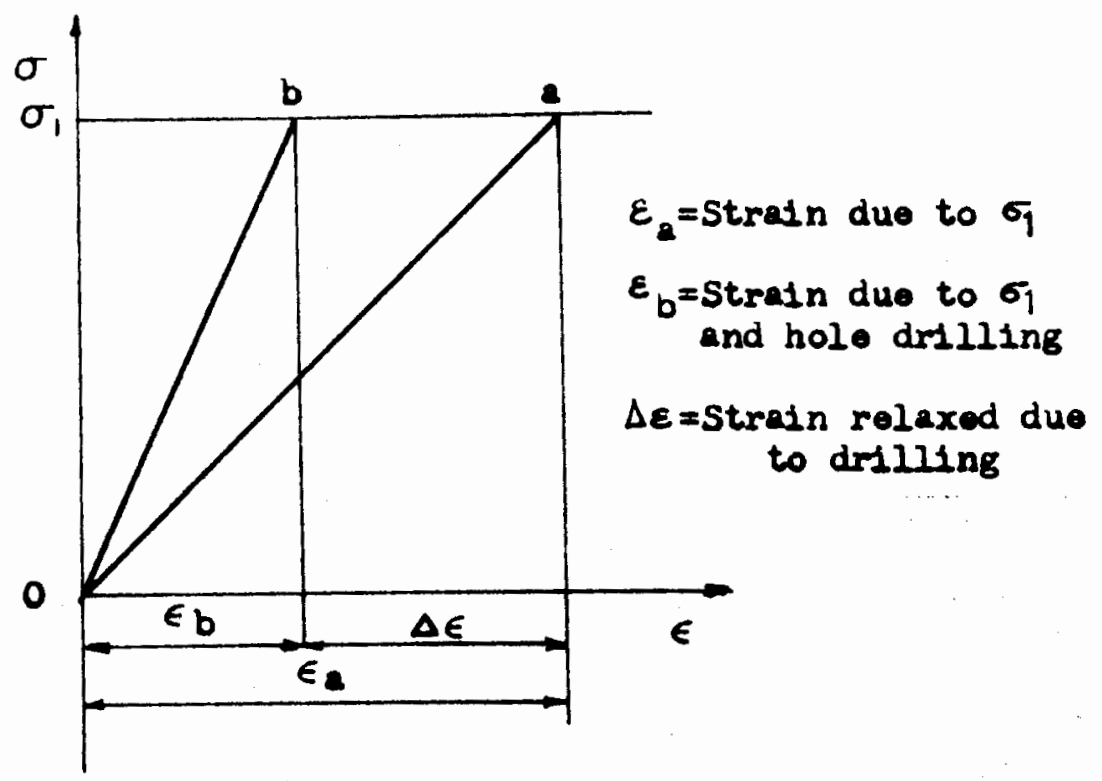

Elgure 2.4 Strata-relaxation dus to drsliting

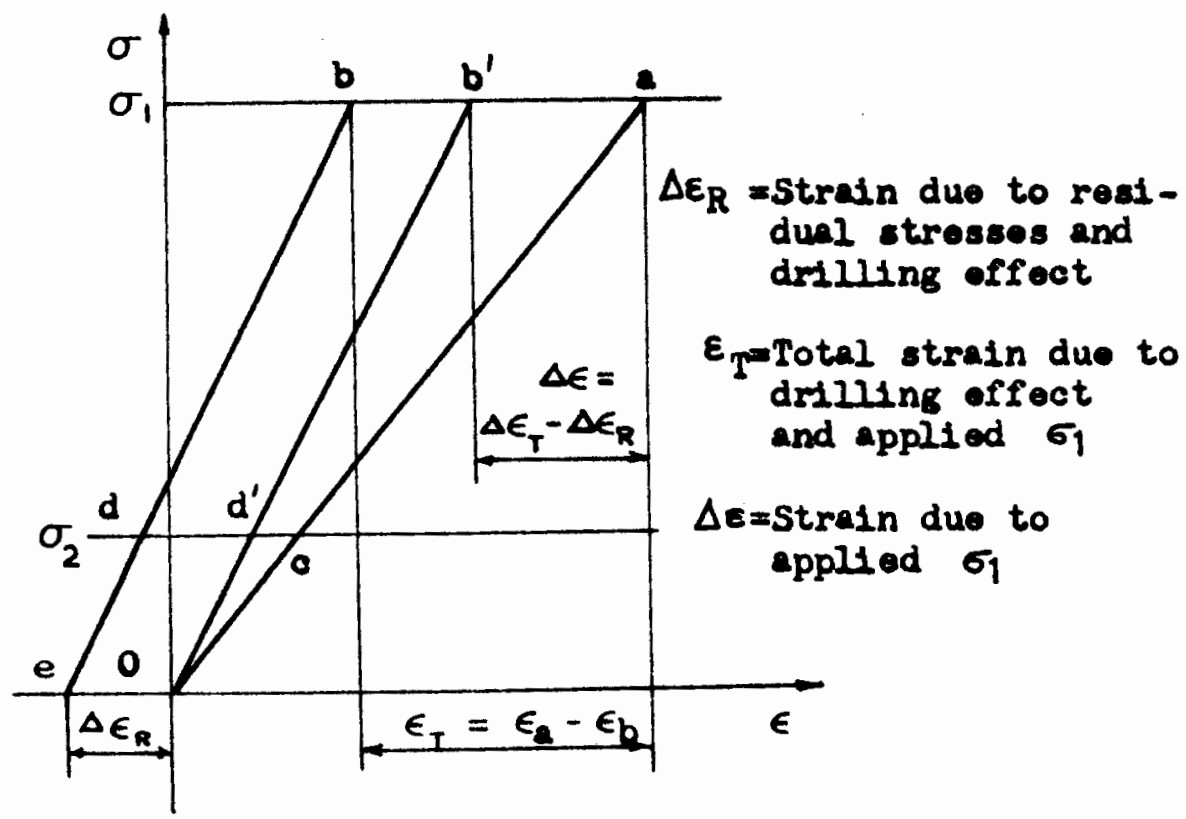

Figure 2.5 Strain separation 
Finally $\Delta \varepsilon_{1}$ is the strain eaused by the applied stress $\sigma_{1}$.

6) At ordinate $\sigma_{2}$, dd' parallel and equal to eo, represents the strain due to drilling effects and unknown residual stresses, and the segment $d^{\prime} c$ is the strain due to the applied load $\sigma_{2}$

7) The above strain- relaxation has been obtained from a known applied stress for a determined direction. In the case of the gage rosette, it is necessary to calculate the strainrelaxation for three different directions ( $a, b, c, 45$ degrees apart) under an uniaxial load.

\subsubsection{Experiment of tensioning a steel plate specimen for calibration.}

The purpose of this experiment is to determine the modulus of elasticity of the steel of the plate, to check the existence of initial residual stresses and stresses induced by drilling and finally, to determine the calibration coefficients, first by the method of strain-relaxation due to drilling, then by the method of strain separation.

Experimental set-up and results are described in detail and 11lustrated with numerical values in Chapter III, sections 3.1 .3 and 3.2.2.

\subsection{COMPUTER PROGRAMS}

In this part, three computer programs will be presented pertaining to 1) the calculations of princlpal stresses, 2) of 1ongitudinal and circumferential stresses and 3) of longitudinal strain, when radial strains in three directions (gages) $a, b, c$ are known. Two more computer programs will be discussed relating to force and moment 
balance before and after calibration.

As the system of the actual longitudinal residual stresses is in equilibrium in the tube, the summation of forces and moments with respect to an axis must equal zero. The first program computes the balance of forces and moments of measured longitudinal residual stresses. The second program deals with the balance pertaining to residual stresses recalculated using calibration coefficients.

\subsubsection{Computer program for calculating principal stresses $\sigma_{1}$ and $\sigma_{2}$} when strains in directions $a, b, c$ are known. Calculations are based on equations (3a):

$$
\begin{aligned}
& \sigma_{1}=S / 4 A+D / 4 B \cos 2 B \\
& \sigma_{2}=S / 4 A-D / 4 B \cos 2 B
\end{aligned}
$$

$$
\operatorname{Tan} 2 \beta=\left(S-2 \varepsilon_{b}\right) / D
$$

with

$$
\begin{aligned}
& S=\varepsilon_{a}+\varepsilon_{c} \\
& d=\varepsilon_{a}-\varepsilon_{c}
\end{aligned}
$$

These equations are used by Redner (10).

The computer program is shown in Appendix IV.

\subsubsection{Computer program for calculating longitudinal and circumferential} stresses when strains in three directions $a, b, c$ are known. In this program, the equation of a Mohr's circle constructed with principal stresses is established. The equation of the straight line representing both longltudinal and circumferential directions is also computed. The abscissas of the points of intersection between the line and the 
circle will be the longltudinal and circumferential stresses. (see Figure A.6.1).

The computer program is presented in Appendix VI.

2.4.3 Computer program for calculating longitudinal and clrcumferential strains when strains in three directions are known. In this program, the equation of a strain Mohr's circle is established. Also computed is the equation of the line of the longitudinal strain direction which is the same for the circumferential strain direction. (The angle between longitudinal and circumferential direction is 90 degrees for the tube; but this angle is double and equals 180 degrees In Mohr's circle.) The abscissas of the points of Intersection between the strain Mohr's circle and the line, w11l be the longltudinal and circumferential strains. (See Figure A.7.1)

The computer program is presented in Appendix VIII. 
CHAPTER III

EXPERIMENTAL PROGRAM

This chapter documents the testing procedure and presents the numerical results of the laboratory tests.

Laboratory tests consist of experiments of drilling outside and Inside holes in the steel tube and of an experiment of tensioning a steel plate specimen for calibration.

\subsection{PHYSICAL TESTS}

The first experiments consist of drilling a series of eleven holes on the outside surface of a welded fabricated steel tube.

\subsubsection{Drilling holes on outside surface.}

A) Material and gages.

1) The steel tube specimen used has the following characterIstics:

Length: 6 feet

Outside diameter: 22 inches

Th1ckness of wa11: 5/16 inch

Section modulus: 118.79 cubic Inches

Yleld axia1 load: $870.8 \mathrm{kips}$

Bending moment at first yleld $\mathrm{M}_{\mathrm{y}}: 4859$ in. k1p

A-36 Amertcan made plate

The steel used in the tensioning experiment has the following specifications: 
Conform to ASTM-36.75

Yield strength: $\quad 40.90 \mathrm{ksi}$

Ultimate strength: $61.50 \mathrm{ks}$

U1timate strength: $61.50 \mathrm{ks}$

Modulus of elasticity: $29000 \mathrm{ksi}$

Chemical analysis: Carbon: $.14 \%$

Manganese: $.67 \%$

Phosphor: $\quad .009 \%$

Sulfur: $\quad .018 \%$

Silicium: $.22 \%$

2) Strain-gages used are of two types:

a) Rosette 0.125" (see Figure 3.2)

Gage type: EA .06-125 RE-120

Resistance in ohms: $120.0 \pm 0.2 \%$

Lot number: $\quad$ R $\quad$ A $35 \mathrm{AD} 48$

Quantity: $\quad 5$ gages per box

Option: $\quad$ S

Gage factor at $75^{\circ} \mathrm{F}$ : Nominal $2.03+1.0 \%$

Manufactured by Micro-Measurement $M-M$, Romulus, Michigan

This rosette is used with a drill bit of 0.125 inch to dri1l holes of 0.125 inch diameter.

b) Rosette $0.062^{\prime \prime}$

Gage type: EA. 06-062 RE - 120

This resistance strain gage has specifications similar to those of Rosette $0.125 \mathrm{in}$. except for its smaller dimensions and is used for holes 0.062 in. In diameter. 


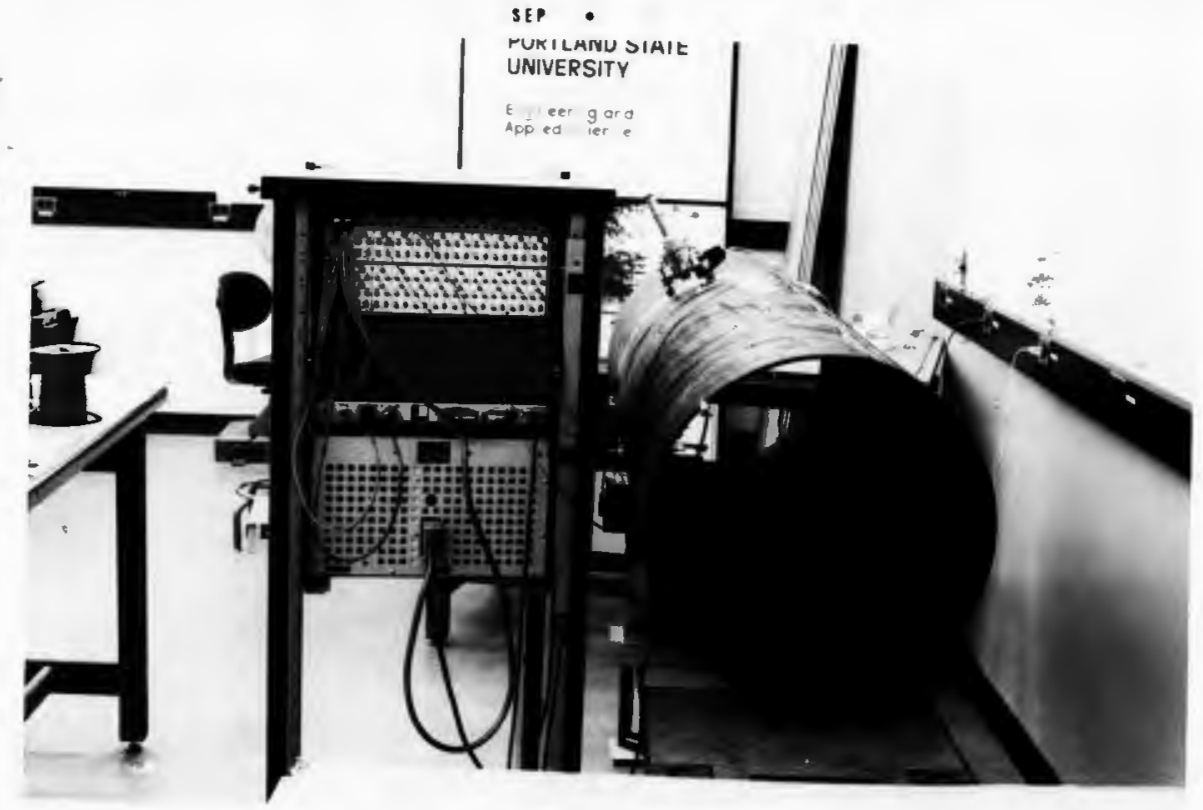

Figure 3.1 Steel tube

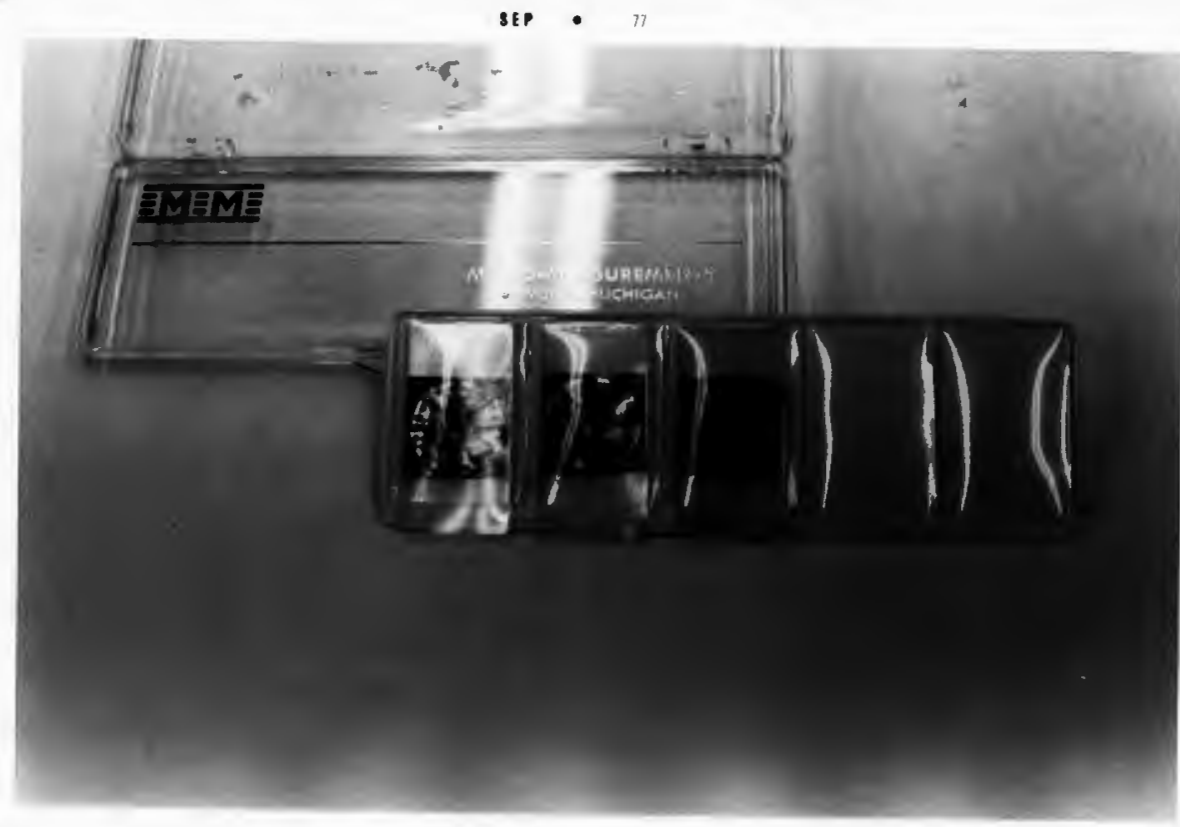

Figure 3.2 Strain gage rosette 


\section{B) Apparatus .}

1) Milling guide.

As mentioned previously, the difficulty of obtaining a good alignment of the bored hole with respect to the gages can be overcome by the use of a preciston milling guide (see Figure 3.3).

The apparatus used in this experiment is a RS-200 spectal milling guide (12) capable of allowing an alignment within \pm 0.001 inch of the rosette center and insuring the concentricity and guidance of the milling bar.

This guide is supported by a rigid body adfustable in two orthogonal directions. The body is easily attachable to curved or flat surfaces by means of an adfustable swivel tripod. When the gage is cemented to the test piece, alignment is realized by putting the microscope Into the guide and centering the guide over the center of the gage rosette by acting adjusting screws. When alfgnment is done, the microscope is removed and the mlling bar armed with rotating cutter is introduced Into the guide. The cutter currently used is of $0.125 \mathrm{in}$. diameter.

According to Vigness and Rendler (4), end mills are normally equipped with cutting edges on the end and side of the mill. The mill will cut either with an axial or lateral feed motion. But, in 1966, Greenweld and Rendler (10) made a complete and valuable study on this matter and found an optimum shape for the drilling tool, insuring that the boring progresses in a straight line, without side pressure or friction at the non-cutting edge. This shape of dri11 bit has been applied to the equipment used in the present experiment and allowed a 
smooth drilling without side pressure or side friction.

The milling bar is also equipped with a special micrometer screw adapter to allow drilling in small increments in depth (generally $0.01 "$ per increment). After drilling, the diameter of the hole is measured by the micrometer inside the microscope. This measured diameter is necessary to compute the ratio $r=R / R_{0}$ distance of the gage to the center, to radius of the hole, to determine the data reduction coefficients $4 \mathrm{~A}$ and $4 \mathrm{~B}$ leading to the computations of the principal stresses.

2) Strain indicator.

After the installation of the rosette, its three gages are soldered to six wires (one pair of wires to one gage) connected to the strain indicator (see Figures 3.4 and 3.5 ). The gage factor is set up to the required value (2.03 for the EA .06-125 RE - 120 Rosette) and when the reading is reset to zero the test should yield a reading of \pm 3400 microstrains for each gage connected to the strain indicator.

C) Experimental set up

The experimental set up comprises the following operations:

1) Location of holes, marking.

The longitudinal residual stresses were assumed to be symmetric with respect to the dimetral plan passing through the longitudinal weld. Therefore only the investigation of the stresses on a semi-circular section of the tube was considered. A section two feet from the edge (see Figure 3.6) has been defined and the holes were drilled on a semi-circular section commencing from the weld (see Figure 3.7). 


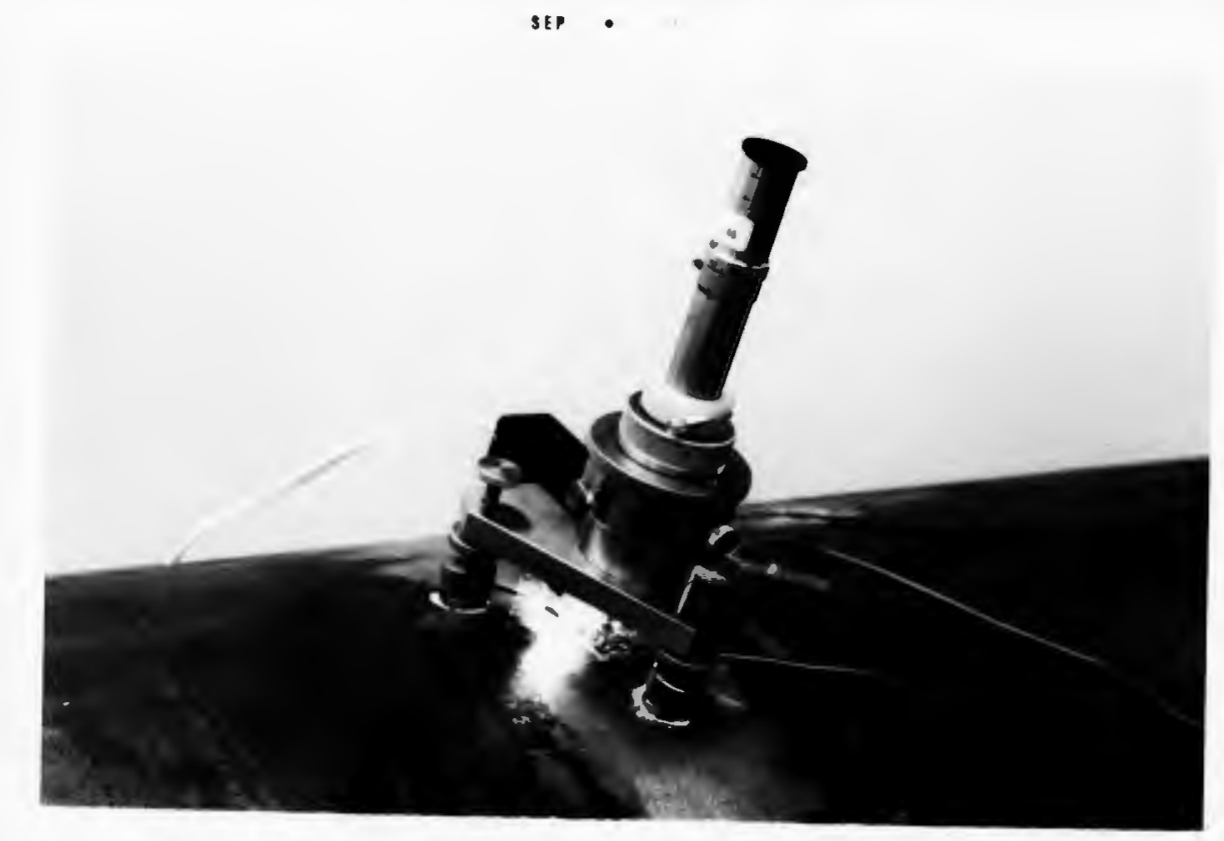

Figure 3.3 Milling guide

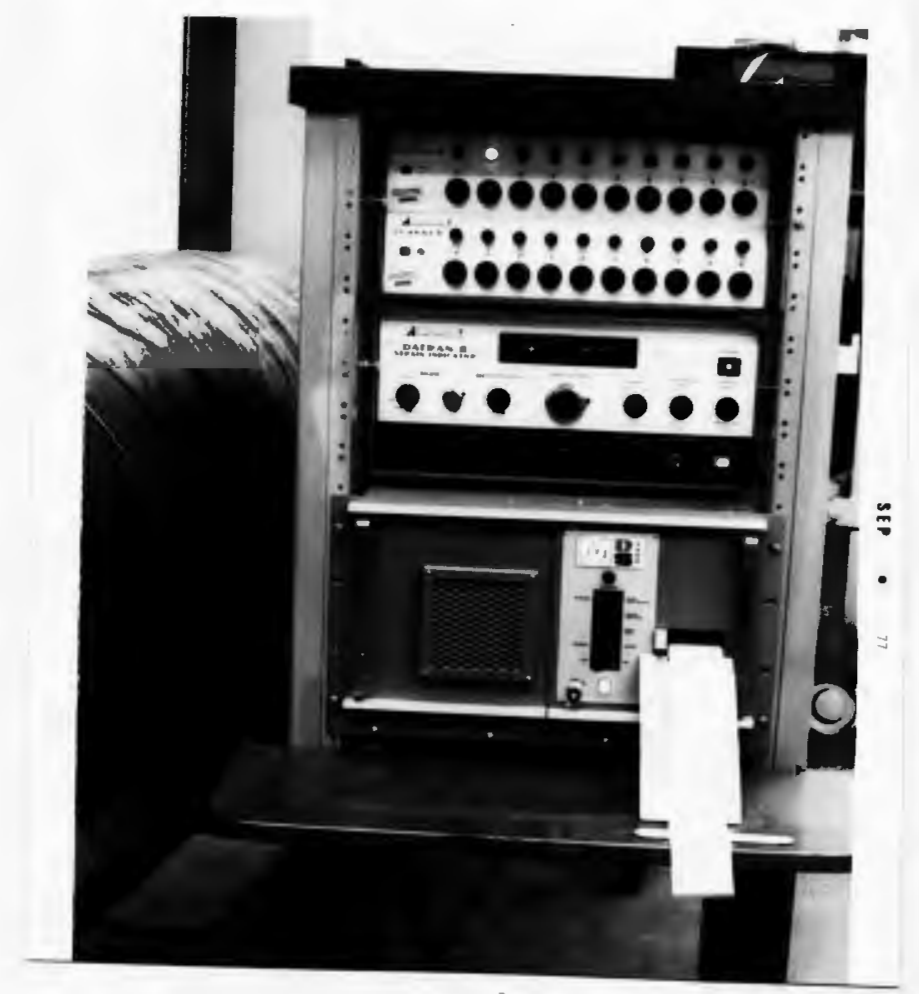

Figure 3.4 Strain indicator 


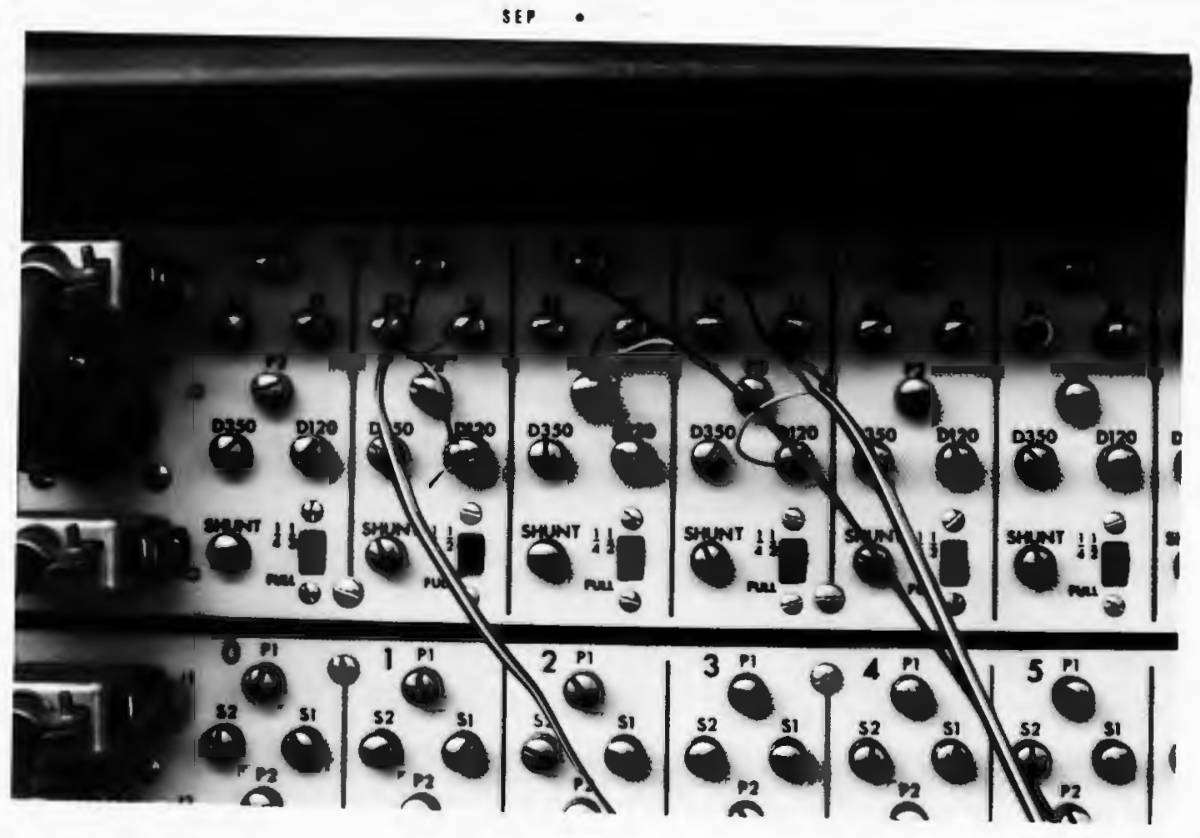

Figure 3.5 Strain indicator (rear view) 
Eleven holes were drilled and located from the weld as follows:

$\begin{array}{cc}\text { Hole } & \text { Angle from weld } \\ 1 & 45^{\circ} \\ 2 & 90^{\circ} \\ 3 & 135^{\circ} \\ 4 & 180^{\circ} \\ 5 & 22^{\circ} 30 \\ 6 & 67^{\circ} 30 \\ 7 & 112^{\circ} 30 \\ 8 & 157^{\circ} 30 \\ 9 & \text { near weld } \\ \text { A } & 11^{\circ} 15 \\ \text { B } & 33^{\circ} 45\end{array}$

Each hole is marked with a sharp steel blade on the wall of the pipe, strongly enough to leave a faint sign of a cross even after sanding, but not so strongly as to create extraneous residual stresses in the tube.

2) Cleaning the area ready for cementing the gages and the swivel feet for mounting the milling guide.

-Sanding. As the outside wall of the steel tube is covered with scales caused by the hot-rolling operation, it is required to clean with sand cloth, around the marking sign, an area large enough to receive the gage and the tripod. Sanding has to be done cautlously to prevent introduction of induced stresses. Sanding is stopped when the area assigned to recelve the cementing of the gage and the swivel feet are polished and clean. A good sanding requires about 


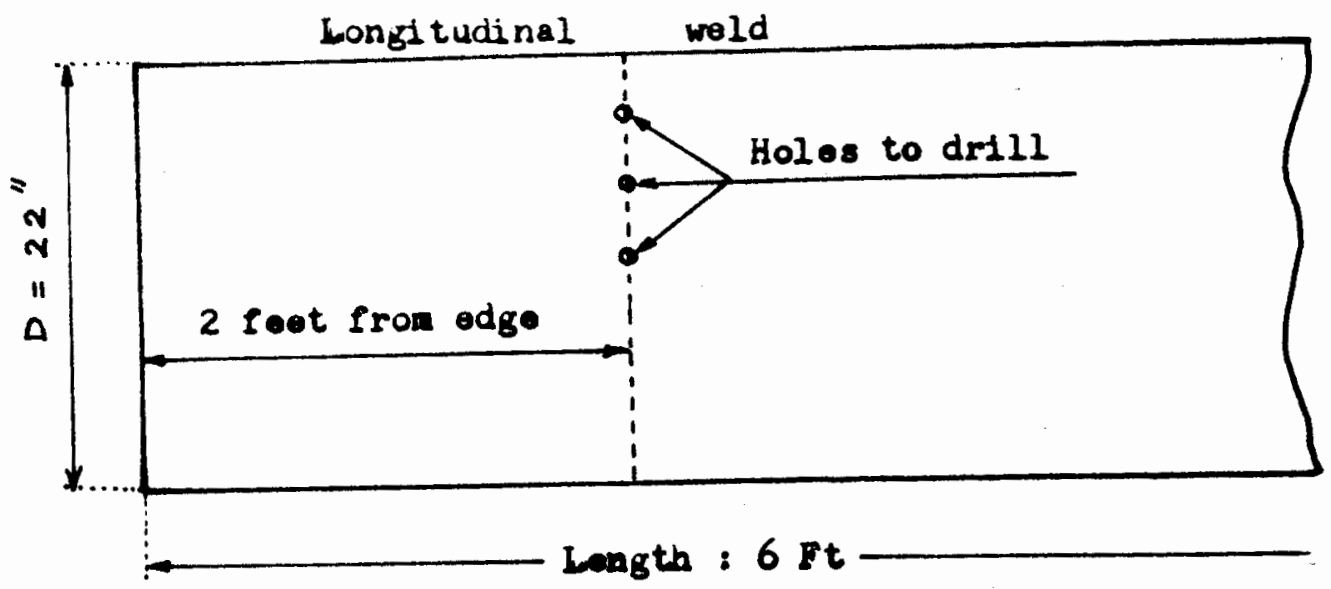

Pgure 3.6 locetion of hole section

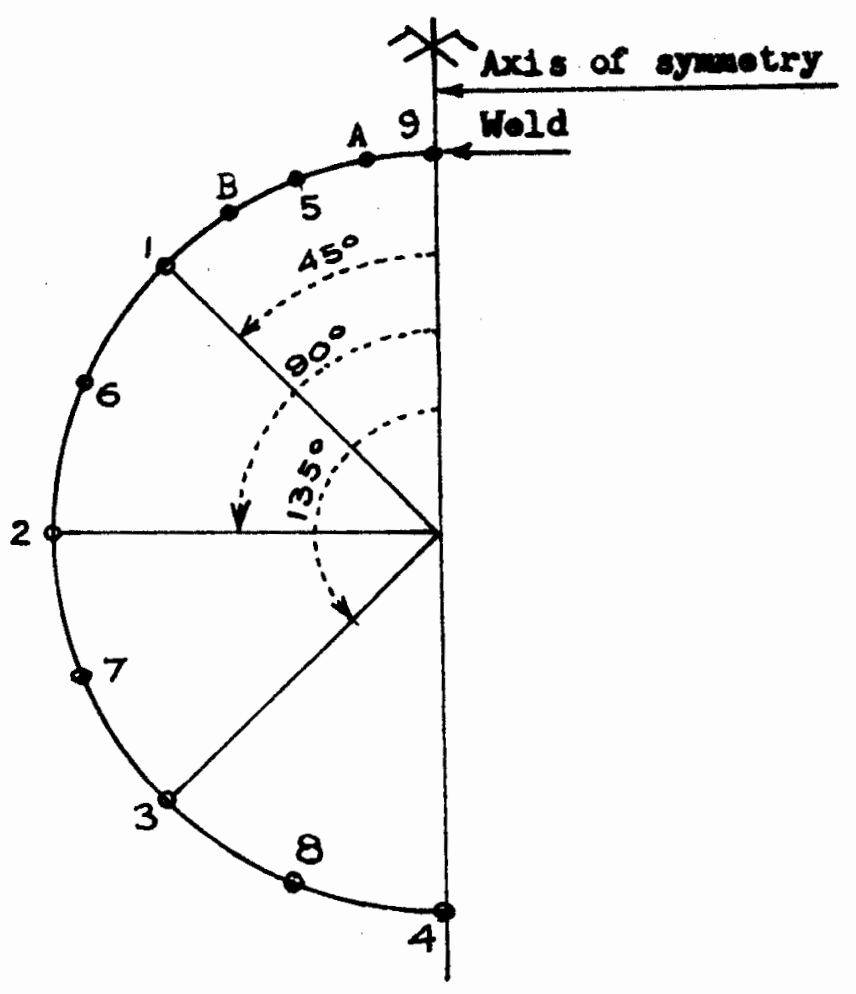

Pigure 3.7 Postion of drilled holes 
one hour of work for one set-up.

-Chemical cleaning. After sanding is completed, a solution of acetone is applied three to four times to remove dust or dirt. Then it is cleaned with "Conditioner A", a water-based acidic surface cleaner. Finally, a water-based alkaline surface cleaner "Neutralizer 5" is applied to neutralize the effects of the remaining acidic solution and to complete the cleaning operation.

3) Cementing gage.

$125 \mathrm{RE}$ type rosette $1 \mathrm{~s}$ shown in Figure 3.8 with its three directions $a, b, c$. It is more convenient to adopt a unique orientation of the gage rosette with respect to the longitudinal axis to make it uniform for all set-ups. The adopted orlentation is shown In Figure 3.9.

The gage rosette is first put on a flat surface and two short scotch tape bands are mounted on 1t. The mount 1s set in place for a gage positioning check. A thin coat of "200 Catalyst" is applied on the back side of the rosette. Then a coat of "M-Bond 200 Adhesive" is painted on the film side of "200 Catalyst". Now it is required to spread with a thumb the scotch tape bands, sticking the gage on the steel tube and squeezing out the excessive adhesive.

\section{4) Soldering gage}

Two terminals of each gage of the rosette are soldered to a pair of wires connecting to the rear side of the strain indicator (see Figure 3.5). To check soldering and cementing of the gage, $a$ load is applied by hand at the surrounding areas of each gage. The gages should record a slight change on the indicator. 


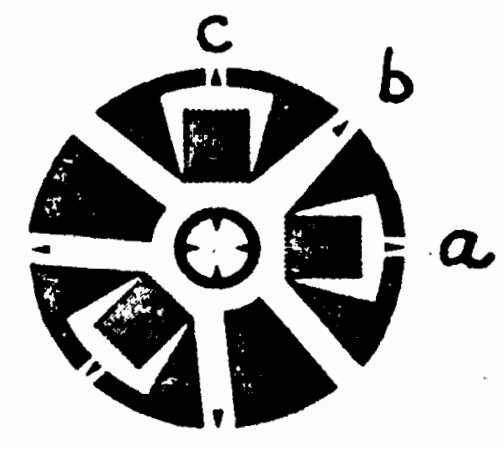

Figure 3.8 Rosette pattern onlarged

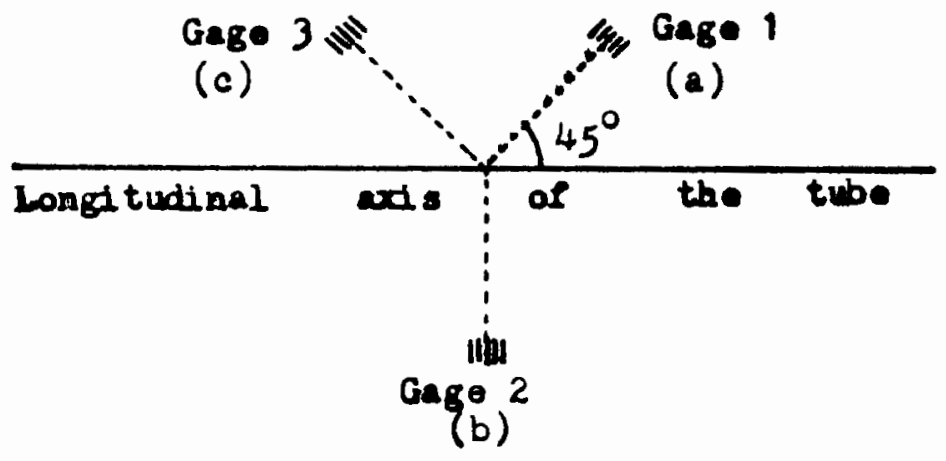

Figure 3.9 Orientation of rosotto gagos 
5) Cementing tripod.

For mounting the milling guide, the three adjustable swivel feet must be cemented in suitable positions (see Figure 3.10).

A "Grip-Cement" powder is mixed with a "Grip-Cement" Iiquid to form a resinous type dental cement sulted for attaching the swivel feet to the test piece.

6) Strain indicator set up.

Electric power in the strain indicator has to be set up at least one hour before using to warm it up. The gage factor is to be dialed at 2.03 for the $125 \mathrm{RE}$ - 120 rosette. When the reading for each is zeroed, the equipment turned to "test" should read \pm 3400 microstrains.

7) Aligning procedure

A microscope is inserted into the milling guide. Looking through the eyeplece, the operator centers the guide over the exact center of the strain gage rosette by manipulating the adjusting screws. After the adjusting screws are tightly locked, the microscope is removed and the milling bar equipped with a $0.125^{\prime \prime}$ drill bit (see Figure 3.11) is introduced in its place.

8) Drilling

The strain reading is set to zero for all three channels. An electric drill is adapted to the milling bar by means of a universal joint. A micrometer screw adapter (see Figures 3.11 and 3.12 ) is set to zero but can allow several increments of hole depth totalling $0.125^{\prime \prime}$. Now the screw adapter is set to $0.01^{\prime \prime}$ to permit a drill of $0.01^{\prime \prime}$ deep hole. The trigger of the $\mathrm{dr} 111$ is squeezed moderately to operate it 


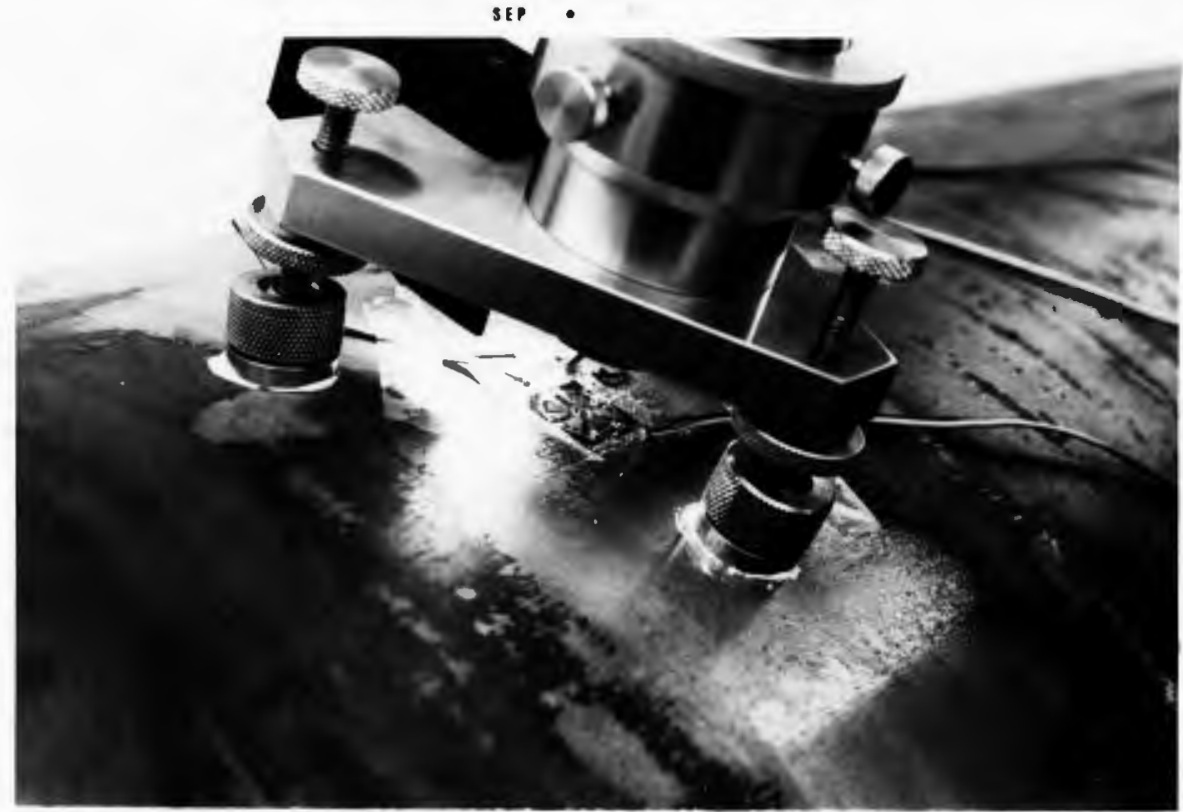

Figure 3.10 Adjustable swivel feet

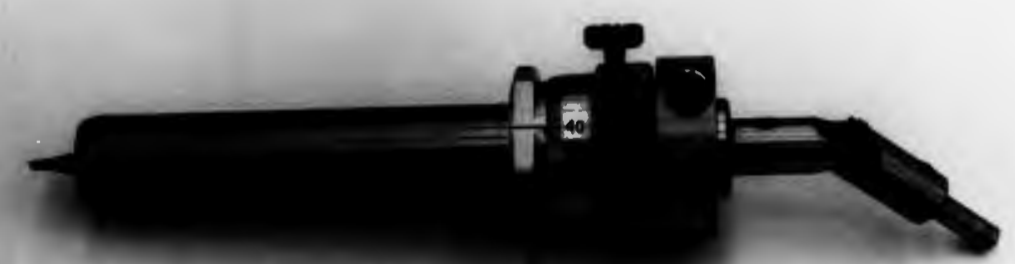




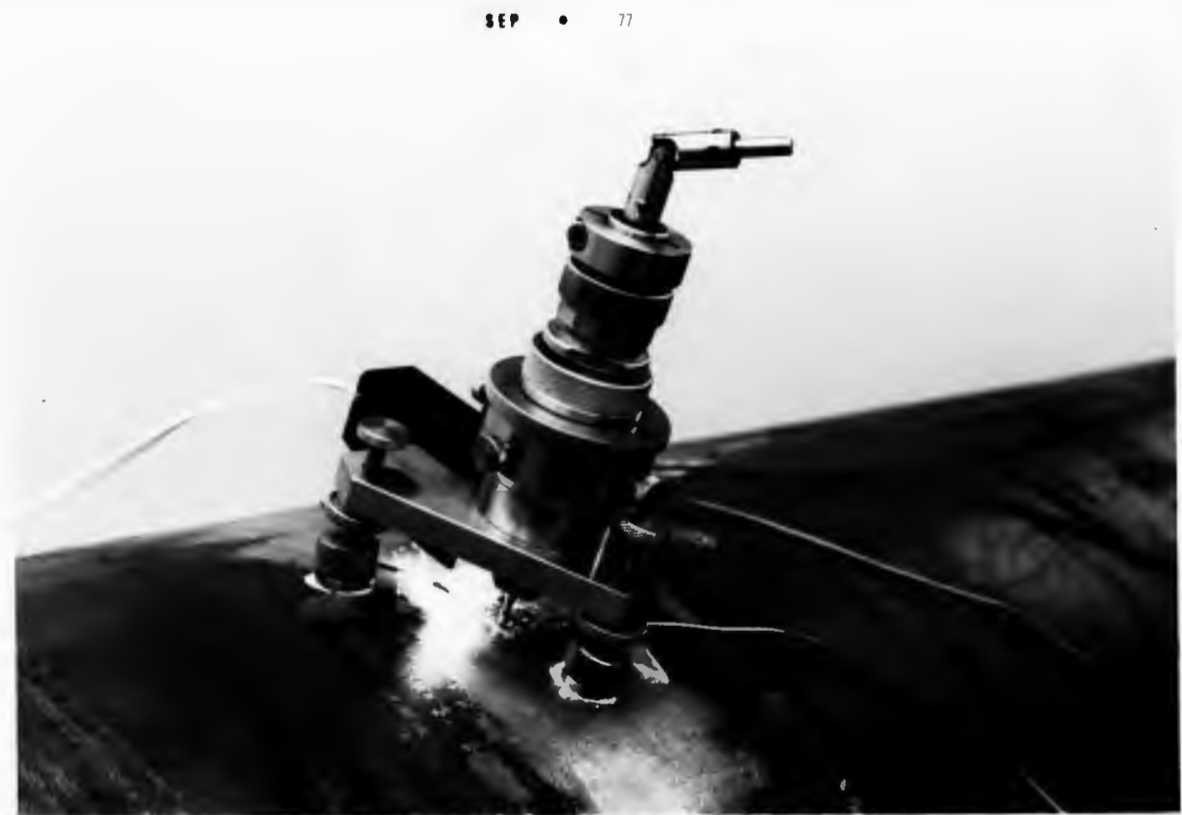

Figure 3.12 Drilling set up

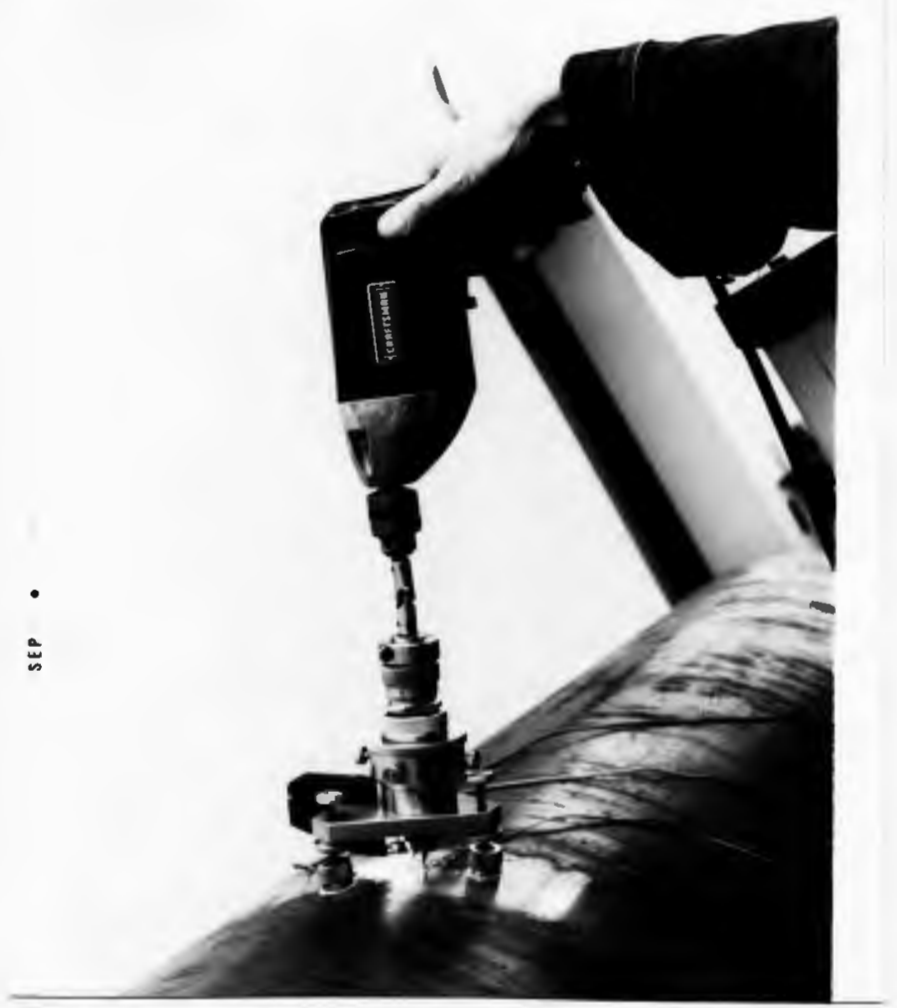

Figure 3.13 Drilling under action 
(see Figure 3.13) allowing the boring bar to rotate at a speed of about $200 \mathrm{rpm}$ (4). When the desired depth is reached, the strain reading is made and results printed. Then the micrometer screw adapter is set to $0.02 "$ (constant increase of depth of $0.01^{\prime \prime}$ each time). The operation is relterated until reaching a hole depth of $0.12^{\prime \prime}$. Readings are studied to see whether they reach a maximum for each channel. Then the screw adapter is set to $0.125^{\prime \prime}$ (Ratlo Depth/Diameter $=1.0$ ). A depth of $0.125^{\prime \prime}$ is assumed to yleld fully relleved strains, therefore fully relaxed restdual stresses around the hole (10). Two more depth Increments are made up to 0.130 and $0.140^{\prime \prime}$ and drilling is stopped.

\section{8) Measuring hole diameter.}

After the drilling bar is removed and the microscope inserted into the guide, the illuminator is switched on, the diameter of the finished hole is measured. The number of divisions are counted by using the micrometer and this number is multiplied by $0.00165^{\prime \prime}$ set by manufacturer to obtain the hole diameter. Then the ratio $r=R / R_{0}$ is calculated.

D) Validity of results and remarks.

The gage rosette works perfectly if it is well cemented and good solder connections are obtalned. Hole drilling should be done slowly. All screws of the milling guide are to be properly tightened to prevent the drilling shaft from wobbling. Avolding using intensive electric power in the surroundings of the strain indicator is required when strain readings are taken; otherwise an induction generated inside the strain indicator yields invalid results. 
3.1.2 Drilling inside holes. Instde hole drilling is similar to outside hole drilling procedure. Figures 3.14-3.17 show the test detalls.

\subsubsection{Experiment of tensioning a steel plate specimen for the de-}

termination of calibration coefficients. This experiment provides information to calculate calibration coefficients under a controlled condition for use in data adjustment of the results obtained from the hole-drilling technique applied to the tube.

The experiment consists of tensioning a steel plate with an initial force of known magnitude and measuring strains by means of a rosette and a reference gage, before and after drilling a hole in the plate. Then, the strains measured are analyzed to separate strains due to applied stresses from strains due to unknown residual stresses In the test plate. In this analysis, the effects of residual stresses are eliminated, and the calibration coefficients are determined by the strain-relaxation due to drilling method or by the method of separation of Induced stresses and applied stresses.

A) Material and gages.

The test plece is a steel plate 5/16" thick having the shape shown in Figure 3.18 .

Three gages - rosette 125RE, position A (to measure initial residual stresses) rosette $125 R E$, position $B$ (to measure strain-relaxation due to drilling) and reference gage $250 \mathrm{BG} 120$ - is cemented to the test plece (see Figure 3.18).

The reference gage belongs to a general purpose family of constantant strain gages widely used in experimental stress analysis. 
I

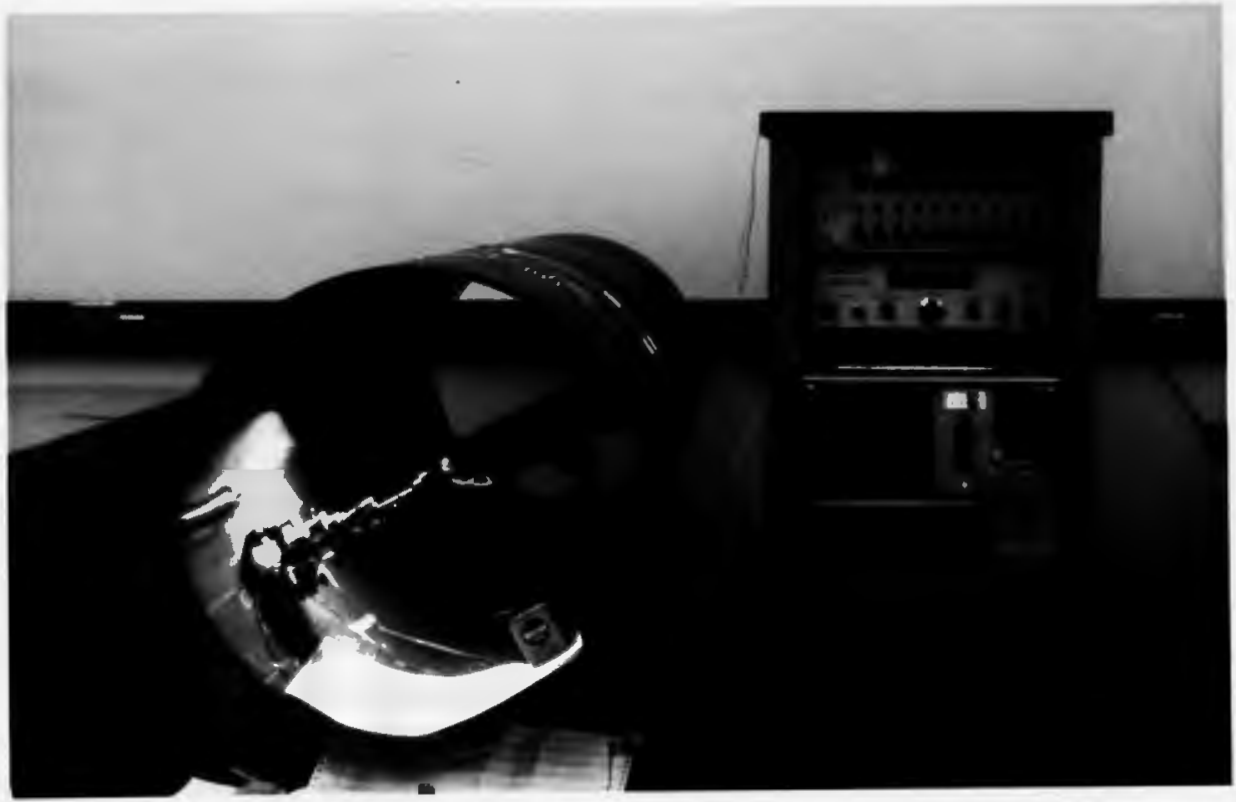

Figure 3.14 Set up for drilling inside hole

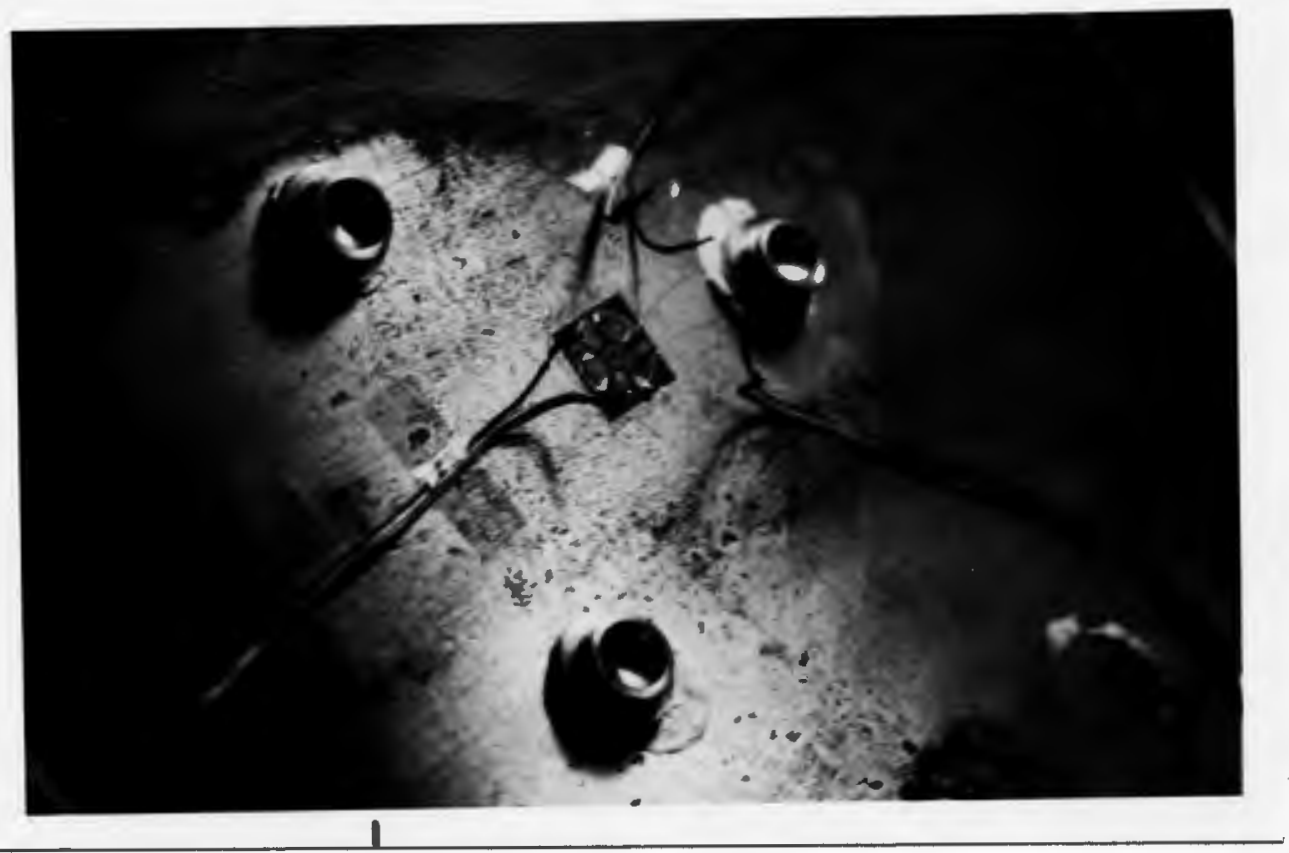

Figure 3.15 Cementing swivel feet 


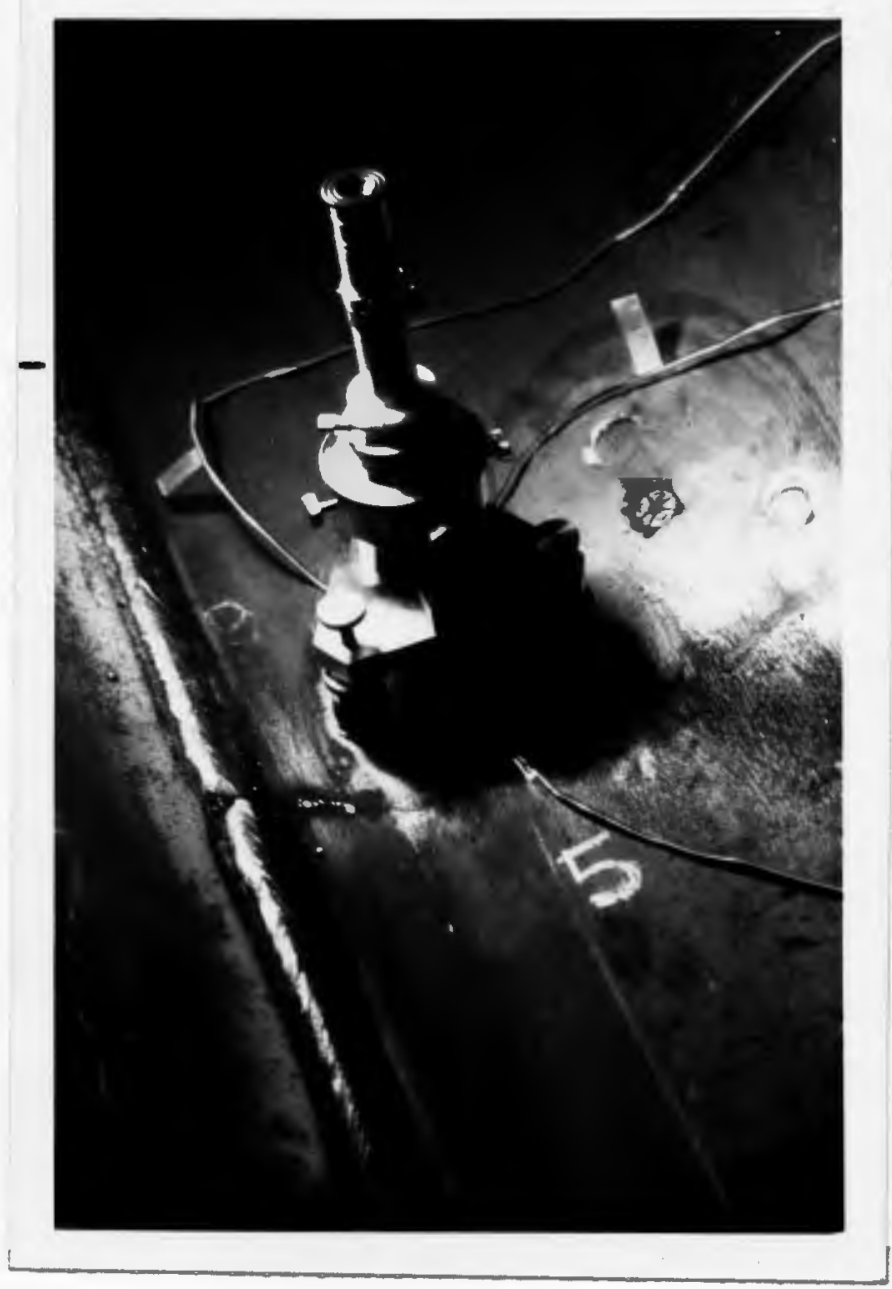

Figure 3.16 Alignment set up before drilling (inside surface) 


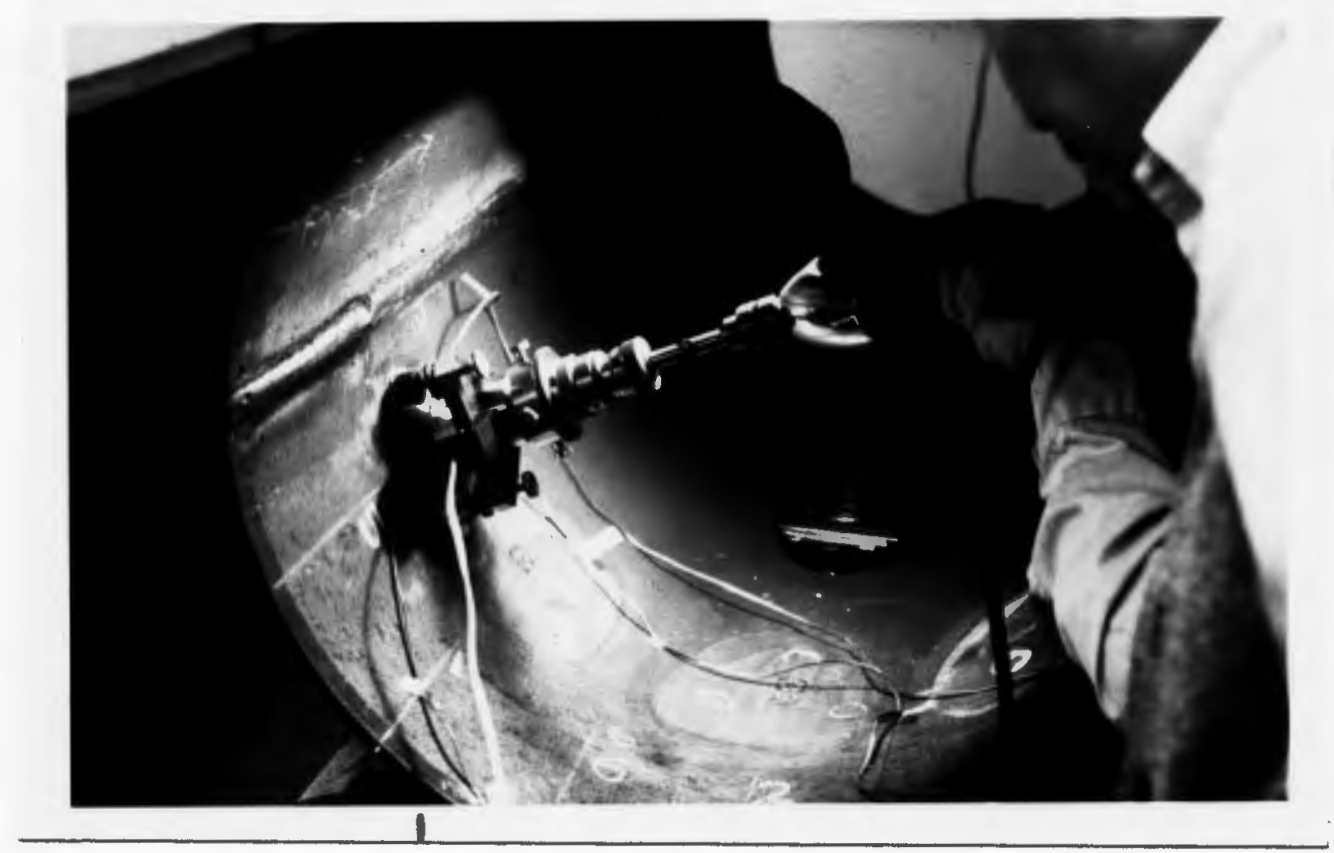

Figure 3.17 Inside hole drilling under action 


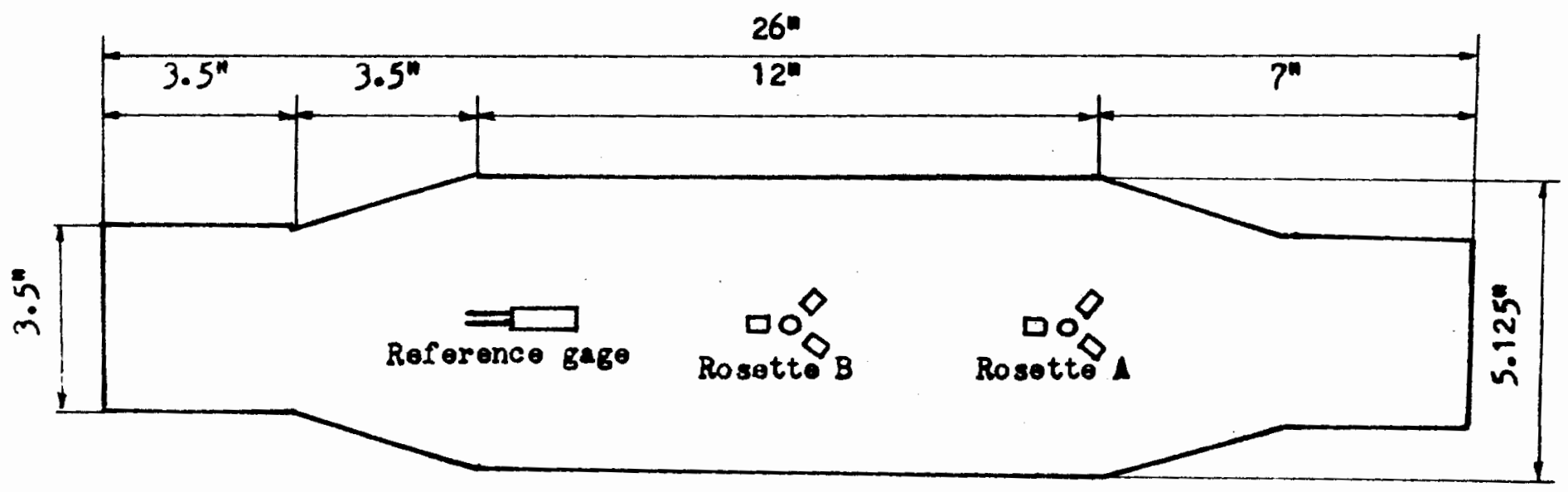

Figure 3.18 Shape of the steel plate specimen and position of gages (Rosettes $A$ and $B$ and reforence-gago) 
Its characteristics are:

Gage type: EA-06-250 BG -120

Resistance in ohms: $120.0 \pm .15 \%$

Gage factor at $75^{\circ} \mathrm{F}: 2.06 \pm 0.5 \%$

Option: L

Temperature range" $-100^{\circ} \mathrm{F}$ to $+350^{\circ} \mathrm{F}$

Strain limits: 5\% for gage lengths $1 / 8^{\prime \prime}$ and larger.

Cements: compatible with M-M 200 Catalyst and M-Bond 200 Adhesive or M-Bond 610 .

B) Apparatus.

The apparatus used to apply a series of tensions to the test plate is a Material Testing System (MTS) with a load cell of 50 metric ton capacity, Mode1 661-23A-02, serial number 152. (See Figures 3.19 and 3.20.) The strains relieved from the operation of tensioning the test piece as well as of hole drilling (holes A and B) will be measured by a strain indicator (see Figures 3.4 and 3.5).

C) Experimental set up.

1) Experiment of checking the existence of residual stresses in the steel pipe.

The test plate cut to dimensions as shown in Figure 3.18 is put on a flat table. After installation of gage $A$ on the plate (see Figure 3.21) set to zero the strain indicator.

No load is applied during this experiment.

Attach the milling guide and drill hole with increment of 0.01 " hole depth each time up to total depth of 0.125 " and record results (see Figure 3.22). 


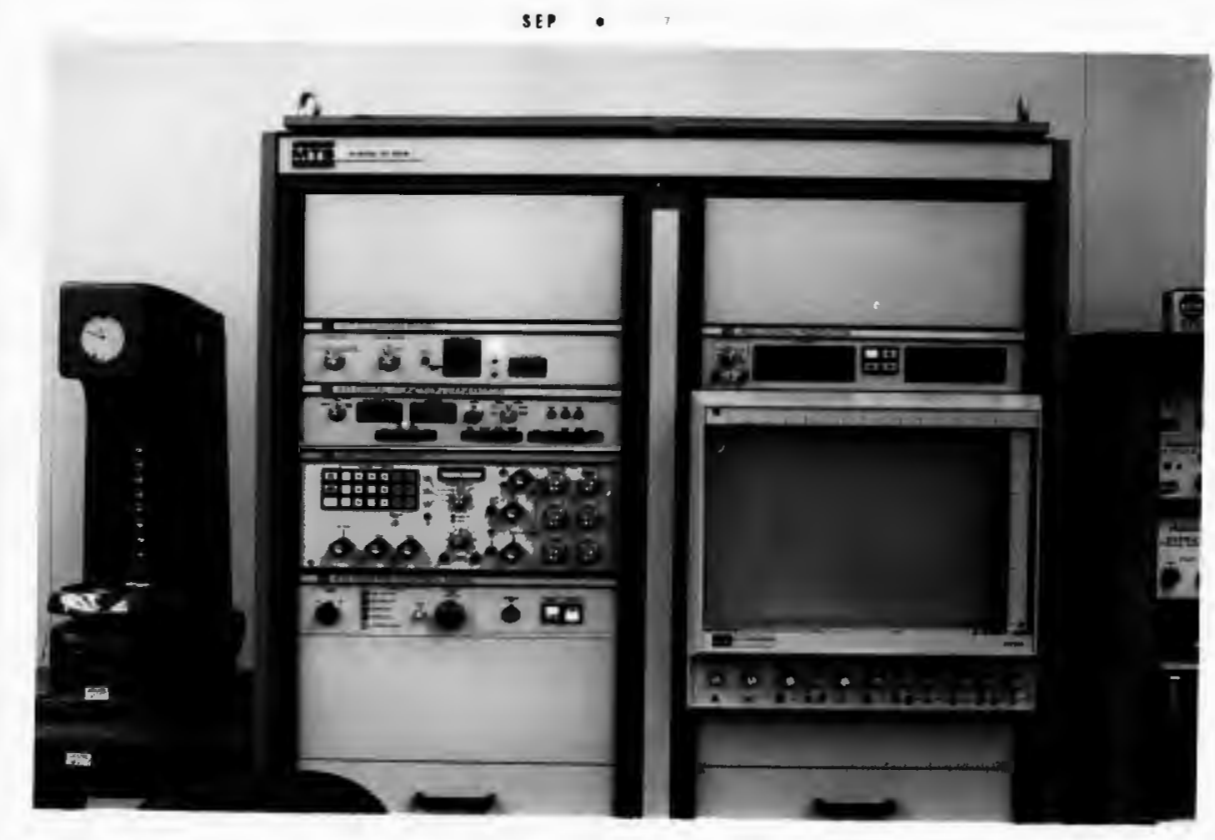

Figure 3.19 Material Testing System (MTS)

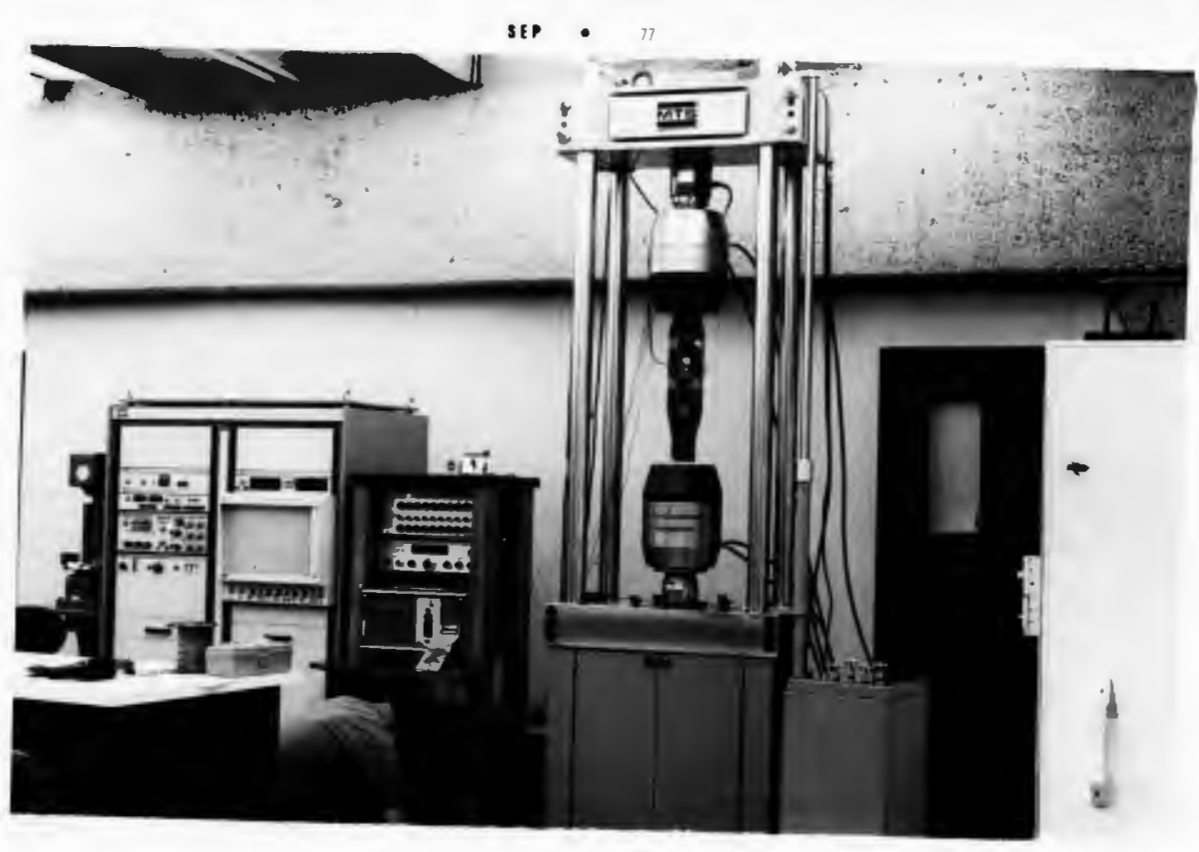

Figure 3.20 Material Testing System with load cell 


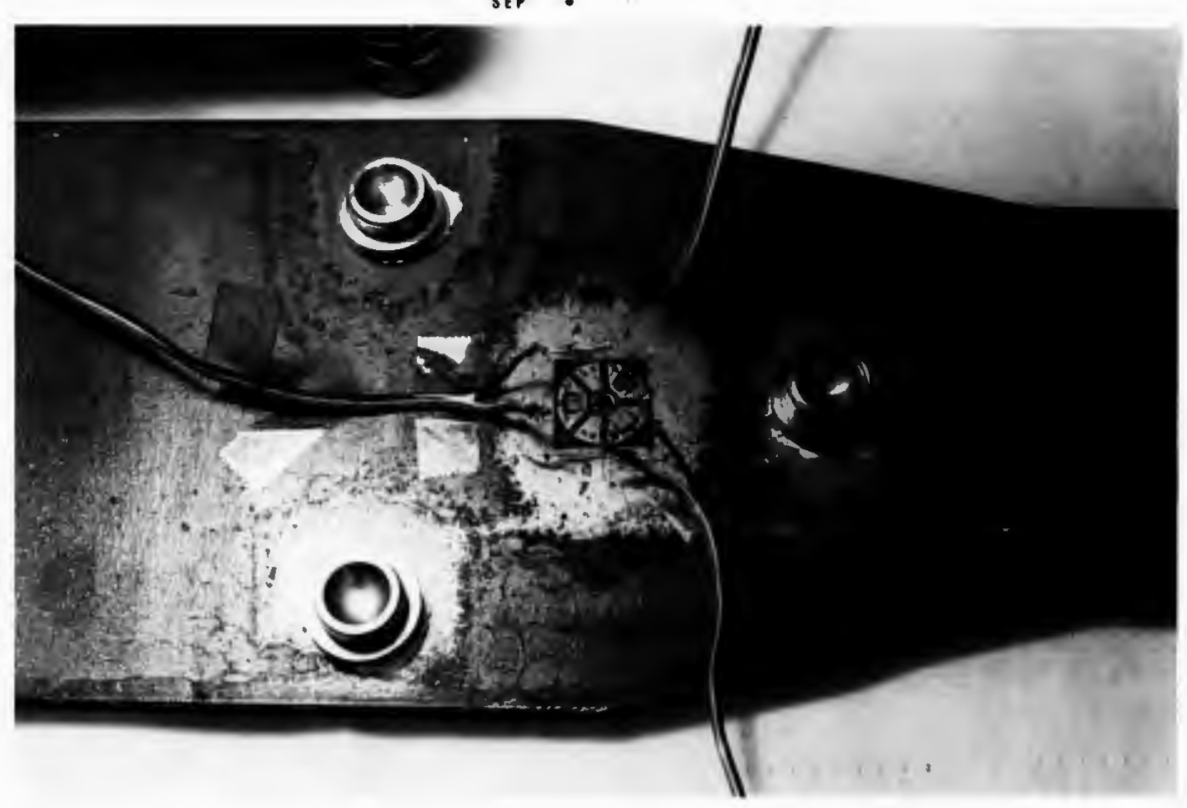

Figure 3.21 Gage A for a residual stress check

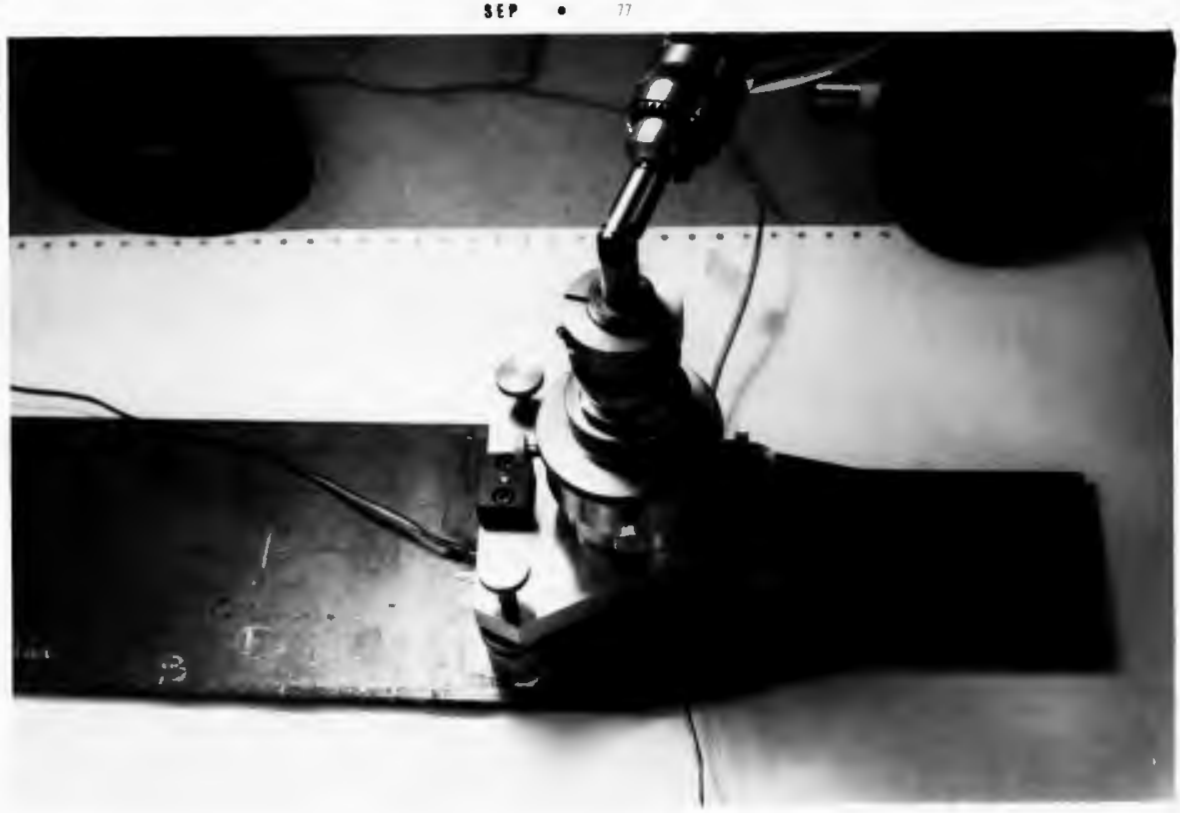

Figure 3.22 Hole in gage A under drilling 
The results of this experiment indicated a residual stress in the order of magnitude of $1000 \mathrm{psi}$. It will be seen later that the effect of this stress is eliminated in the determination of calibration coefficients.

2) Experiment of measuring the modulus of elasticity of the test plate steel.

Apply tensions $\sigma_{1}$ and $\sigma_{2}$ to the plate and record from the reference gage the corresponding strains $\varepsilon_{1}$ and $\varepsilon_{2}$.

The modulus of elasticity $E$ will be given by:

$$
E=\left(\sigma_{1}-\sigma_{2}\right) /\left(\varepsilon_{1}-\varepsilon_{2}\right)
$$

The computations done in paragraph 3.2 .2 show $\mathrm{E}=29$ * $10^{6} \mathrm{psi}$

3) Experiment of determination of strain-relaxation due to drilling.

The gage $B$ as shown in Figure 3.18, to measure disturbed strains, is cemented on the test plate and the latter is installed on the Material Testing System (see Figure 3.23).

The strain indicator is set to zero.

A tension $\mathrm{T}_{1}=26.84 \mathrm{kip}$ is applied to the test plece so that the piece is under a stress $\sigma_{1}=16.73 \mathrm{ksi}$. For each gage in the rosette, a strain reading is made, $\varepsilon_{a}$ for example.

Now load $\mathrm{T}_{1}$ is released. A hole of 0.125 in diameter and of 0.01 in depth is drilled through gage B (see Figure 3.24). Zero strain reading, the same stress $\sigma_{1}$ is reapplied for the same direction 1 , another strain reading is made, $\varepsilon_{b}$ for example. 


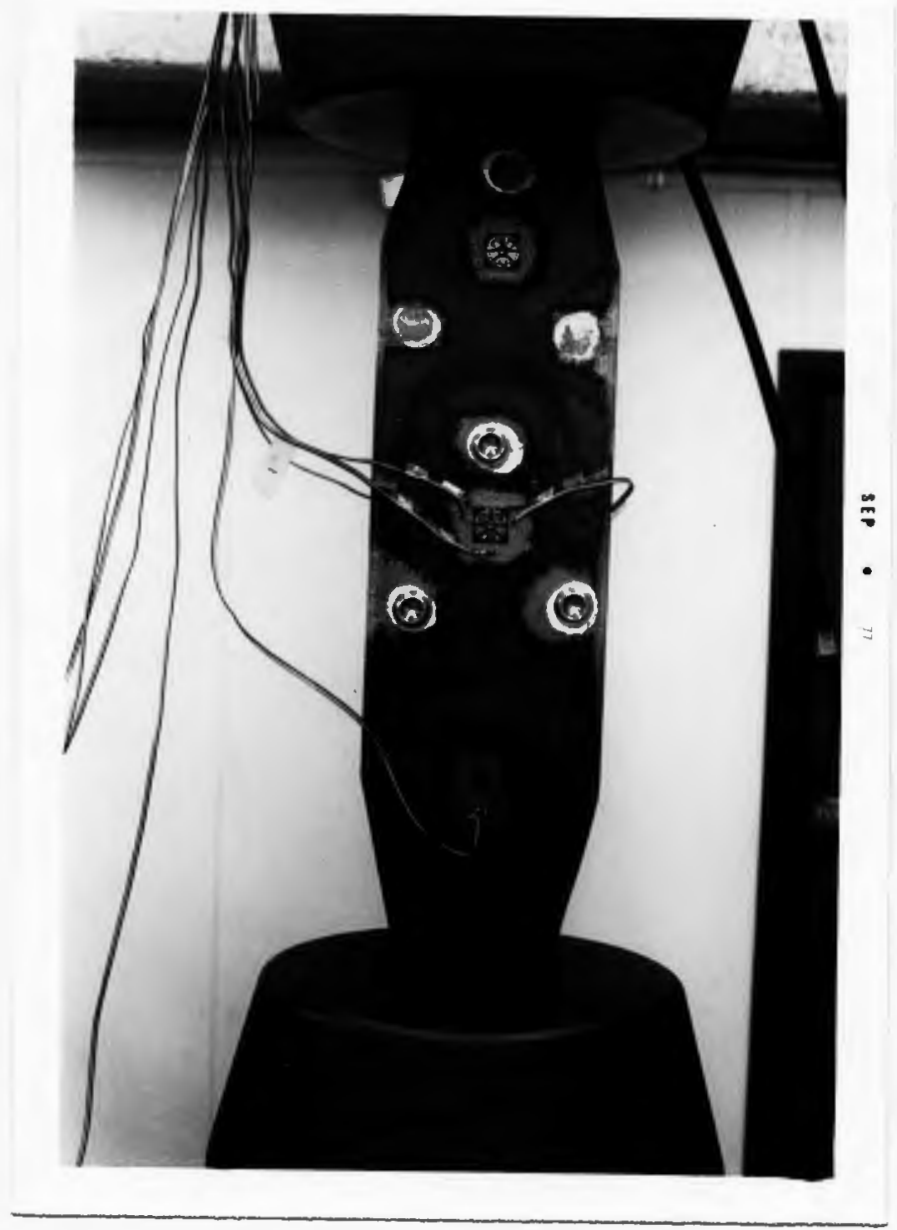

$\frac{\text { Figure } 3.23}{\text { Testing System }}$ Seting test plece in the jaws of the Material 
Compute $\Delta \varepsilon=\varepsilon_{a}-\varepsilon_{b}$. This difference between two readings before and after drilling, with the same load applied to the plate, represents the strain-relaxation due to drilling pertaining to a hole depth of 0.01 inch, for the direction 1 .

The cycle of operations is reiterated until the total hole depth of 0.125 inch is reached.

The diameter of the hole is measured and checked with the expected value of 0.125 inch.

At the end of one cycle of operations, readings are made and recorded for other directions (gages) 2,3 and for the reference gage for an eventual comparison. (See Figure 3.25.)

Finally for a total hole depth of 0.125 inch is reached,

$$
\begin{aligned}
& \Delta \varepsilon_{1}=\varepsilon_{\mathrm{a} 1}-\varepsilon_{\mathrm{b} 1}=\text { strain relaxation due to drilling for direction } 1 \\
& \Delta \varepsilon_{2}=\varepsilon_{\mathrm{a} 2}-\varepsilon_{\mathrm{b} 2}=\text { strain relaxation due to drilling for direction } 2 \\
& \Delta \varepsilon_{3}=\varepsilon_{\mathrm{a} 3}-\varepsilon_{\mathrm{b} 3}=\text { strain-relaxation due to drilling for direction } 3 .
\end{aligned}
$$

These three relaxed strains $\Delta \varepsilon_{1}, \Delta \varepsilon_{2}, \Delta \varepsilon_{3}$ are treated as regular measured strains to provide calibration coefficients. The testing procedure has eliminated any effect of initial residual stresses. Results will be shown in the paragraph 3.2.2 "Test results".

4) Experiment of separation of induced stresses and applied stresses.

The gage $B$ as shown in Figure 3.18 is cemented on the plate which is mounted on the Material Testing System.

The strain indicator is set to zero. A tension $\mathrm{T}_{1}=$ 


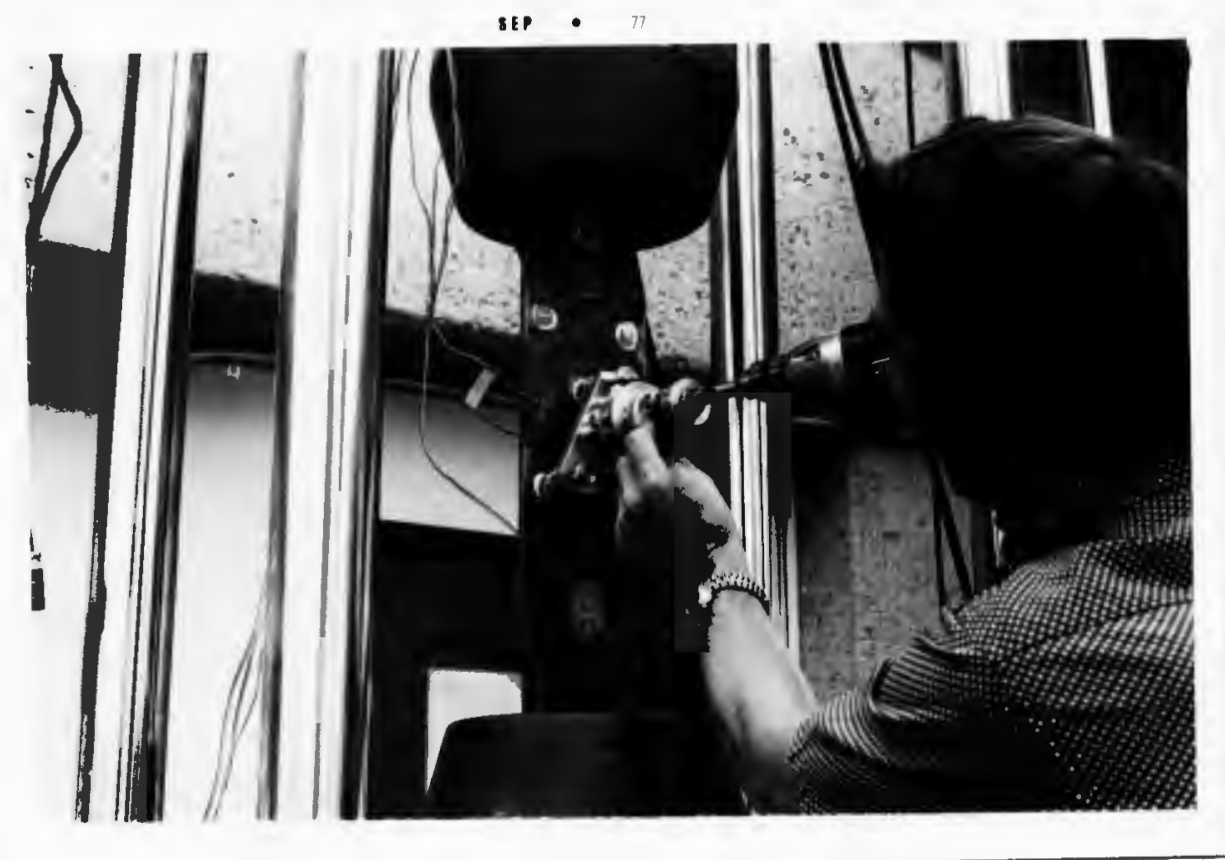

Figure 3.24 Hole in gage B under drilling

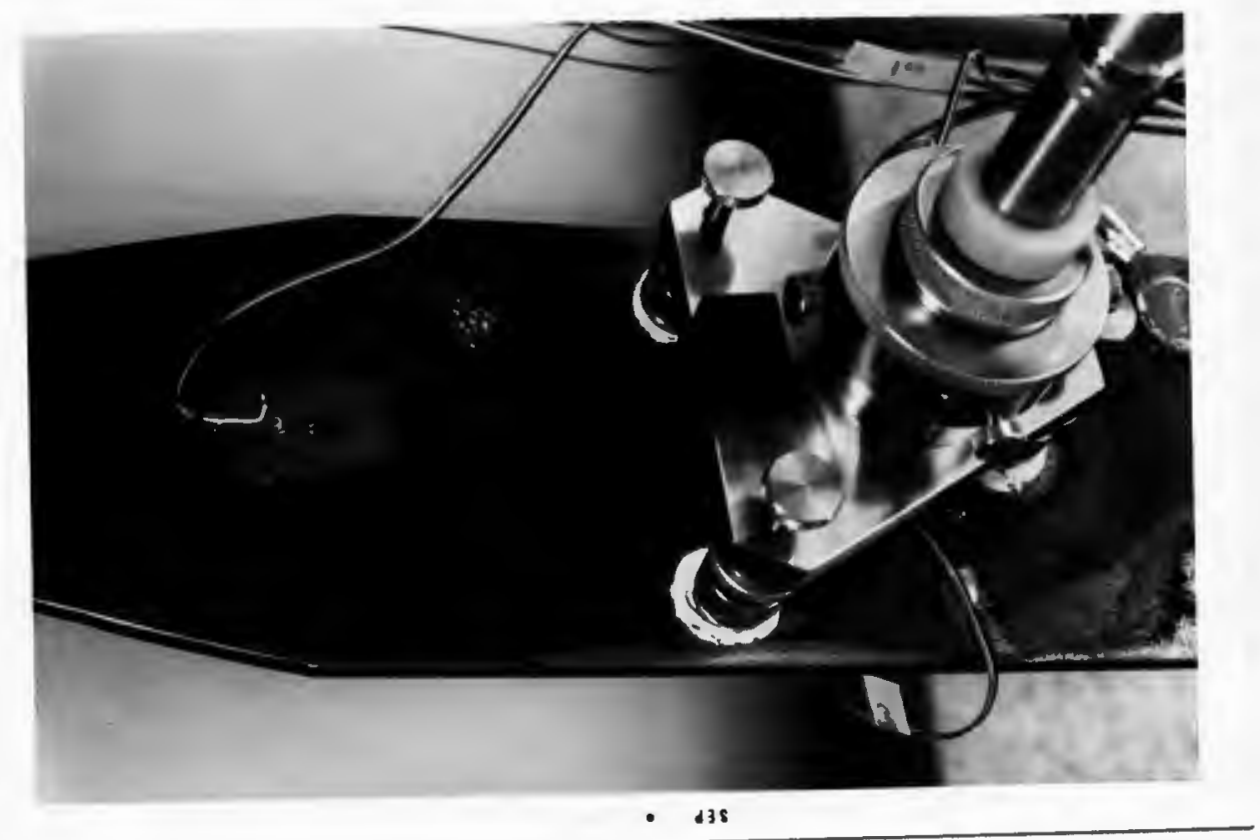

Figure 3.25 Reference gage at left hand side 
$26.84 \mathrm{kip}$ is applied to the plate so as to have a stress $\sigma_{1}=16.73 \mathrm{ksi}$ in 1 , then a strain reading is made for each direction 1,2 , and 3 . While maintaining the same tension and the same stress, a hole is drilled of 0.125 in diameter and of 0.01 in depth (see Figure 3.24) and strain readings made for each direction 1, 2, and 3 . Now the tension is reduced to $\mathrm{T}_{2}=\mathrm{T}_{1} / 2=13.42 \mathrm{kip}$ so as to obtain a stress $\sigma_{2}=\sigma_{1} / 2=8.37 \mathrm{ksi}$ and a reading is made for each direction.

$$
\text { Only three trials: }
$$

Trial 1, hole depth $0.0^{\prime \prime}$, stress $16.73 \mathrm{ksl}$

Trlal 2, hole depth $0.125^{\prime \prime}$, stress $16.73 \mathrm{ksI}$

Trial 3, hole depth $0.125^{\prime \prime}$, stress $8.36 \mathrm{ksi}$

are needed for this experiment to provide 3 corresponding strains for each direction 1,2 , and 3 . These data are shown in Table 3.6.

For each direction, three strains have been recorded. For example, for Direction 1:

Trial 1: strain 202, stress $16.73 \mathrm{ksi}$

Tr1al 2: strain 115, stress $16.73 \mathrm{ksi}$

Trial 3: strain $\underline{56}$, stress $8.36 \mathrm{ksi}$

The strain relaxed is then the difference between the strain reading before and after drilling with the plate subjected to $\sigma_{1}$

$$
\begin{aligned}
& \text { Numerically: } 115-202=-87 \text { microstrains. } \\
& \text { By graphical interpolation shown in Figure } 3.26 \text {, the }
\end{aligned}
$$
strain caused by already present residual stresses and drilling effects is -3 microstrains. 


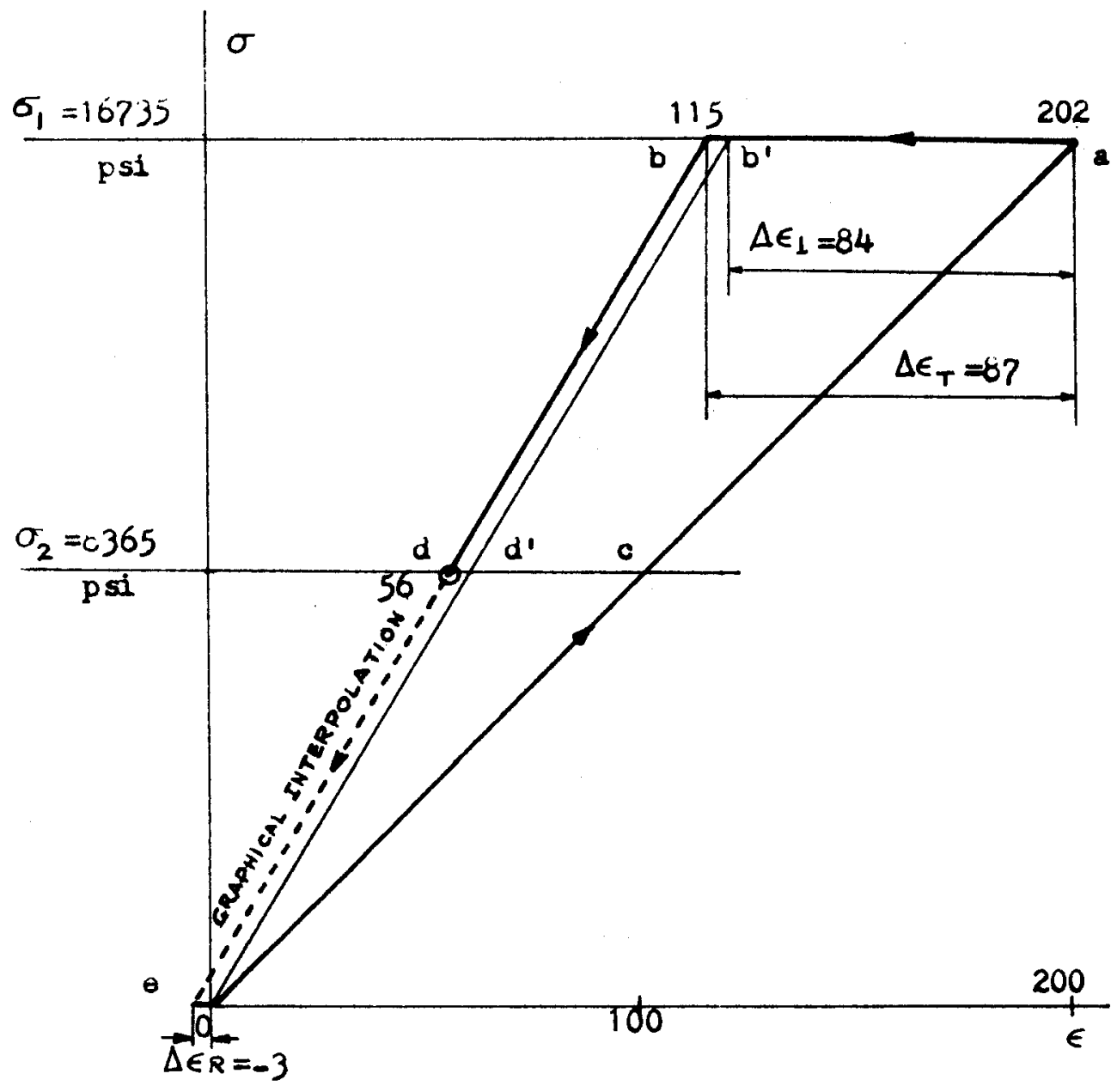

Elgure 3.26. Strain separation for Direction 1 wh th numerical application 
Strain due to applied stress $\Delta \varepsilon_{1}=-87-(-3)=-84$

By the same approach, it has been found:

$$
\begin{aligned}
& \Delta \varepsilon_{2}=-143 \\
& \Delta \varepsilon_{3}=-25
\end{aligned}
$$

These strains due to applied stresses are treated as measured strains:

$$
\begin{aligned}
& S=\Delta \varepsilon_{1}+\Delta \varepsilon_{3}=-84-25=-109 \\
& D=\Delta \varepsilon_{1}-\Delta \varepsilon_{3}=-84-(-25)=-59 \\
& \text { Tan } 2 \beta=\left(S-2 \Delta \varepsilon_{2}\right) / D=(-109-2(-143)) /-59=-177 / 59 \\
& \text { Cos } 2 \beta=0.316227 \\
& \text { From equations }(3 \mathrm{a}), \text { Appendix III: } \\
& 4 \mathrm{~A}=2 \mathrm{~S} /\left(\sigma_{1}+\sigma_{2}\right) \\
& 4 \mathrm{~B}=2 \mathrm{D} /\left(\left(\sigma_{1}-\sigma_{2}\right) \text { Cos } 2 \beta\right) \\
& \text { The experiment has provided: } \\
& \sigma_{1}=16730 \text { psi, } \sigma_{2}=0 \\
& \text { Fina11y: } \\
& \text { 4A }=2(-109) 10^{-6} / 16730=-1.30\left(10^{-8}\right) \\
& 4 \mathrm{~B}=2(-59) 10^{-6} /(16730 * 0.316227)=-2.23\left(10^{-8}\right) \\
& 3.2 \text { TEST RESULTS }
\end{aligned}
$$

3.2.1 Results from the hole drilling experiments on the steel tube. Results from the experiments of hole drilling from the outside surface of the tube for Hole \#1 are shown in detall in Tables 3.1 and 3.2. These tables give for 13 trial hole depths, measured strains for gages $a, b, c$, principal stresses $\sigma_{1}$ and $\sigma_{2}$ for each set of strains in three directions, longitudinal stresses $\sigma_{L}$ and circumferential stresses 
TABLE 3.1

EXPERIMENT OF OUTSIDE HOLE DRILLING

RESULTS FOR HOLE 1

\begin{tabular}{|c|c|c|c|c|}
\hline Trial & Hole & \multicolumn{3}{|c|}{ Measured strains } \\
\hline$\#$ & Depth & Gage a & Gage b & Gage $c$ \\
\hline 1 & $0.01^{\prime \prime}$ & 2 & 10 & 8 \\
\hline 2 & 0.02 & 3 & 14 & 14 \\
\hline 3 & 0.03 & 5 & 22 & 25 \\
\hline 4 & 0.04 & 4 & 24 & 39 \\
\hline 5 & 0.05 & 7 & 31 & 49 \\
\hline 6 & 0.06 & 7 & 30 & 55 \\
\hline 7 & 0.07 & 6 & 30 & 62 \\
\hline 8 & 0.08 & 6 & 30 & 67 \\
\hline 9 & 0.09 & 5 & 27 & 70 \\
\hline 10 & 0.10 & 2 & 26 & 72 \\
\hline 11 & 0.11 & 3 & 30 & 73 \\
\hline 12 & 0.125 & 4 & 27 & 75 \\
\hline 13 & 0.13 & 3 & 26 & 72 \\
\hline
\end{tabular}


TABLE 3.2

(Continued)

\begin{tabular}{|c|c|c|c|c|c|c|}
\hline $\begin{array}{c}\text { Trial } \\
\text { 非 }\end{array}$ & $\begin{array}{l}\text { Hole } \\
\text { Depth }\end{array}$ & $\begin{array}{r}\sigma_{1} \\
p s i\end{array}$ & $\begin{array}{r}\sigma_{2} \\
\text { psi }\end{array}$ & $\begin{array}{l}{ }^{\sigma}{ }_{\mathrm{L}} \\
\mathrm{psi}\end{array}$ & $\begin{array}{r}\sigma_{\mathrm{T}} \\
\mathrm{psi}\end{array}$ & $\sigma_{\mathrm{L} / \mathrm{y}}$ \\
\hline 1 & $0.01^{\prime \prime}$ & -1190 & -1799 & -1744 & -1214 & -0.04 \\
\hline 2 & 0.02 & -1332 & -2576 & -2394 & -1514 & -0.06 \\
\hline 3 & 0.03 & -2472 & -4425 & -4008 & -2888 & -0.09 \\
\hline 4 & 0.04 & -3528 & -6357 & -5143 & -4743 & -0.12 \\
\hline 5 & 0.05 & -4730 & -8134 & -6677 & -6197 & -0.16 \\
\hline 6 & 0.06 & -5205 & -9048 & -7206 & -7046 & -0.18 \\
\hline 7 & 0.07 & -5554 & -10079 & -8136 & -7496 & -0.20 \\
\hline 8 & 0.08 & -5896 & -10885 & -8911 & -7871 & -0.22 \\
\hline 9 & 0.09 & -5880 & -11353 & -9461 & -7781 & -0.23 \\
\hline 10 & 0.10 & -5571 & -11411 & -9386 & -7626 & -0.23 \\
\hline 11 & 0.11 & -5863 & -11600 & -9376 & -8096 & -0.23 \\
\hline 12 & 0.125 & -6200 & -11920 & -10080 & -8080 & -0.24 \\
\hline 13 & 0.13 & -5711 & -11530 & -9541 & -7701 & -0.23 \\
\hline
\end{tabular}


$\sigma_{T}$, ratio of $\sigma_{L}$ to yield stress $\sigma_{y}$.

As the quantity of data is great, it has been simplified and shown in Table 3.3. Only data relating to depth 0.125 inch is shown, comprising strains in three directions, values of data reduction coefficients $4 A$ and $4 B$, principal stresses $\sigma_{1}$ and $\sigma_{2}$, longitudina 1 , circumferential stresses and ratio of $\sigma_{L}$ to yield stress $\sigma_{y}$.

In Table 3.4 are shown results pertaining to inside holes comprising longitudinal, circumferential stresses, ratio of $\sigma_{L}$ to yield stress $\sigma_{y}$ for hole depth of 0.125 inch.

In light of the data shown in these tables, an evaluation of results can be made, leading to some pertinent remarks and proving that the stress field in the welded fabricated steel tube is uniform.

\section{A) Remarks .}

A survey of values of strains for each gage in Table 3.2 shows that they gradually increase with hole depth, reach a peak for a 0.125 inch depth then slightly decrease (see Figure 3.27). This fact confirms the assertion by Bush and Kromer (2) and by $S$. Redner (10) that the strains relieved attain a limiting value and a maximum when hole depth approaches the hole diameter.

A second remark is that the values of stresses computed from strains measured by three gages $a, b, c$ for one hole gradually increase and reach a maximum for ratio depth to hole radius equal to 1.0 and slightly decrease further.

Finally, values of longltudinal residual stresses found from outside and inside holes agree. In fact, for four holes number $3,4,5$ and 6 , the ratio of $\sigma_{L}$ to $\sigma_{y}$ for outside and inside holes are 
TABLE 3.3

EXPERIMENT OF OUTSIDE HOLE DRILLING

DATA AND RESULTS FOR 11 HOLES

(HOLE DEPTH $\left.0.125^{\prime \prime}\right)$

\begin{tabular}{|c|c|c|c|c|c|}
\hline \multirow{2}{*}{$\begin{array}{l}\text { Hole } \\
\qquad \#\end{array}$} & \multicolumn{3}{|c|}{ Micro-strains } & \multirow{2}{*}{$\begin{array}{c}4 \mathrm{~A} * \\
\left(* 10^{-8}\right)\end{array}$} & \multirow{2}{*}{$\begin{array}{c}4 \mathrm{~B} * \\
\left(* 10^{-8}\right)\end{array}$} \\
\hline & $\varepsilon_{\mathbf{a}}$ & $\varepsilon_{b}$ & $\varepsilon_{c}$ & & \\
\hline 1 & 40 & 27 & 75 & -0.87 & -2.50 \\
\hline 2 & -41 & -25 & -77 & -0.88 & -2.50 \\
\hline 3 & -24 & -36 & -41 & -0.88 & -2.50 \\
\hline 4 & -51 & 15 & 18 & -1.05 & -2.68 \\
\hline 5 & 149 & 30 & 59 & -0.85 & -2.45 \\
\hline 6 & -31 & -18 & -32 & -0.88 & -2.50 \\
\hline 7 & -32 & -90 & -102 & -0.85 & -2.45 \\
\hline 8 & -35 & -17 & -21 & -0.85 & -2.45 \\
\hline 9 & -89 & 79 & -104 & -0.95 & -2.60 \\
\hline A & 97 & 101 & 29 & -0.83 & -2.37 \\
\hline B & 20 & 12 & 92 & -0.83 & -2.37 \\
\hline
\end{tabular}

* These values of $4 A$ and $4 B$ based on Figure 2.3 
TABLE 3.3

(Continued)

\begin{tabular}{|c|c|c|c|c|c|}
\hline Hole & $\sigma_{1}$ & $\sigma_{2}$ & $\sigma_{\mathrm{L}}$ & $\sigma_{\mathrm{T}}$ \\
$\mathrm{psi}$ & $\mathrm{psi}$ & $\sigma_{\mathrm{L} i}$ & $\sigma_{\sigma_{\mathrm{y}}}$ \\
\hline 1 & -6070 & -12091 & -10080 & -8080 & -0.24 \\
\hline 2 & 10331 & 16487 & 16090 & 16130 & 0.24 \\
\hline 3 & 6651 & 8122 & 7106 & 7666 & 0.17 \\
\hline 4 & 6629 & -343 & 792 & 5494 & 0.02 \\
\hline 5 & -31541 & -17401 & -30510 & -18430 & -0.75 \\
\hline 6 & 6078 & 8240 & 6079 & 8239 & 0.13 \\
\hline 7 & 12346 & 19184 & 13890 & 17640 & 0.34 \\
\hline 8 & 7652 & 5524 & 5690 & 7486 & 0.14 \\
\hline 9 & 6803 & 33828 & 33820 & 6816 & 0.80 \\
\hline A & -19484 & -10878 & -18390 & -11970 & -0.45 \\
\hline B & -8696 & -18292 & -17210 & -9781 & -0.42 \\
\hline
\end{tabular}


TABLE 3.4

EXPERIMENT OF INSIDE HOLE DRILLING

RESULTS FOR FOUR HOLES

\begin{tabular}{|c|c|c|c|}
\hline $\begin{array}{c}\text { Hole } \\
\#\end{array}$ & $\begin{array}{r}\sigma_{L} \\
p s i\end{array}$ & $\begin{array}{r}\sigma_{T} \\
\mathrm{psI}\end{array}$ & ${ }^{\sigma_{L}} / \sigma_{y}$ \\
\hline 3 & 6455 & 11160 & 0.16 \\
\hline 4 & -600 & -420 & -0.01 \\
\hline 5 & -29500 & -668 & -0.72 \\
\hline 6 & 5800 & 11160 & 0.14 \\
\hline
\end{tabular}




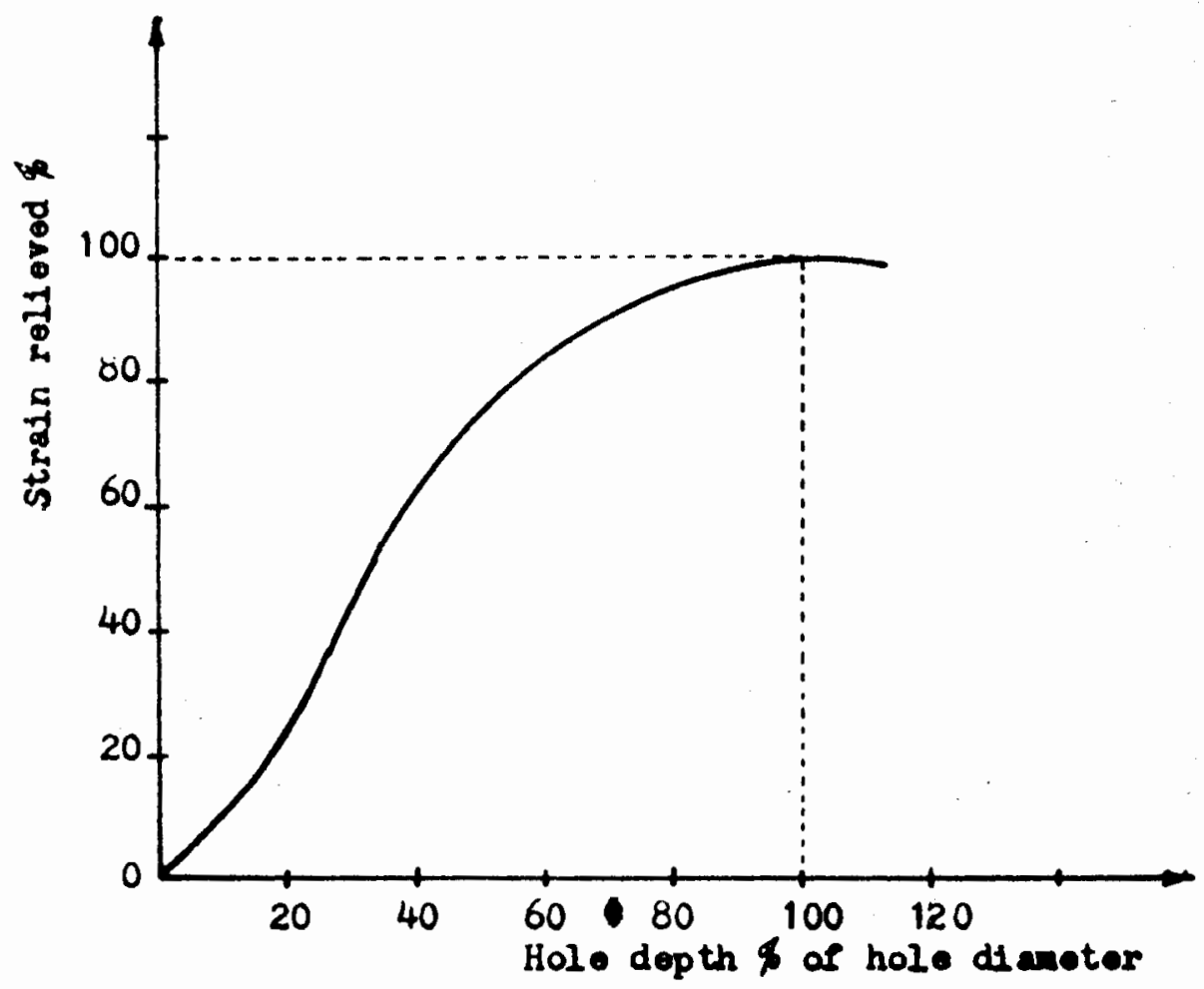

Flgure 3.27 Strain relleved vo depth (Hole 1.gage o) 
respectively:

$$
\begin{aligned}
& 0.17 \text { and } 0.16 \text { (deviation } 0.01 \text { of } \sigma_{y} \text { ) } \\
& 0.02 \text { and }-0.01 \text { (deviation } 0.03 \text { of } \sigma_{y} \text { ) } \\
& -0.75 \text { and }-0.73 \text { (deviation } 0.02 \text { of } \sigma_{y} \text { ) } \\
& 0.13 \text { and } 0.14 \text { (deviation } 0.01 \text { of } \sigma_{y} \text { ) }
\end{aligned}
$$

These deviations appear low and suggest a well behaved stress distribution.

B) The substantiation of the unfform field of residual stresses in the tube is now presented.

$$
\text { According to Kelsey (1), in a unfform fleld of stresses, }
$$
the relationship between surface strain and hole depth is proportional to the magnitude of the stress. In other words, the incremental change in surface strain $\Delta \varepsilon_{z i}$, for an incremental change in hole depth $\Delta z_{1}$ is proportional to the magnitude of the stress $\sigma_{21}$.

For a material following Hooke's law

$$
\varepsilon=\sigma / E
$$

but for the hole drilling method, the incremental strain is not a direct measure of the average residual stress in a given increment of hole depth. Therefore, a factor of proportionality $\mathrm{K}$ must be introduced :

$$
\Delta \varepsilon_{z i}=\mathrm{K} \sigma_{z i} / \mathrm{E}
$$

Equations for the strains corresponding to the stresses in two perpendicular directions are:

$$
\begin{aligned}
& \varepsilon_{L}=\sigma_{L} / E-\mu \sigma_{T} / E \\
& \varepsilon_{T}=\sigma_{T} / E-\mu \sigma_{L} / E
\end{aligned}
$$


In the hole drilling method, the above equations become:

$$
\begin{aligned}
& { }^{\Delta \varepsilon_{L}}=\mathrm{K}_{1} \sigma_{\mathrm{L}} / \mathrm{E}-\mu \mathrm{K}_{2} \sigma_{\mathrm{T}} / \mathrm{E} \\
& \Delta \varepsilon_{\mathrm{T}}=\mathrm{K}_{1} \sigma_{\mathrm{T}} / \mathrm{E}-\mu \mathrm{K}_{2} \sigma_{\mathrm{L}} / \mathrm{E}
\end{aligned}
$$

Solving (3) and (4) in terms of $L$ and $T$ gives:

$$
\begin{aligned}
& \sigma_{L}=E /\left(K_{1}^{2}-\mu^{2} K_{2}^{2}\right)\left(K_{1}\left(\Delta \varepsilon_{L}\right)+\mu K_{2}\left(\Delta \varepsilon_{T}\right)\right) \\
& \sigma_{T}=E /\left(K_{1}^{2}-\mu^{2} K_{2}^{2}\right)\left(K_{1}\left(\Delta \varepsilon_{T}\right)+K_{2}\left(\Delta \varepsilon_{L}\right)\right)
\end{aligned}
$$

Now solving equations (3) and (4) for the factors of proportionality gives:

$$
\begin{aligned}
& \mathrm{K}_{1}=\mathrm{E} /\left(\sigma_{\mathrm{L}}^{2}-\sigma_{\mathrm{T}}^{2}\right)\left(\sigma_{\mathrm{L}}\left(\Delta \varepsilon_{\mathrm{L}}\right)-\sigma_{\mathrm{T}}\left(\Delta \varepsilon_{\mathrm{T}}\right)\right) \\
& \mathrm{K}_{2}=\mathrm{E} / \mu\left(\sigma_{\mathrm{T}}^{2}-\sigma_{\mathrm{L}}^{2}\right)\left(\sigma_{\mathrm{L}}\left(\Delta \varepsilon_{\mathrm{T}}\right)-\sigma_{\mathrm{T}}\left(\Delta \varepsilon_{\mathrm{L}}\right)\right)
\end{aligned}
$$

Using the steel plate data,

$$
\begin{array}{rlrl}
\sigma_{L} & =16730 \mathrm{psi} & \sigma_{T} & =0 \\
\mu & =0.29 & \mathrm{E} & =29\left(10^{6}\right) \\
\varepsilon_{L} & =195\left(10^{-6}\right) & \varepsilon_{\mathrm{T}} & =40\left(10^{-6}\right)
\end{array}
$$

and using equations (7) and (8) to compute $k_{1}$ and $k_{2}$ for the test plate:

For the hole depth from 0.0 to $0.025^{\prime \prime}$,

$$
\begin{aligned}
& K_{1}=\frac{29\left(10^{6}\right)}{(16730)^{2}-0}\left(16730(195)\left(10^{-6}\right)-0\right)=0.338 \\
& K_{2}=\frac{29\left(10^{6}\right)}{0.29\left(0-16730^{2}\right)}\left(16730(40)\left(10^{-6}\right)-0\right)=-0.239
\end{aligned}
$$

The computed values of $K_{1}$ and $K_{2}$ for different hole depths varying from 0 to $0.125^{\prime \prime}$, are summarized in Table 3.5 . 
TABLE 3.5

VALUES OF FACTORS OF PROPORTIONALITY $k_{1}$ AND $k_{2}$ FOR THE PLATE

\begin{tabular}{|c|c|c|}
\hline Hole depth & $\mathrm{K}_{1}$ & $\mathrm{~K}_{2}$ \\
\hline $0.0-0.025^{\prime \prime}$ & 0.338 & -0.239 \\
$0.025-0.050$ & 0.324 & -0.236 \\
$0.050-0.075$ & 0.310 & -0.281 \\
$0.075-0.100$ & 0.296 & -0.304 \\
$0.100-0.125$ & 0.286 & -0.329 \\
\hline
\end{tabular}

Kelsey (1) has shown in his Table I for his first serles of tests relating to a uniform stress field, that when his plate lo subject to a tension $T_{1}$ (causing a uniform stress $\sigma_{1}$ in his plate) and subject later to a tension $T_{2}$ (causing a uniform stress $\sigma_{2}$ ) the respective longitudinal and transverse strains $\varepsilon_{\mathrm{L} 1}, \varepsilon_{\mathrm{T} 1}$ and $\varepsilon_{\mathrm{L} 2} \varepsilon_{\mathrm{T} 2}$ are bound by the relationships:

$$
\frac{\varepsilon_{\mathrm{L} 1}}{\varepsilon_{\mathrm{L} 2}}=\frac{\varepsilon_{\mathrm{T} 1}}{\varepsilon_{\mathrm{T} 2}}=\frac{\sigma_{1}}{\sigma_{2}} \quad(=2.0 \text { for h1s case })
$$

A first sample of calculation to prove the equality of the above ratios is taken from a study by Kelsey (1, Table I):

For the depth of $0.250^{\prime \prime}$ of a hole drilled in a uniform stress field :

$$
\begin{aligned}
& \varepsilon_{\mathrm{L} 1}=-376 \text { microstrains, } \varepsilon_{\mathrm{T} 1}=122 \text { microstrains, } \sigma_{\mathrm{L} 1}=9700 \mathrm{ps} 1 \\
& \varepsilon_{\mathrm{L} 2}=-800-\varepsilon_{\mathrm{T} 2}=249-\sigma_{\mathrm{L} 2}=19400 \mathrm{ps} 1
\end{aligned}
$$


Ratios:

$$
\frac{\varepsilon_{\mathrm{L} 2}}{\varepsilon_{\mathrm{L} 1}}=2.1, \quad \frac{\varepsilon_{\mathrm{T} 2}}{\varepsilon_{\mathrm{T} 1}}=2.0, \quad \frac{\sigma_{\mathrm{L} 2}}{\sigma_{\mathrm{L} 1}}=2.0
$$

A second sample of calculation to substantiate the equality of these ratios is taken from the case of our steel plate subject to unfform tensions $T_{1}$ and $T_{2}$, data read from the Hole $B$ with a hole depth of $0.125^{\prime \prime}$ :

$$
\begin{array}{llrl}
\varepsilon_{\mathrm{L} 1} & =82 \text { microstrains, } \varepsilon_{\mathrm{T} 1}=27 \text { microstrains, } \sigma_{\mathrm{L} 1}=8370 \mathrm{ps} 1 \\
\varepsilon_{\mathrm{L} 2}=165-\varepsilon_{\mathrm{T} 2} & =55-\sigma_{\mathrm{L} 2}=16730 \mathrm{ps} 1
\end{array}
$$

Ratios:

$$
\frac{\varepsilon_{L 2}}{\varepsilon_{L 1}}=2.0, \quad \frac{\varepsilon_{T 2}}{\varepsilon_{T 1}}=2.0, \quad \frac{\sigma_{L 2}}{\sigma_{L 1}}=2.0
$$

The values of these ratios of strains and stresses show good agreement.

To prove that a non-uniform stress field does not have these characteristics: that is $=$

$$
\frac{\varepsilon_{\mathrm{L} 2}}{\varepsilon_{\mathrm{L} 1}} \neq \frac{\varepsilon_{\mathrm{T} 2}}{\varepsilon_{\mathrm{T} 1}} \neq \frac{\sigma_{\mathrm{L} 2}}{\sigma_{\mathrm{L} 1}}
$$

reference is again made to Kelsey, Table II (1) for a non-uniform stress field studied by Kelsey shows that the ratios $\frac{\varepsilon_{L 2}}{\varepsilon_{L 1}}, \frac{\varepsilon_{T 2}}{\varepsilon_{T 1}}$, $\frac{\sigma_{L 2}}{\sigma_{L 1}}$ are not equa1 (see Table 3.6 ). 
TABLE 3.6

DATA FROM A NON-UNIFORM STRESS FIELD

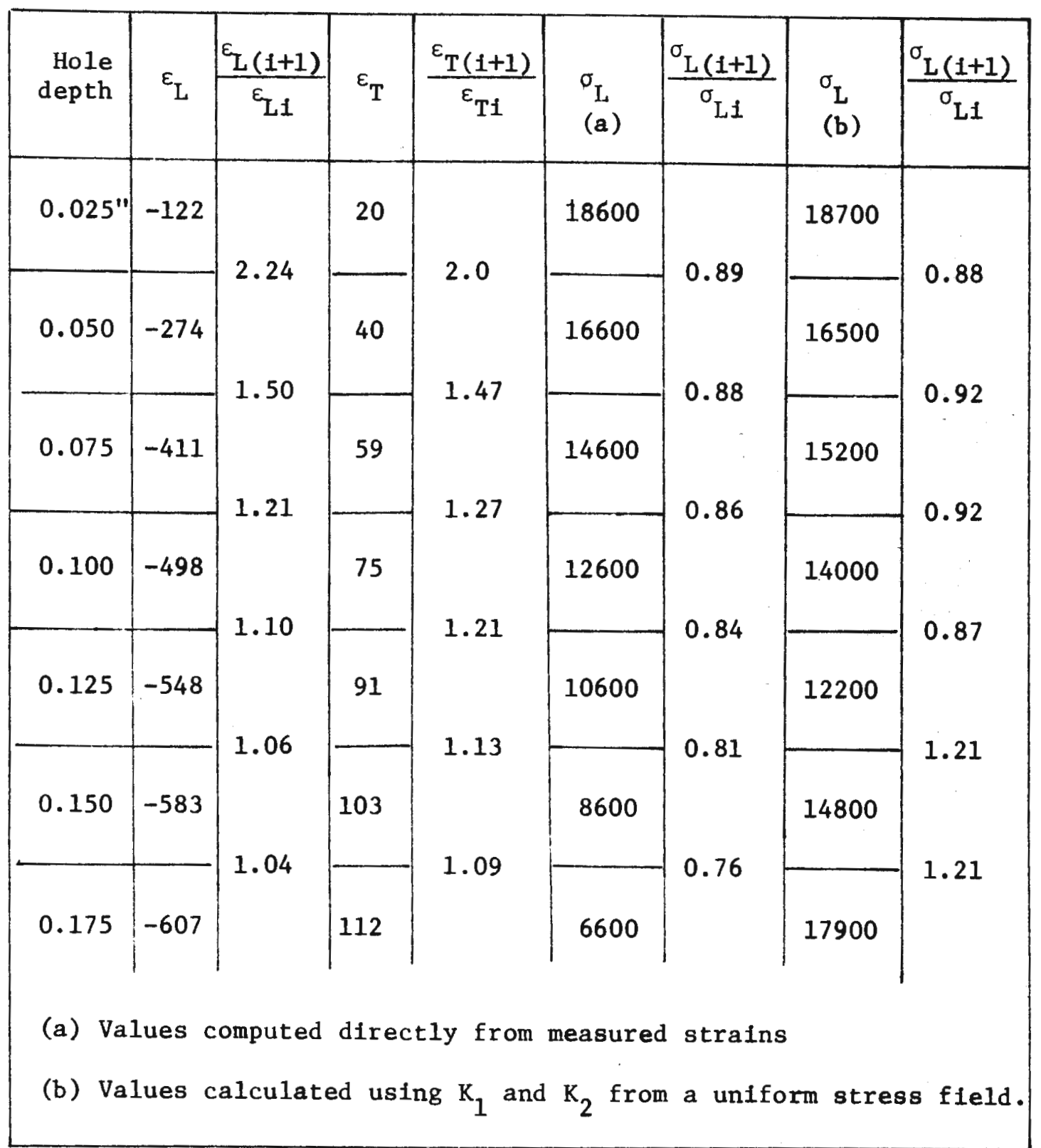

In order to substantiate that the field of residual stresses present in the steel tube is uniform, through the depth, we first calculate the stresses $\sigma_{L 1}$ and $\sigma_{L(i+1)}$ corresponding to hole depths 
$\mathrm{Z}_{i}$ and $\mathrm{z}_{i+1}$ in the steel tube, using $\mathrm{K}_{1}$ and $\mathrm{K}_{2}$ obtained from the test plate and the corresponding hole depths in the test plate. The second step is to compute the ratios $\frac{\varepsilon_{L(1+1)}}{\varepsilon_{L 1}}, \frac{\varepsilon_{T(1+1)}}{\varepsilon_{T 1}}$ and

$\frac{\sigma_{L(i+1)}}{\sigma_{L i}}$ and compare.

Sample calculation:

Step 1. Trial 1. For hole depth of $0.25^{\prime \prime}$ in the test plate, $k_{1}=$ $0.338, K_{2}=-0.239$ (see Table A). With these values of $K_{1}$ and $K_{2}$ (from the plate) and values of $\varepsilon_{L}=-3\left(10^{-6}\right), \varepsilon_{T}=10^{-6}$ of the same hole depth of the Hole 4 in the tube, compute $\sigma_{L 1}$, for this Hole:

$$
\begin{aligned}
\sigma_{L 1} & =\frac{29\left(10^{6}\right)}{0.338^{2}-(0.29 * 0.239)^{2}}[0.338(-3)+(0.29)(-0.239)(1)]\left(10^{-6}\right) \\
& =-287 \mathrm{psi}
\end{aligned}
$$

Trial 2. For the hole depth of $0.050^{\prime \prime}$ in the test plate, with the values of $k_{1}=0.324, K_{2}=-0.263$ and the values of $\varepsilon_{L}=$ $-15\left(10^{-6}\right), \varepsilon_{T}=4\left(10^{-6}\right)$ of the same hole depth of the Hole 4 in the tube, compute $\sigma_{L 2}$ for this Hole:

$$
\begin{aligned}
\sigma_{L 2} & =\frac{29\left(10^{6}\right)}{0.324^{2}-(0.29 *-0.263)^{2}}[(0.234)(-15)+(0.29)(-0.263)(4)]\left(10^{-6}\right) \\
& =-1510 \mathrm{psi} .
\end{aligned}
$$

Step 2. Compute the ratios:

$$
\begin{array}{ll}
\frac{\sigma_{\mathrm{L} 2}}{\sigma_{\mathrm{L} 1}}=\frac{-1510}{-287}=5.2, & \frac{\sigma_{\mathrm{T} 2}}{\sigma_{\mathrm{T} 1}}=\frac{4}{0.8}=5.0 \\
\frac{\varepsilon_{\mathrm{L} 2}}{\varepsilon_{\mathrm{L} 1}}=\frac{-15}{-3}=5.0 &
\end{array}
$$


The deviation: $(5.2-5.0) / 5.0=0.04$ of $\varepsilon_{L 2} / \varepsilon_{L 1}$ appears acceptable.

The computations of $\sigma_{L}$ and $\sigma_{T}$ and the required ratios are summarized in Table 3.7 .

The ratios of $\frac{\varepsilon_{L(1+1)}}{\varepsilon_{L 1}}, \frac{\varepsilon_{T(i+1)}}{\varepsilon_{T 1}}, \frac{\sigma_{L(1+1)}}{\sigma_{L 1}}$ show close agreement, and the uniform stress field assumed in Chapter II 1 s substantiated by numerical calculation.

\subsubsection{Tensioning and calibration experiment.}

A) Results of the test.

Data derived from the experiment of strain-relaxation due to drilling are condensed in Table 3.8. These data w111 be used in section 3.2 .2 .c to compute the values of calibration coefficients $4 \mathrm{~A}$ and $4 \mathrm{~B}$.

Data pertaining to the experiment of separation of Induced stresses and applied stresses are shown in Table 3.9. Callbration coefficients $4 \mathrm{~A}$ and $4 \mathrm{~B}$ are computed from these data and described in section 3.2.2.d.

B) Computation of the value of modulus of elasticity. The modulus of elasticity in a strain-stress curve is given by the slope of the straight part of the curve. As the maximum stress applied to the plate is $0.40 \mathrm{~F}$ (within the limit of elasticlty) Hooke's law is valid and:

$$
E=\sigma / \varepsilon \text { or } \quad E=\left(\sigma_{2}-\sigma_{1}\right) /\left(\varepsilon_{2}-\varepsilon_{1}\right)
$$

A measurement of the thickness and width of the plate provides : 
TABLE 3.7

RESULTS OF APPLICATION TO TUBE DATA. (HOLE 4)

\begin{tabular}{|c|c|c|c|c|c|c|c|c|c|}
\hline Trial & $\begin{array}{l}\text { Hole } \\
\text { depth }\end{array}$ & $\begin{array}{c}\varepsilon_{\mathrm{L}} \\
(\mu \text { strain })\end{array}$ & $\begin{array}{c}\varepsilon_{\mathrm{T}} \\
\left(\begin{array}{l}\mu \text { strain }\end{array}\right)\end{array}$ & $\begin{array}{r}\sigma_{L} \\
p \$ i\end{array}$ & $\begin{array}{r}\sigma_{\mathrm{T}} \\
\mathrm{psi}\end{array}$ & $\frac{\varepsilon_{L(1+1}}{\varepsilon_{L(1)}}$ & $\frac{\sigma_{L(i+1)}}{\sigma_{L(i)}}$ & $\frac{\varepsilon_{T(1+1)}}{\varepsilon_{T(1)}}$ & $\frac{\sigma_{T}(1+1)}{\sigma_{T}(i)}$ \\
\hline 1 & $.025^{\prime \prime}$ & -3 & 0.8 & -287 & 145 & \multirow{2}{*}{5.0} & \multirow{2}{*}{5.2} & \multirow{2}{*}{5.0} & \multirow{2}{*}{4.9} \\
\hline 2 & .050 & -5 & 4 & -1510 & 714 & & & & \\
\hline 3 & .075 & -24 & 6 & -2570 & 1237 & 1.6 & 1.7 & 1.5 & 1.7 \\
\hline 4 & .100 & -26 & 7 & -3019 & 1585 & 1.1 & 1.1 & 1.2 & 1.2 \\
\hline 5 & .125 & -30 & 9 & -3765 & 2151 & 1.2 & 1.2 & 1.3 & 1.3 \\
\hline
\end{tabular}


TABLE 3.8

EXPERIMENT OF TENSIONING \& CALIBRATION

DATA FROM STRAIN-RELAXATION METHOD

\begin{tabular}{|c|c|c|c|c|c|c|c|}
\hline $\begin{array}{c}\text { Trial } \\
\#\end{array}$ & $\begin{array}{l}\text { Hole } \\
\text { Depth }\end{array}$ & $\begin{array}{l}\text { Hole } \\
\text { Diame- } \\
\text { ter }\end{array}$ & $\begin{array}{r}\text { Mea } \\
\text { mi } \\
\text { st } \\
0\end{array}$ & $\begin{array}{l}\text { ured } \\
\text { ro- } \\
\text { cains }\end{array}$ & & $\begin{array}{c}\text { Reference } \\
\text { gauge }\end{array}$ & $\begin{array}{l}\text { Stress } \\
\text { Applied } \\
\text { (ksi) }\end{array}$ \\
\hline 1 & 0.0 & 0.0 & 202 & 533 & 193 & 572 & 16.73 \\
\hline 2 & .025 & .20 & 197 & 515 & 185 & 572 & 16.73 \\
\hline 3 & .050 & .40 & 182 & 474 & 171 & 572 & 16.73 \\
\hline 4 & .075 & .60 & 171 & 442 & 161 & 572 & 16.73 \\
\hline 5 & .100 & .80 & 165 & 423 & 156 & 570 & 16.73 \\
\hline 6 & .125 & 1.00 & 162 & 407 & 155 & 571 & 16.73 \\
\hline
\end{tabular}


TABLE 3.9

EXPERIMENT OF TENSIONING AND CALIBRATION

DATA FROM METHOD OF STRAIN RELAXATION

\begin{tabular}{|c|c|c|c|c|c|c|c|}
\hline \multirow[t]{2}{*}{$\begin{array}{c}\text { Trial } \\
\#\end{array}$} & \multirow[t]{2}{*}{$\begin{array}{l}\text { Hole } \\
\text { Depth }\end{array}$} & \multirow{2}{*}{$\begin{array}{l}\text { Hole } \\
\text { Depth } \\
\text { Diame- } \\
\text { ter }\end{array}$} & \multicolumn{3}{|c|}{$\begin{array}{l}\text { Measured } \\
\text { mirco- } \\
\text { strains }\end{array}$} & \multirow[t]{2}{*}{$\begin{array}{c}\text { Reference } \\
\text { gauge }\end{array}$} & \multirow{2}{*}{$\begin{array}{l}\text { Stress } \\
\text { applied } \\
\text { (ksi) }\end{array}$} \\
\hline & & & $\varepsilon_{1}$ & $\varepsilon_{2}$ & $\varepsilon_{3}$ & & \\
\hline 0 & 0 & 0 & 0 & 0 & 0 & 0 & 0 \\
\hline 1 & $0.0^{\prime \prime}$ & 0.0 & 202 & 533 & 193 & 572 & 16.73 \\
\hline 6 & 0.125 & 1.0 & 115 & 395 & 172 & 570 & 16.73 \\
\hline 7 & 0.125 & 1.0 & 56 & 200 & 88 & 285 & 8.36 \\
\hline
\end{tabular}


Thickness: $5 / 16^{\prime \prime}$ or $0.3125^{\prime \prime}$

Width: $51 / 8^{\prime \prime}$ or $5.125^{\prime \prime}$

True cross-sectional area: 1.60 square Inches

As applied tensions were $26.8 \mathrm{kip}$ and $13.4 \mathrm{kip}$ and

parallel to longitudinal axis, relative stresses would be respectively:

$$
\begin{aligned}
& \sigma_{L 2}=26.8 / 1.6=16.73 \mathrm{ks} 1 \\
& \sigma_{L 1}=13.4 / 1.6=8.37 \mathrm{ks} 1
\end{aligned}
$$

The corresponding strains measured were:

$$
\begin{aligned}
& \varepsilon_{L 2}=574 \text { microstrains } \\
& \varepsilon_{L 1}=286 \text { microstrains }
\end{aligned}
$$

Fina11y:

$$
\begin{aligned}
E & =(16.73-8.37) 10^{3} /(574-286) 10^{-6} \\
& =29 \times 10^{6} \mathrm{psi}
\end{aligned}
$$

c) Results from method of strain-relaxation due to drilling. From Table 3.5, the strain-relaxation due to drilling (2) equals the difference of strain readings before and after drilling (depth $0.125^{\prime \prime}$ ) when the test plate is under the same applied load $(16.73 \mathrm{ksI}):$

For direction 1:

$$
=-202+162=-40 \text { microstrains }
$$

For direction 2:

$$
=-533+407=-126 \text { microstrains }
$$

For direction 3:

$$
=-193+155=-38 \text { microstrains }
$$

These strains of strain-relaxation due to drilling are treated as measured strains (see equations (3a), Appendix III): 


$$
\begin{aligned}
& S=\Delta \varepsilon_{1}+\Delta \varepsilon_{3}=-78 \\
& D=\Delta \varepsilon_{1}-\Delta \varepsilon_{e}=-2
\end{aligned}
$$

$\operatorname{Tan} 2 \beta=\left(S-2 \Delta \varepsilon_{2}\right) / D=-87$

$\operatorname{Cos} 2 \beta=0.011493$

From equations (3a) (Appendix III)

$$
\begin{aligned}
& 4 \mathrm{~A}=2 \mathrm{~S} /\left(\sigma_{1}+\sigma_{2}\right) \\
& 4 \mathrm{~B}=2 \mathrm{~S} /\left(\left(\sigma_{1}-\sigma_{2}\right) \cos 2 \beta\right)
\end{aligned}
$$

The experiment thus provides: $\sigma_{1}=\sigma_{L}=\frac{\text { Tension }}{\text { Area }}$,

$$
\begin{aligned}
& \sigma_{1}=26.9 /(0.3125 * 5.125)=16.73 \mathrm{ks} 1 \text { or } 16730 \mathrm{ps} 1 \\
& \sigma_{2}=\sigma_{\mathrm{T}}=0 .
\end{aligned}
$$

Therefore, calibration coefficlents are:

$$
\begin{aligned}
& 4 \mathrm{~A}=2(-78) 10^{-6} / 16730=-0.93 * 10^{-8} \\
& 4 \mathrm{~B}=2(-2) 10^{-6} /((16730)(0.011493))=-2.08 * 10^{-8}
\end{aligned}
$$

D) Results from method of separation of induced stresses and applied stresses.

Using the method of separating induced stresses and applied stresses, it is found by graphical procedure:

For direction 1: (see Figure 3.26)

Total strain relaxes: $-(202-115)=-87$ microstrains

Strain due to residual stresses: -3

Strain due to applied stress only: $\Delta \varepsilon_{1}=-87-(-3)=-84$

For direction 2:

Tota1 strain relaxed: $-(533-395)=-138$

Strain due to residual stresses: +5

Strain due to applied stress: $\Delta \varepsilon_{2}=-138-(5)=-143$ 
For direction 3:

Total strain relaxed: $-(193-172)=-1$

Strain due to residual stresses: +4

Strain due to applied stress: $\Delta \varepsilon_{3}=-21-(4)=-25$

These strains due to applied stresses are treated as measured strains:

$$
\begin{aligned}
& S=\Delta \varepsilon_{1}+\Delta \varepsilon_{3}=-109 \\
& D=\Delta \varepsilon_{1}-\Delta \varepsilon_{3}=-59 \\
& \operatorname{Tan} 2 B=\left(S-2 \Delta \varepsilon_{2}\right) / D=-177 / 59 \\
& \operatorname{Cos} 2 \beta=0.316227 \\
& \text { From equations }(3 a) \\
& 4 A=2 S /\left(\sigma_{1}+\sigma_{2}\right) \\
& 4 B=2 D /\left(\left(\sigma_{1}-\sigma_{2}\right) \operatorname{Cos} 2 \beta\right)
\end{aligned}
$$

It has been found by experiment that:

$$
\sigma_{1}=16730 \mathrm{psi}, \quad \sigma_{2}=0
$$

Therefore:

$$
\begin{aligned}
& 4 A=2(-109) 10^{-6} / 16730=-1.30 * 10^{-8} \\
& 4 B=2(59) 10^{-6} /(16730 * 0.316227)=-2.23 * 10^{-8}
\end{aligned}
$$

E) Summary of results.

In this investigation, four ways of computing the values of $4 \mathrm{~A}$ and $4 \mathrm{~B}$ were used.

1) For each hole drilled, its radius $R_{0}$ is measured and the ratio $r$ of the distance of the gage to center $R\left(R=0.202^{\prime \prime}\right.$ for Rosette 125RE) to radius of hole drilled $R_{0}\left(r=R / R_{0}\right)$ is evaluated. In Figure 2.3 the line of abscissa $r$ parallel to vertical axis, cuts the curve $4 \mathrm{~A}$ at point $\mathrm{a}$ and the curve $4 \mathrm{~B}$ at point $\mathrm{b}$, the 
ordinates of $a$ and $b$ are the values of $4 \mathrm{~A}$ and $4 \mathrm{~B}$. The values of $4 \mathrm{~A}$ and $4 \mathrm{~B}$ of the 11 drilled holes are summarized in Table 3.10 .

It is of interest to note that in Table $3.104 \mathrm{~A}$ and $4 \mathrm{~B}$ differ for different holes, because they are determined from equations which are functions of $r, r=R / R_{0}, r$ varies with $R_{0}$ where $R_{0}$ is the measured radius of the hole drilled.

TABLE $\quad 3.10$

VALUES OF 4A AND 4B COMPUTED BY CURVES FROM FIGURE 2.3

\begin{tabular}{|c|c|c|}
\hline Hole & $\begin{array}{c}4 \mathrm{~A} \\
\left(10^{-8}\right)\end{array}$ & $\begin{array}{c}4 \mathrm{~B} \\
\left(10^{-8}\right)\end{array}$ \\
\hline 1 & -0.87 & -2.50 \\
2 & -0.87 & -2.50 \\
3 & -0.85 & -2.45 \\
4 & -1.05 & -2.48 \\
5 & -0.85 & -2.45 \\
6 & -0.88 & -2.50 \\
7 & -0.85 & -2.45 \\
8 & -0.85 & -2.45 \\
9 & -0.95 & -2.60 \\
A & -0.83 & -2.37 \\
B & -0.83 & -2.37 \\
\hline
\end{tabular}

2) From equation (1)

$$
\begin{aligned}
& \varepsilon_{r}=-\sigma_{1} \frac{1+\mu}{2 E}\left[1 / r^{2}-3 / r^{4}(\operatorname{Cos} 2 \alpha)+4 /(1+\mu)(\operatorname{Cos} 2 \alpha)\right. \\
& \text { and } \\
& \varepsilon_{r}=(A+B \operatorname{Cos} 2 \alpha) \sigma_{1}
\end{aligned}
$$


By identifying the similar terms, it is found:

$$
\text { where } \quad \begin{aligned}
A & =-(1+\mu) /\left(2 E * r^{2}\right) \\
& \mu=0.29, E=29\left(10^{6}\right), \\
& r=0.202 \star 2 / 0.125=3.23
\end{aligned}
$$

Then,

$$
4 A=-\frac{2(1+0.29)}{(3.23)^{2}(29)\left(10^{6}\right)}=-0.86\left(10^{-8}\right)
$$

and

$$
B=(1+\mu) / 2 E\left[3 / r^{4}-4 /\left((1+\mu)\left(r^{2}\right)\right)\right]
$$

Thus,

$$
\begin{aligned}
& 4 B=\frac{2(1+0.29)}{29\left(10^{6}\right)} \frac{3}{(3.23)^{4}}-\frac{4}{1.29(3.23)^{2}} \\
& 4 B=-2.41\left(10^{-8}\right)
\end{aligned}
$$

3) The values of $4 \mathrm{~A}$ and $4 \mathrm{~B}$ found experimentally by the method of strain-relaxation

$$
\begin{aligned}
& 4 A=-1.30\left(10^{-8}\right) \\
& 4 B=-2.08\left(10^{-8}\right)
\end{aligned}
$$

according to the computations shown in paragraph 3.2.2.c (strainrelaxation).

4) The values of $4 A$ and $4 B$ found experimentally by the method of strain separation

$$
\begin{aligned}
& 4 A=-1.30\left(10^{-8}\right) \\
& 4 B=-2.23\left(10^{-8}\right)
\end{aligned}
$$

according to the computations shown in paragraph 3.2.2.d (strainseparation). 
For a better comparison between various calibration coefficients obtained from measurements or computations, results are summarized in Table 3.11 .

TABLE 3.11

SUMMARY OF 4A AND 4B VALUES

\begin{tabular}{|c|c|c|c|}
\hline $\begin{array}{c}\text { Case } \\
\#\end{array}$ & $\begin{array}{l}\text { Measurement or } \\
\text { Method Used }\end{array}$ & $\begin{array}{l}4 \mathrm{~A} \\
\left(10^{-8}\right)\end{array}$ & $\begin{array}{l}4 \mathrm{~B} \\
\left(10^{-8}\right)\end{array}$ \\
\hline 1 & $\begin{array}{l}\text { Measurement of hole diameter } \\
\text { and reading from curves in } \\
\text { Figure } 2.3\end{array}$ & $\begin{array}{l}-0.83 \\
\text { to } \\
-1.05\end{array}$ & $\begin{array}{c}-2.37 \\
\text { to } \\
-2.68\end{array}$ \\
\hline 2 & $\begin{array}{l}\text { Computation from equation (1) } \\
\text { with theoretical hole } \\
\text { diameter } 0.125^{\prime \prime}\end{array}$ & -0.86 & -2.41 \\
\hline 3 & $\begin{array}{l}\text { Computation using method of } \\
\text { strain-relaxation due to } \\
\text { drilling }\end{array}$ & -0.93 & -2.08 \\
\hline 4 & $\begin{array}{l}\text { Computation using method of } \\
\text { separation of induced stress- } \\
\text { es and applied stresses }\end{array}$ & -1.30 & -2.23 \\
\hline
\end{tabular}

In the light of the data in the table, it is revealed that most values of $4 \mathrm{~A}$ and $4 \mathrm{~B}$ computed are reasonable and within the range of acceptable measured values. The criterion used for appreclating the degree of adequacy of each pair of $4 \mathrm{~A}$ and $4 \mathrm{~B}$ is 1ikely the quality of results from the balance of forces and moments of residual stresses. As the system of longitudinal residual stresses present in a circular section of the tube must have a state of force equilibrium and of bending moment equilibrium (3) at the same time, there currently 
is a deviation in the results given by the computation of balancing forces and moments of residual stresses; this deviation derives from accumulation of errors during experimentation. Because force and moment balancing will be described in Chapter IV, it is appropriate to evaluate the results of calibration coefficients after obtaining results of balancing.

F) Application of calibration coefficients to tube data. After obtaining all pairs of calibration coefficients 4A and $4 \mathrm{~B}$ for each case as shown in Table 3.7 , it is necessary to apply these coefficients to tube data and determine the corresponding longitudinal residual stresses, circumferential residual stresses and ratios of longitudinal restdual stresses to yleld stress, and to plot curves of the distribution. Curves are built with $d / R$ on the abscissa ( $d=$ distance of hole to the weld, $R=$ radius of the tube) and $\sigma_{L} / \sigma_{y}$ on the ordinate.

Case 1. Results relating to initial values of longitudinal and circumferential stresses derived from measured strains, are given in Table 3.3. The relative calibration coefficients $4 \mathrm{~A}$ and $4 \mathrm{~B}$ are obtained from the curves in Figure 2.3 .

The corresponding curve of $\sigma_{L} / \sigma_{y}$ is drawn in Figure 3.28 . Case 2. Results pertaining to data reduction coefficlents $4 \mathrm{~A}$ and 4B computed from equation (1), are shown in Table 3.12 .

The corresponding curve is drawn in Figure 3.29. Case 3. Results pertaining to calibration coefficients obtained from method of strain-relaxation due to dril11ng, are condensed in Table 3.13 . 


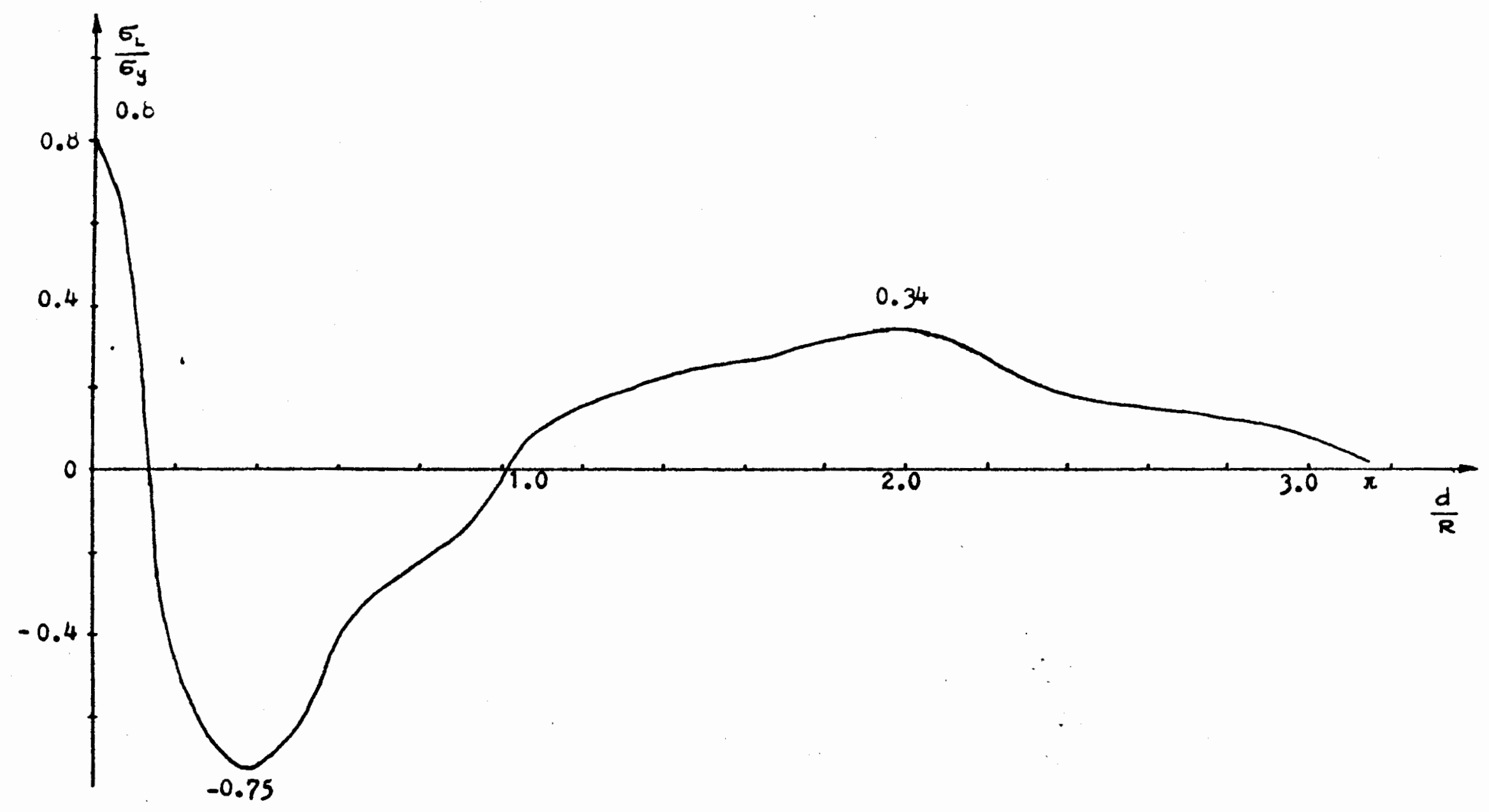

Plgure 3.28 Curve of initiel values of monsured longitudinal residual strosses 
TABLE 3.12

RESULTS WITH COMPUTED CALIBRATION COEFFICIENTS

$$
\begin{aligned}
& 4 A=-0.86\left(10^{-8}\right) \\
& 4 B=-2.41\left(10^{-8}\right)
\end{aligned}
$$

\begin{tabular}{|c|c|c|c|}
\hline $\begin{array}{c}\text { Hole } \\
\qquad \#\end{array}$ & ${ }^{\sigma_{L}}$ & $\begin{array}{r}\sigma_{\mathrm{T}} \\
\mathrm{psi}\end{array}$ & $\gamma_{\sigma}^{\sigma_{L}}$ \\
\hline 1 & -10220 & -8149 & -0.25 \\
\hline 2 & 10900 & 16540 & 0.27 \\
\hline 3 & 7268 & 7849 & 0.18 \\
\hline 4 & 1223 & 6451 & 0.03 \\
\hline 5 & -30330 & -18040 & -0.75 \\
\hline 6 & 6205 & 8446 & 0.15 \\
\hline 7 & 13670 & 17490 & 0.33 \\
\hline 8 & 5599 & 7424 & 0.14 \\
\hline 9 & 37010 & 7877 & 0.90 \\
\hline A & -18390 & -11970 & -0.45 \\
\hline B & -16670 & -9372 & -0.41 \\
\hline
\end{tabular}




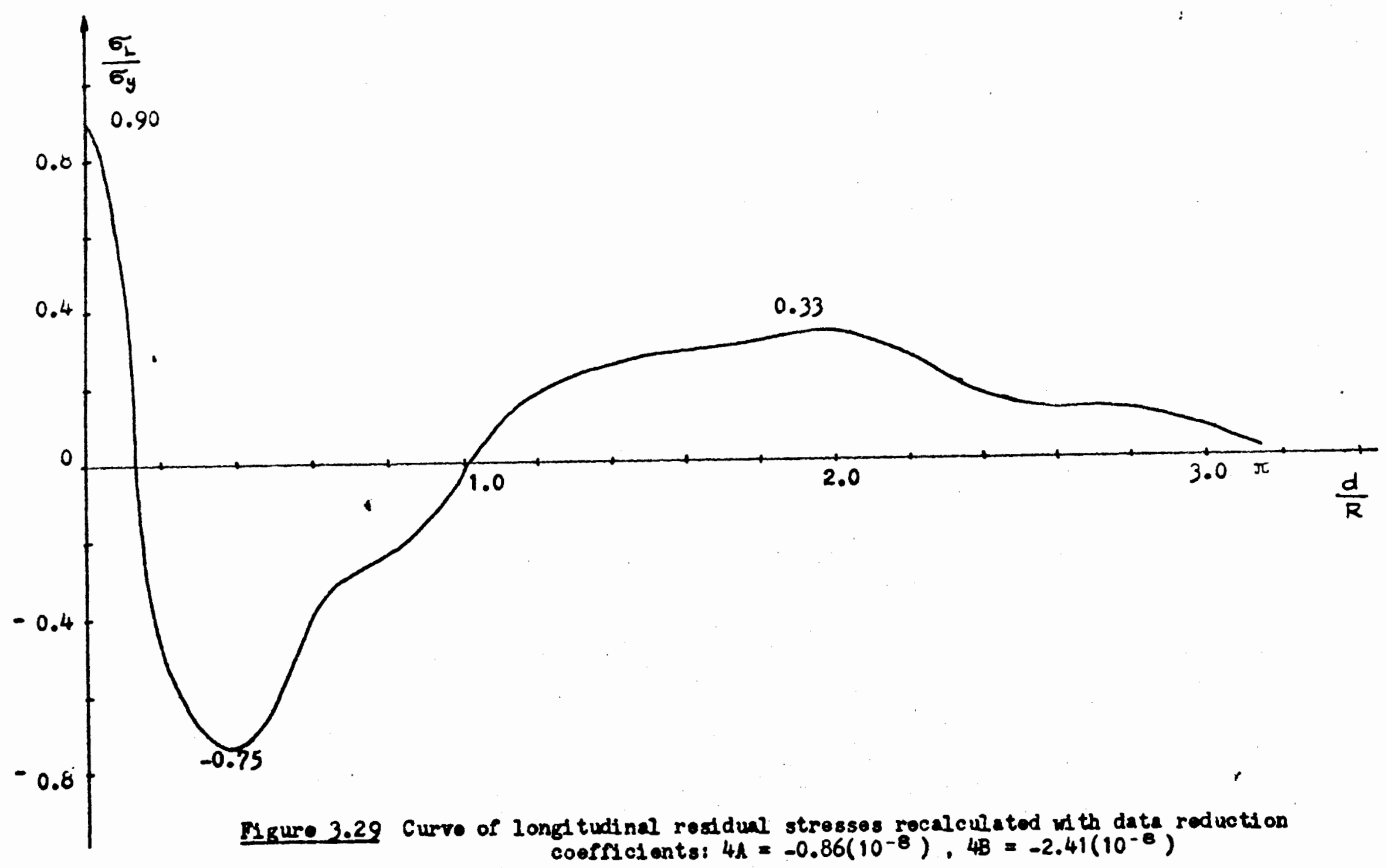


TABLE 3.13

RESULTS FROM METHOD OF STRAIN-RELAXATION DUE TO DRILLING

CALIBRATION COEFFICIENTS

$$
\begin{aligned}
& 4 A=-0.93\left(10^{-8}\right) \\
& 4 B=-2.08\left(10^{-8}\right)
\end{aligned}
$$

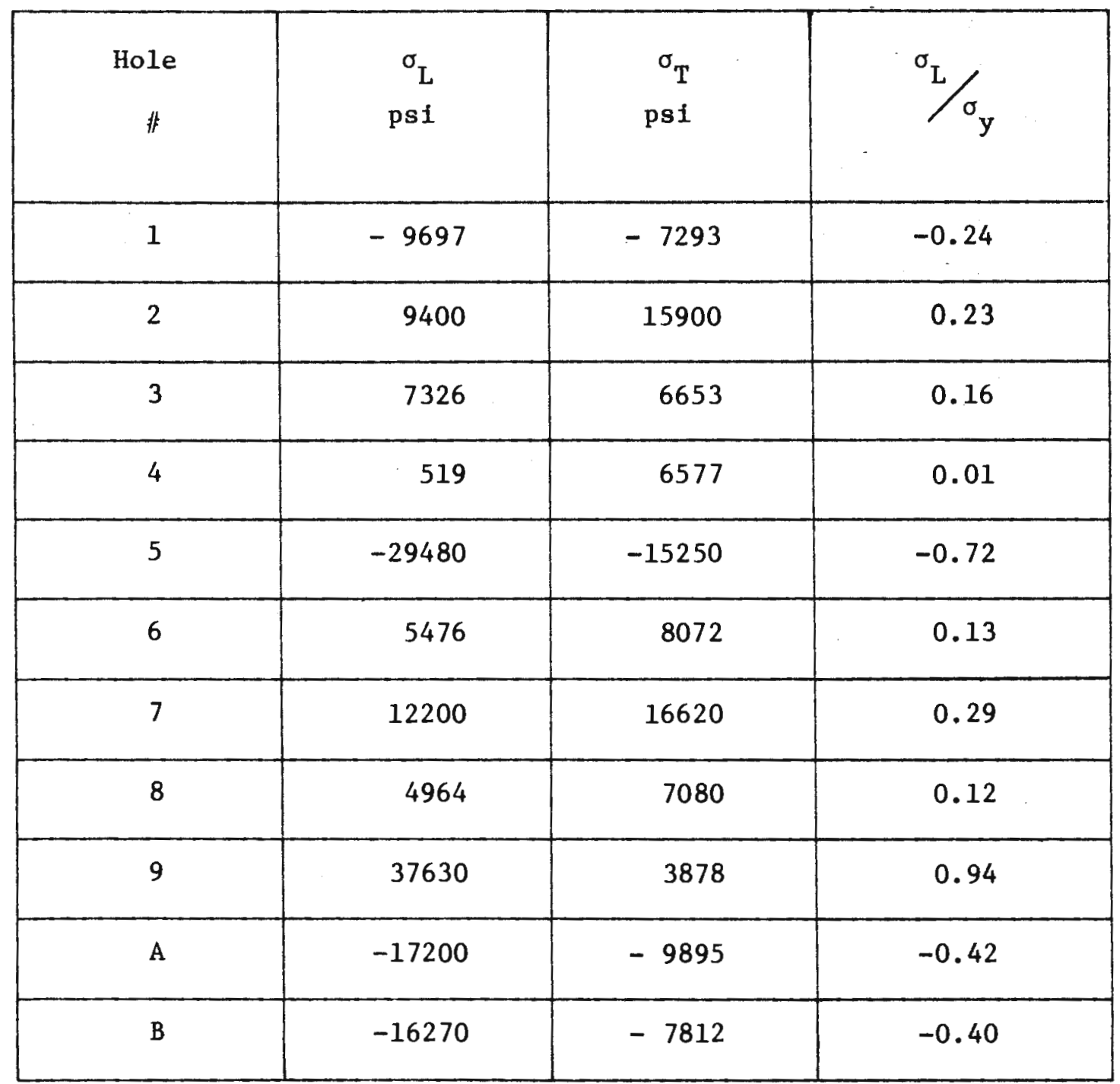


The curve is shown in Figure 3.30 .

Case 4. Results relating to calibration coefficients calculated from method of separation of Induced stresses and applied stresses, are shown In Table 3.14 .

The curve is given in Figure 3.31 .

A preliminary survey of these curves shows that the one in case 4 is likely to lead to good results in balancing forces and moments because of the reduced tension and a slight compressive area at hole number 4 which helps in moment balancing. 


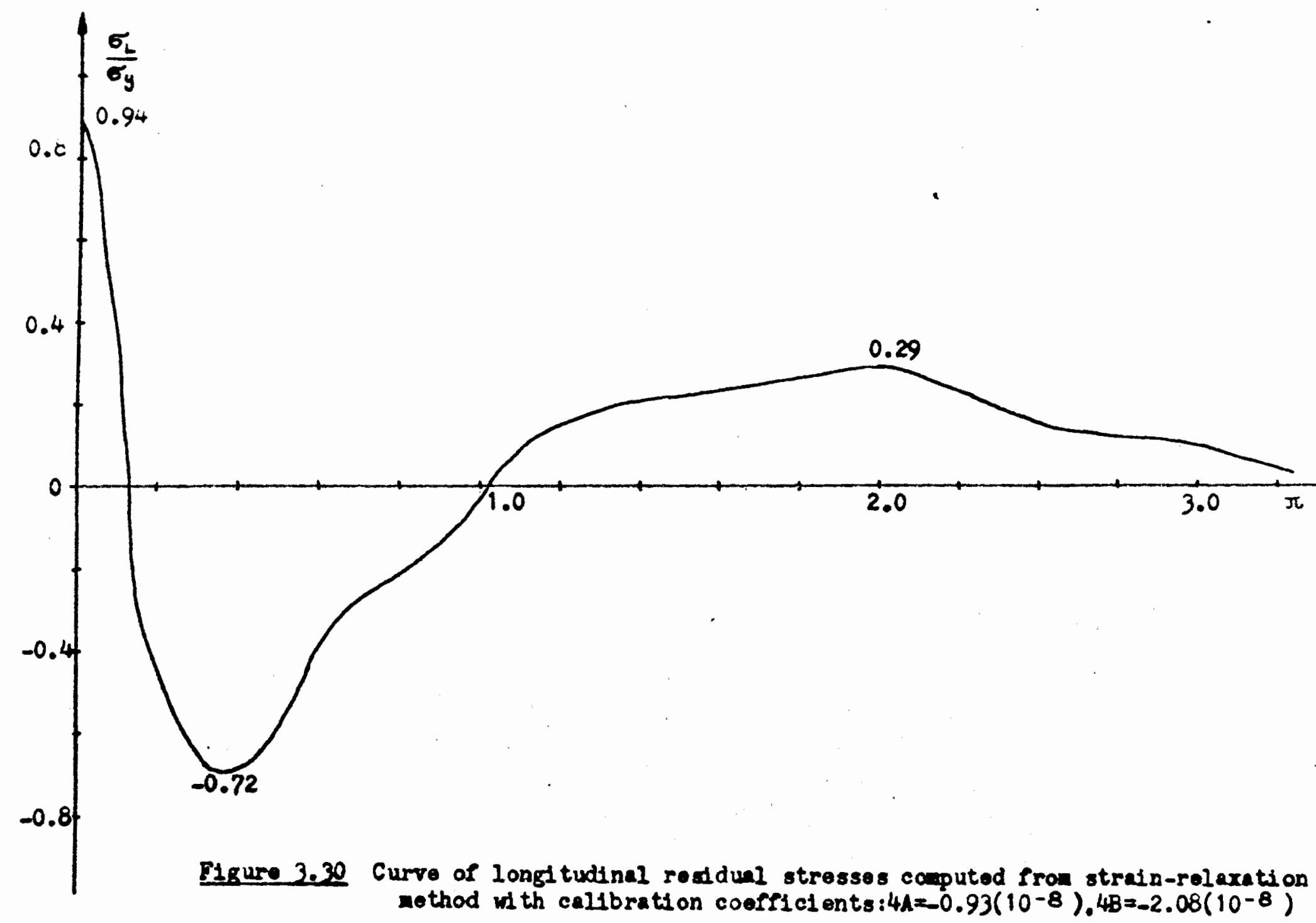


TABLE 3.14

\section{RESULTS FROM METHOD OF STRAIN SEPARATION}

CALIBRATION COEFFICIENTS

$$
\begin{aligned}
& 4 A=-1.30\left(10^{-8}\right) \\
& 4 B=-2.23\left(10^{-8}\right)
\end{aligned}
$$

\begin{tabular}{|c|c|c|c|}
\hline $\begin{array}{c}\text { Hole } \\
\qquad \#\end{array}$ & $\begin{array}{l}\sigma_{L} \\
p s i\end{array}$ & $\begin{array}{r}\sigma_{\mathrm{T}} \\
\mathrm{psi}\end{array}$ & $/_{\sigma_{y}}^{\sigma_{y}}$ \\
\hline 1 & -7198 & -4956 & -0.17 \\
\hline 2 & 6028 & 12130 & 0.15 \\
\hline 3 & 4686 & 5314 & 0.11 \\
\hline 4 & $-\quad 287$ & 5364 & -0.01 \\
\hline 5 & -22640 & -9363 & -0.55 \\
\hline 6 & 3635 & 6057 & 0.09 \\
\hline 7 & 8245 & 12370 & 0.20 \\
\hline 8 & 3321 & 5294 & 0.08 \\
\hline 9 & 30590 & -8938 & 0.75 \\
\hline A & -13100 & -6284 & -0.32 \\
\hline$B$ & -12560 & -4669 & -0.31 \\
\hline
\end{tabular}




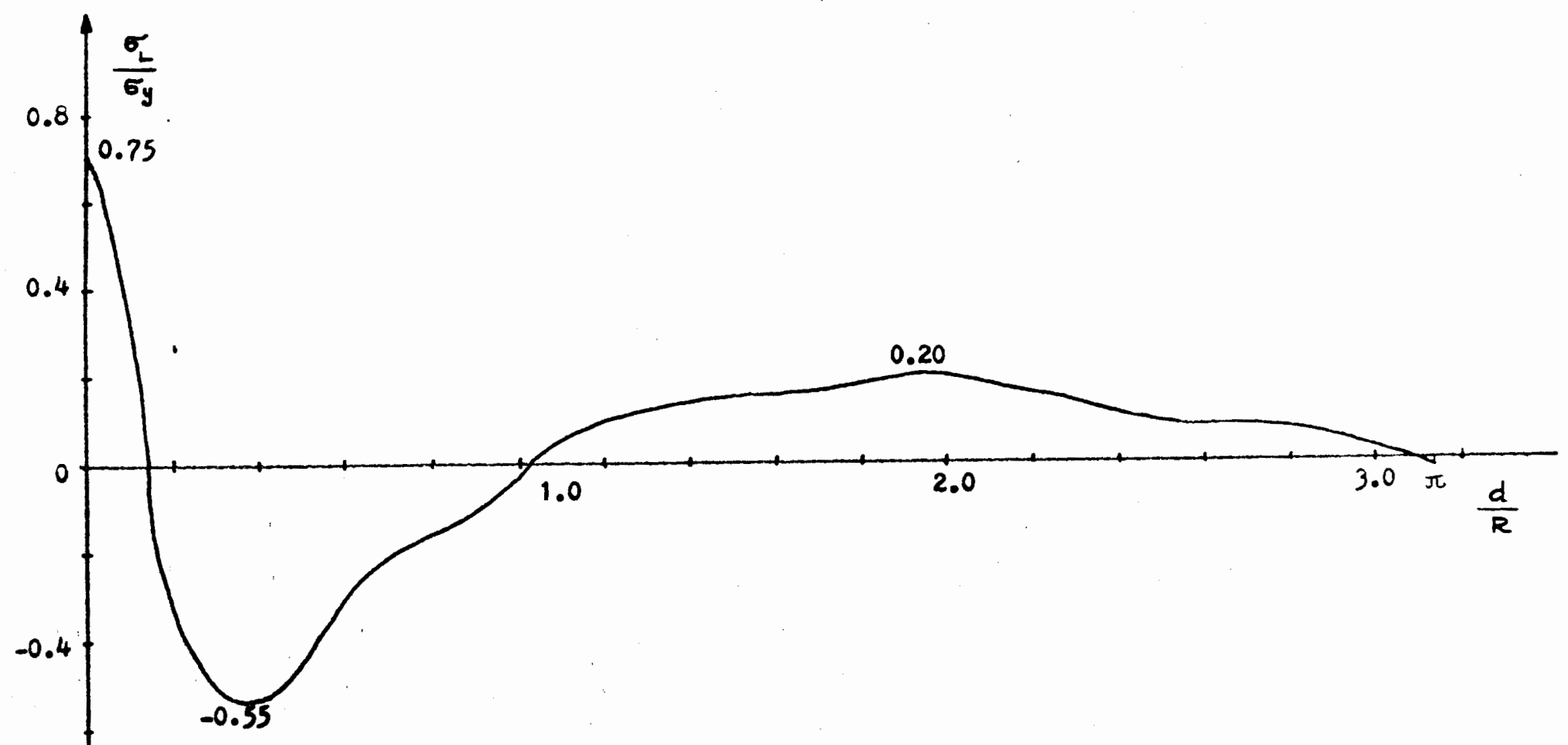

Plgure 3.31 Curve of longl tudinal residval stresses computed from thod of strain separation with callbration coofficionts: $4 A=-1.30\left(10^{-6}\right), 4 B=-2.23\left(10^{-8}\right)$. 
CHAPTER IV

BALANCE OF FORCES AND MOMENTS

As a means of checking the correctness of results of the measurement of residual stresses by the hole-drilling technique a balance of forces and moments pertaining to longitudinal residual stresses is in equilibrium in the steel tube, the summation of forces and moments with respect to an axis must equal zero (3). It is convenient to show the balancing of forces and moments, using calibration coefficients obtained from theory and published literature and experimentally determined.

\subsection{BALANCING FORCES AND MOMENTS OF RESULTS USING ANALYTICALLY DERIVED CALIBRATION COEFFICIENTS}

The development of an analytical approach is presented first, this is then followed by a flow chart and a computer program used to perform the calculation.

\subsubsection{Analytical approach.}

A) Pattern of longitudinal residual stress distribution.

A cross-sectional area, two feet from edge of the steel tube, perpendicular to longitudinal axis shown in Figure 4.1 shows the pattern of longitudinal residual stress distribution. These stresses have been obtained from measured strains, with varlable $4 \mathrm{~A}$ and $4 \mathrm{~B}$, case 1, in Table 3.11. Positive ordinates outside the circle denote tensile stresses and negative ordinates inside the circle fepresent compressive stresses. Therefore positive areas denote tension and 
86

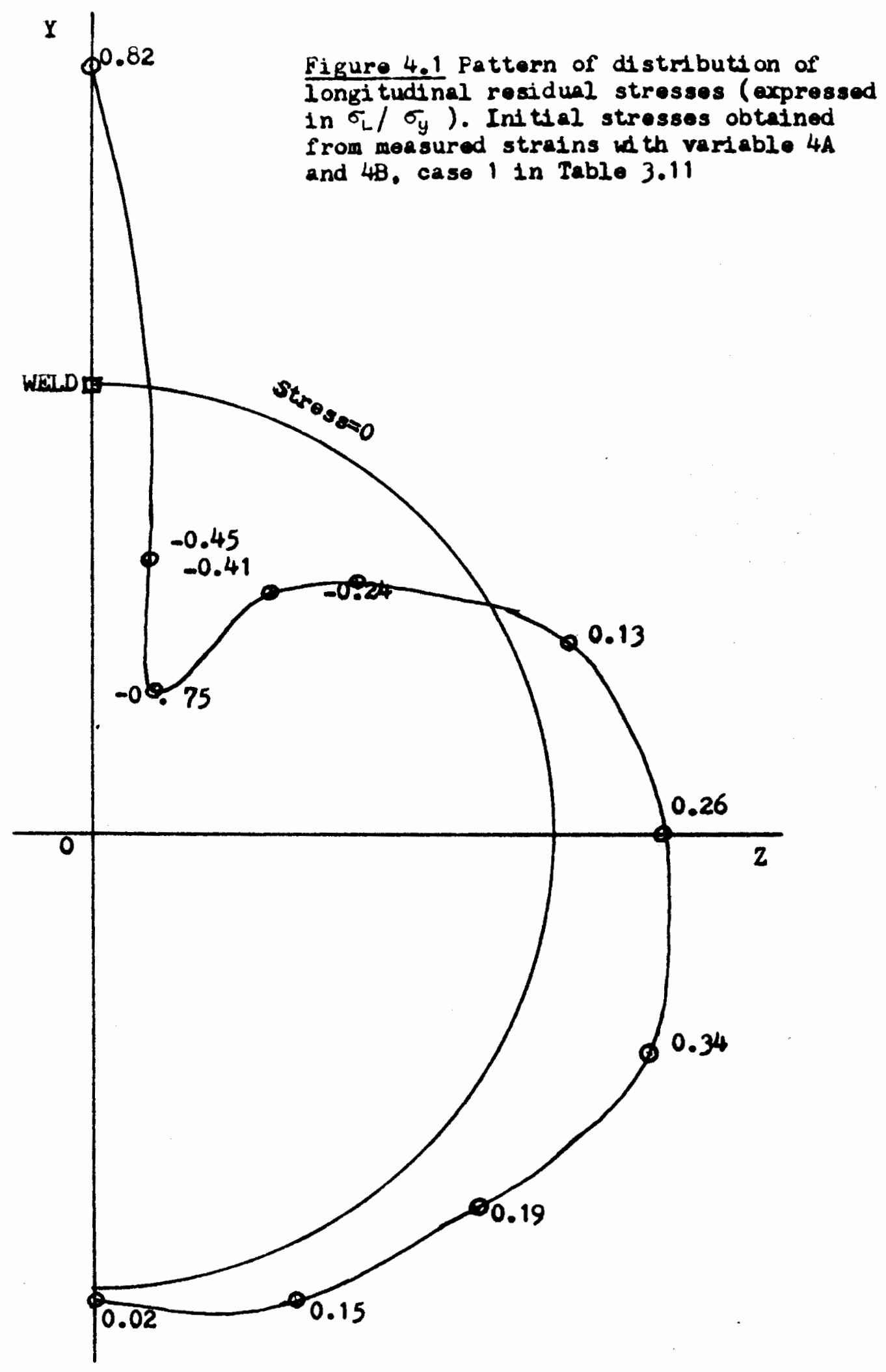


negative areas represent compression.

An attempt will be made to calculate the summation of forces and summation of moments about $\mathrm{Z}$ axis shown in Figure 4.1. As to the sign of moments, it is useful to note that: -For the part above $\mathrm{Z}$ axis:

a moment of a positive area is positive, a moment of a negative area is negative. -For the part below the $\mathrm{Z}$ axis:

a moment of a positive area is negative, a moment of a negative area 18 positive, using the convention of positive sign for a clockwise moment. As to the summation of forces, the computer program defines tt by adding algebraically the positive areas and negative areas. As to the summation of moments of forces in the tube, an algebraic addition is performed on partial moments of area, the sign of each moment relating to the area above or below the $\mathrm{Z}$ axis as defined previously.

It is understood that the moment about $\mathrm{Z}$ axis is the product of the volume of forces (area of forces times the thickness of the tube) and the lever arm which is the distance from the center of gravity of the area to the $\mathrm{Z}$ axis.

B) Area and center of gravity.

The procedure programmed is a form of variable step numerical Integration in which the user, In preparing data for the computer program, defines and calculates the area and the center of gravity of the force segments. The Figure 4.2 shows a possible choice of 


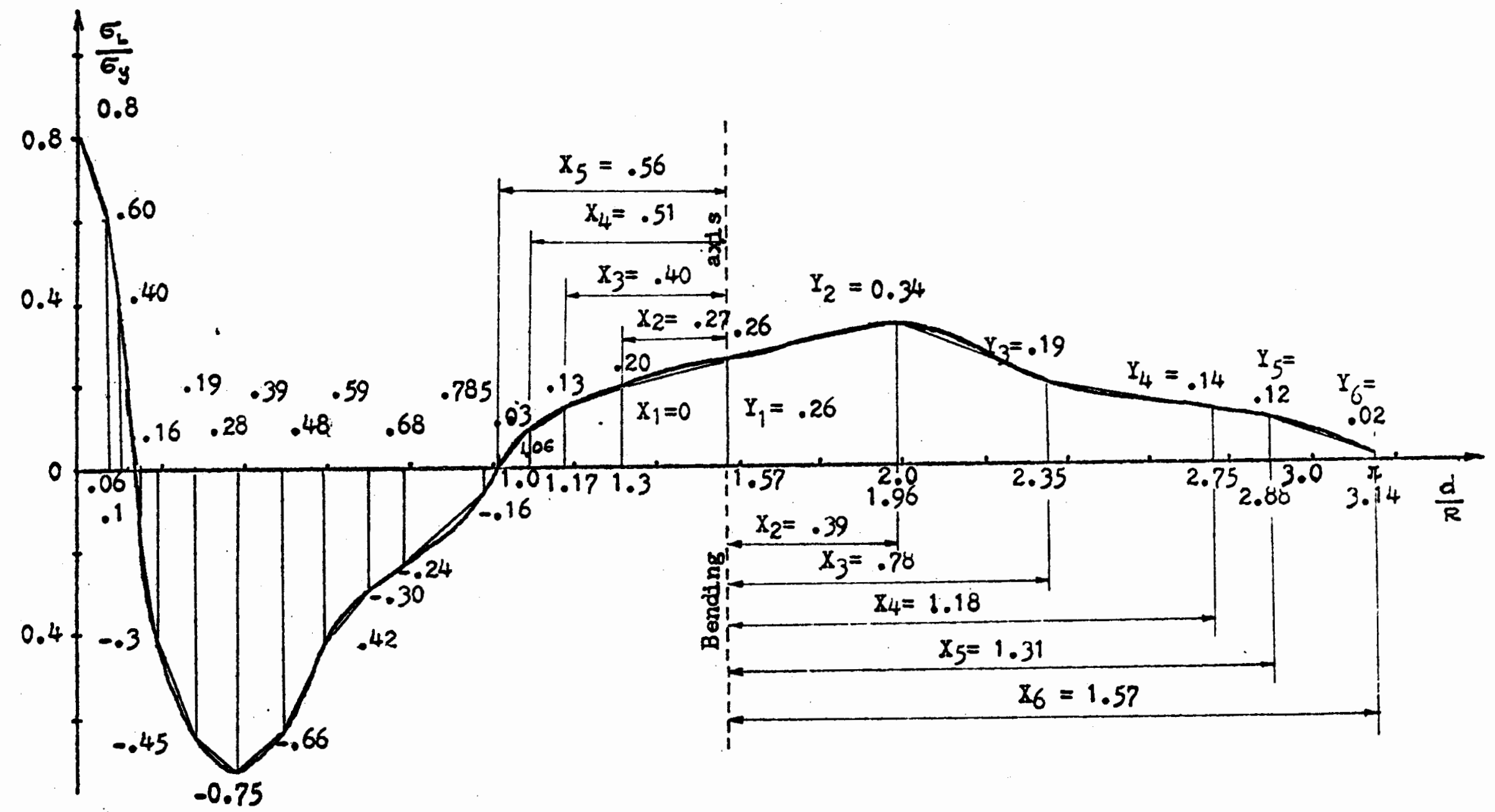

Figure 4.2 Segmental division for preparing date for the computer program 
segmental division.

The following cases give the detalls of the signs and quantities required as input.

Case 1. (see Figure 4.3)

Distance of center of gravity of the rectangle to $Y$ axis:

$$
\mathrm{CG1}=\left(\mathrm{x}_{1}+\mathrm{x}_{2}\right) / 2
$$

Distance of center of gravity of the triangle to $Y$ axis:

$$
\begin{aligned}
\text { CG2 } & =\left(2 X_{2}+X_{1}\right) / 3 \\
\text { Area } A 1 & =\left(X_{2}-X_{1}\right) / Y_{1} \\
\text { Area } A 2 & =\left(X_{2}-X_{1}\right)\left(Y_{2}-Y_{1}\right) / 2
\end{aligned}
$$

Case 2. (see Figure 4.4)

$$
\begin{aligned}
\text { CG1 } & =\left(x_{1}+x_{2}\right) / 2 \\
\text { CG2 } & =\left(2 x_{1}+x_{2}\right) / 3 \\
\text { A1 } & =\left(x_{2}-x_{1}\right) Y_{1} \\
\text { A2 } & =\left(x_{2}-x_{1}\right)\left(Y_{2}-Y_{1}\right) / 2
\end{aligned}
$$

Case 3. (see Figure 4.5)

$$
\begin{aligned}
X_{0} & =\left(X_{2}-x_{1}\right) Y_{1} /\left(Y_{2}+Y_{1}\right) \\
A 1 & =x_{0} Y_{1} / 2 \\
C G 1 & =x_{1}+x_{0} / 3 \\
A 2 & =\left(x_{2}-x_{1}-x_{0}\right) Y_{2} / 2 \\
C G 2 & =\left(2 x_{2}+x_{1}+x_{0}\right) / 3
\end{aligned}
$$

Case 4. (see Figure 4.6)

$$
\begin{aligned}
X_{0} & =-\left(X_{2}-X_{1}\right) Y_{1} /\left(Y_{2}-y_{1}\right) \\
C G 1 & =x_{1}+x_{0} / 3 \\
A 1 & =x_{0} Y_{1} / 2 \\
C G 2 & =\left(2 x_{2}+x_{1}+x_{0}\right) / 3
\end{aligned}
$$




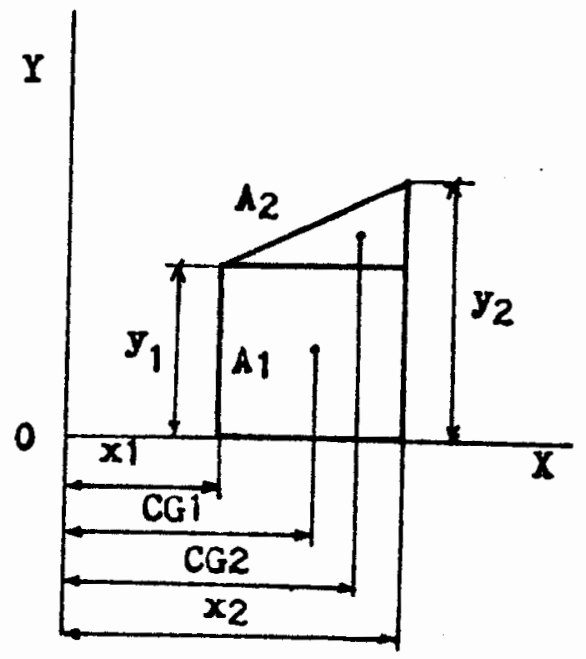

Eigure 4.3 Area and center of gravity.

$C_{2 s e} 1$

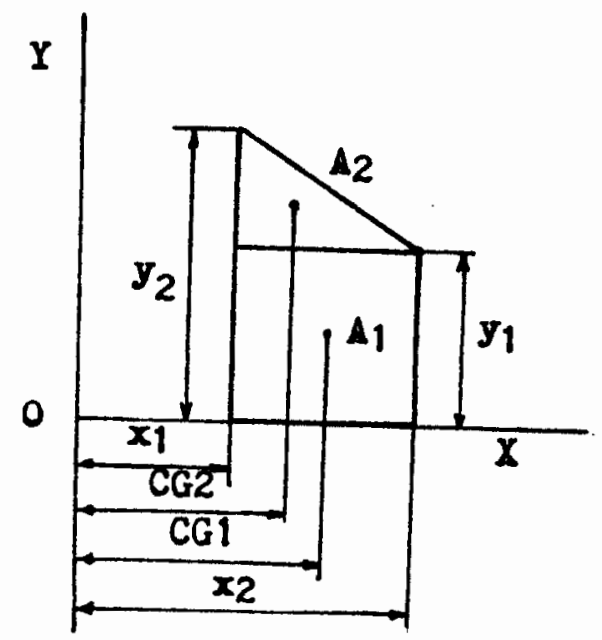

Eigure 4.4 Case 2 


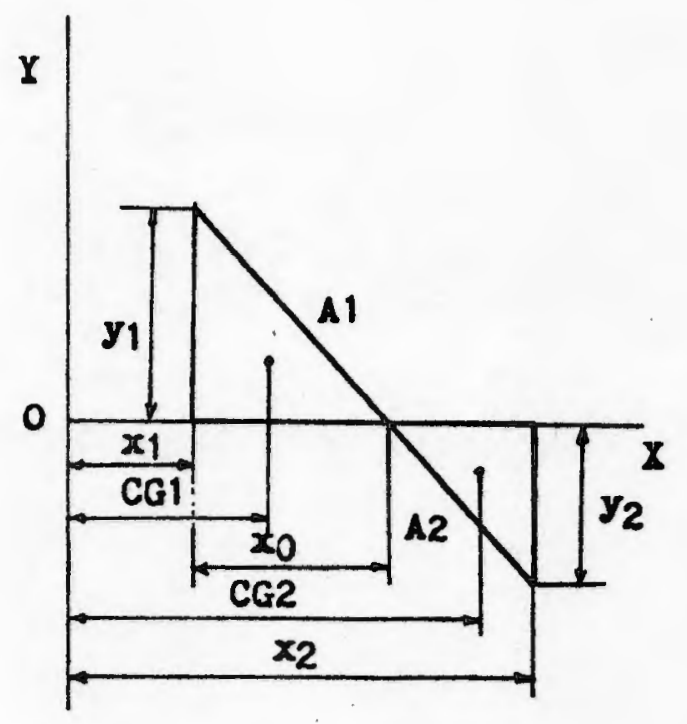

Fyure 4.5 Case 3

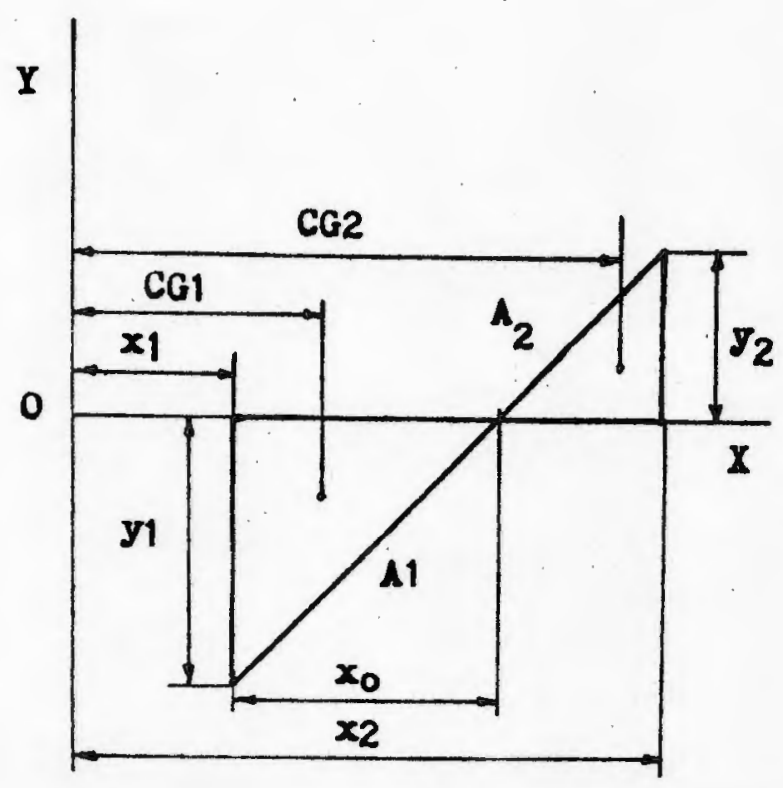

E1gure 4.6 Case 4 


$$
\mathrm{A} 2=\mathrm{Y}_{2}\left(\mathrm{x}_{2}-\mathrm{x}_{1}-\mathrm{x}_{\mathrm{o}}\right) / 2
$$

Case 5. (see Figure 4.7)

Computations give same results as in Case 2 .

Case 6. (see Figure 4.8)

$$
\text { Same results as in Case } 1 \text {. }
$$

It is noted that the obtained results are the same

$$
\begin{aligned}
& \text { for cases } 1 \text { and } 6 \text {, } \\
& \text { for cases } 2 \text { and } 5 \text {, } \\
& \text { for cases } 3 \text { and } 4 \text {. }
\end{aligned}
$$

The number of cases is then reduced from 6 to 3 as to formulas to be used.

C) Application to tube data.

A cross-sectional area containing the centers of drilled holes two feet from the edge of the tube is represented in Figure 4.10 (refer also to Figure 4.1). A sketch of a three-dimensional representation of the tube and an element of area of forces is shown In Figure 4.9.

The distance CGx computed in the six preceding cases is represented by the arc length $A B$ in Figures 4.9 and 4.10 .

Lever arm $\mathrm{D}$ is :

$$
\begin{gathered}
\mathrm{AC}=\mathrm{r} \sin \alpha, \text { with } \alpha=(\mathrm{CGX} / \mathrm{r}) \mathrm{radian} \\
\mathrm{D}=\mathrm{r} \sin (\mathrm{CGX} / \mathrm{r})
\end{gathered}
$$

Therefore, a moment of an elementary area can be computed as follows:

$$
\text { Moment }=\text { Force } *(\text { lever arm })
$$




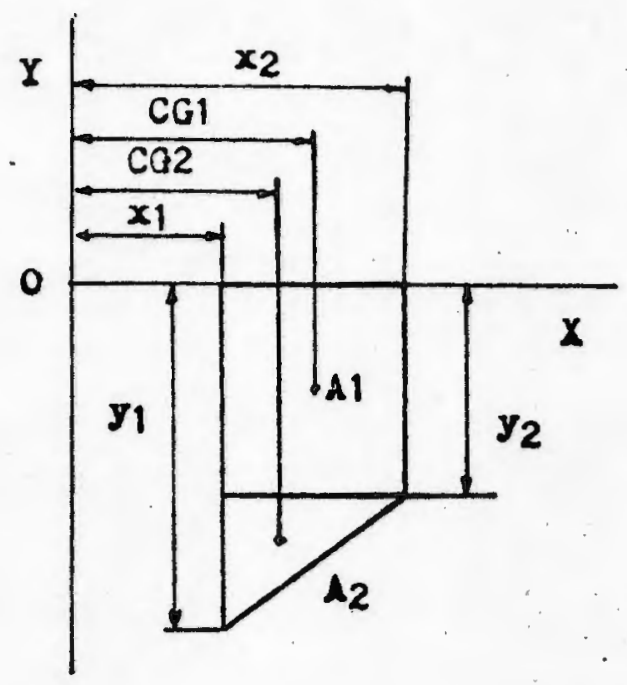

PIgure 4.7 Case 5

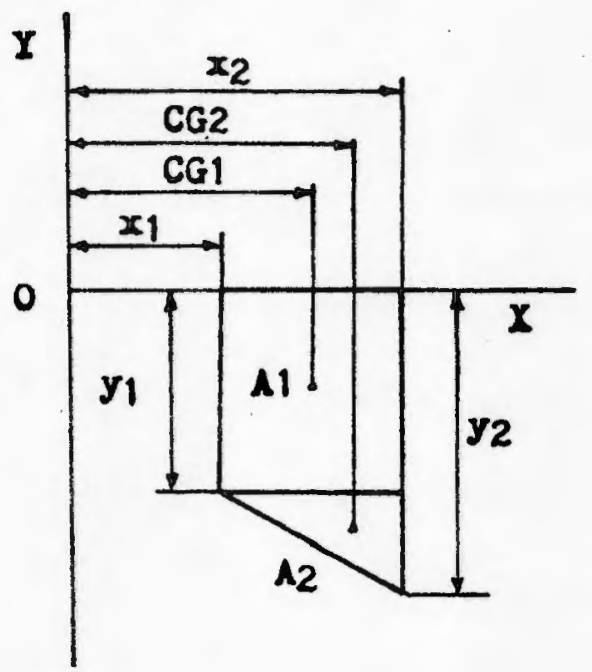

- FIgure 4.8 Case 6 


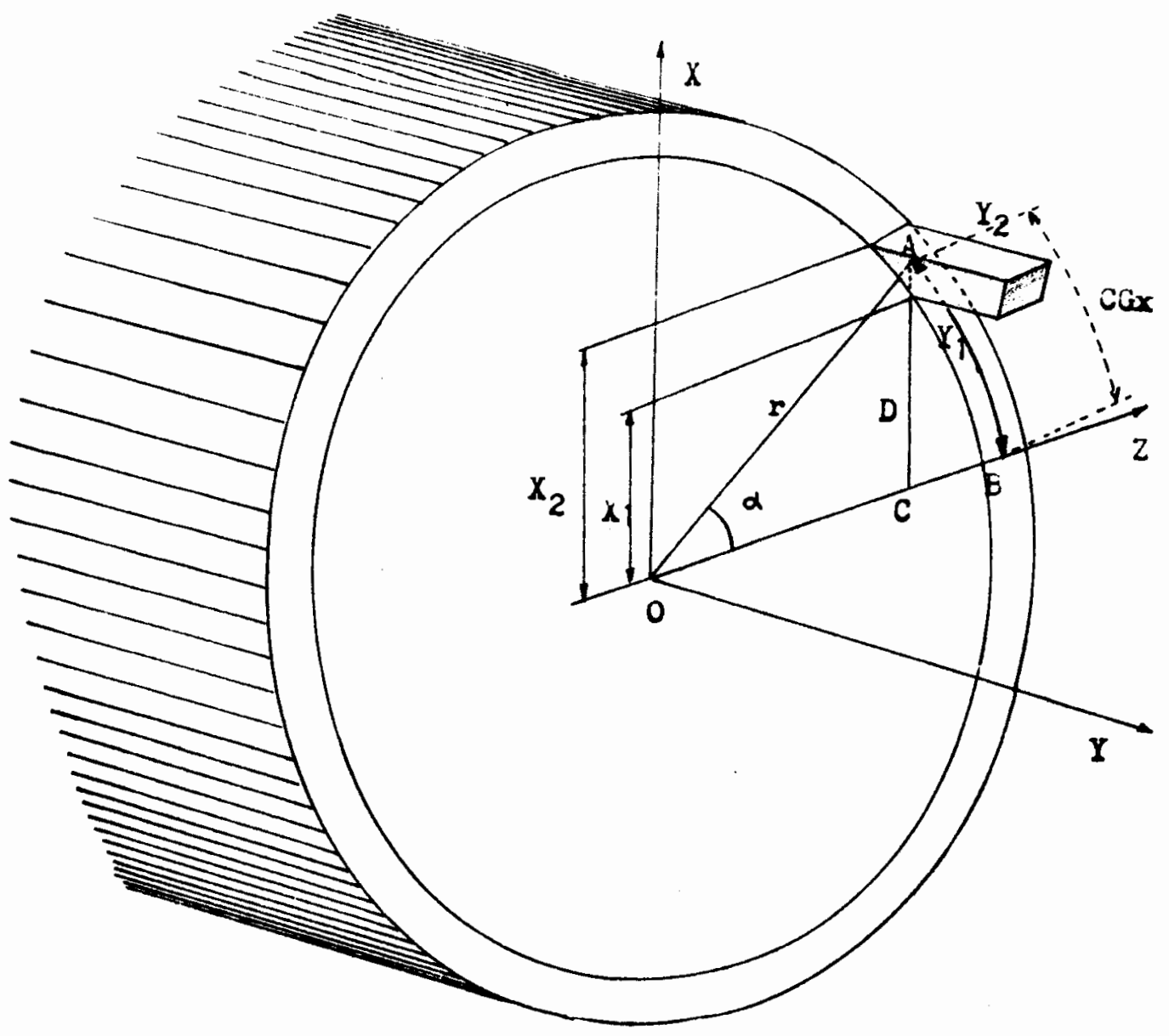

Flgure 4.9 Sketch of a three-dimensional represuntation of the tube and an elerent of area of forces

Note. 1) For a true representation of an area of forces, cut the tube along longitudinal weld and flatton the cylindor on a plane parallel to XY plane.

2) The lever arm of the moment of forces wh thespect to the 2 axis is $D=r \sin (C G x / r)$ 


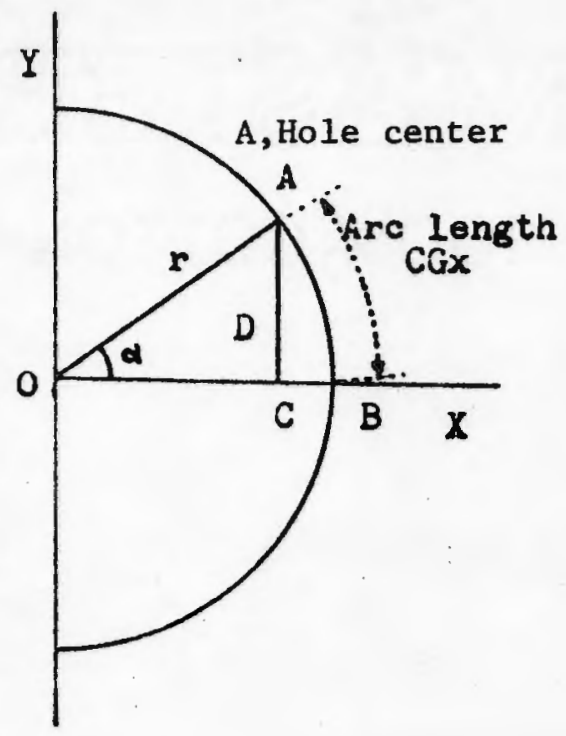

Figure 4.10 Cross-section of the tube

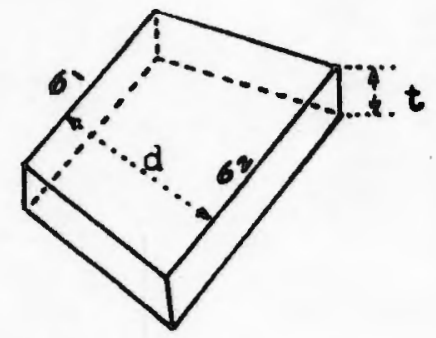

Figure 4.11 Sketch of a volume of forces 


$$
\begin{aligned}
m= & \left(\left(x_{2}-x_{1}\right) y_{1}\right)\left(r \sin \frac{x_{2}+x_{1}}{2 r}\right)+ \\
& \left(\left(x_{2}-x_{1}\right)\left(Y_{2}-Y_{1}\right) / 2\right)\left(r \sin \frac{x_{2}+2 x_{1}}{3 r}\right)
\end{aligned}
$$

This procedure is applied in the computer program.

D) Determination of dimensions and values for summation of forces and moments.

1) Dimensions and values for forces.

Suppose the area of forces is a trapezoid (see Figures

4.9 and 4.11$)$.

Its area is:

Area $=\sigma_{L} * d$, with $\sigma_{L}=\left(\sigma_{1}+\sigma_{2}\right) / 2$

Volume of forces $=$ Area $*$ thickness

$$
=\left(\sigma_{L} d\right) t
$$

where:

$d=$ distance or height of the trapezoid

$t=$ thickness of the tube

$r=$ radius of the tube

$\sigma_{L}=$ average longitudinal residual stress

$\sigma_{y}=$ yield stress of the steel

As $\sigma_{L} / \sigma_{y}$ is used in ordinate and $d / R$ used in abscissa in

the curve (see Figures 3.27 and 4.1 ) the force is defined by:

$$
\begin{aligned}
& \rho=\frac{\sigma_{L}}{\sigma_{y}} \times \frac{d}{r} \times \frac{t}{t} \\
& \rho=\frac{\text { Force }}{\sigma_{y} r} t
\end{aligned}
$$

let $P=\sigma_{y} \mathbf{r}$ 
As

$$
\begin{aligned}
& \sigma_{y}=40.9 \mathrm{ks} \\
& r=11^{\prime \prime} \\
& t=0.3125^{\prime \prime} \\
& p=140.6 \mathrm{kip}
\end{aligned}
$$

Then, force is $\rho$ * (140.6) kip

$$
\begin{gathered}
\text { Compute yield axial force } P_{y} \\
P_{y}=\sigma_{y} * \frac{\pi}{4}\left(d^{2}-d_{1}^{2}\right) \\
\text { where } d=22^{\prime \prime}, d_{1}=21.375^{\prime \prime}, \quad P_{y}=870.8 \mathrm{klps}
\end{gathered}
$$

Suppose the ratio $\rho$ calculated 180.014 , the summation of forces w111 be:

$$
F=0.014(140.6) \mathrm{kIps}=1.968 \mathrm{kIps}
$$

And the ratio of summation of forces to yleld axtal load $P_{y} 18$ :

$$
\frac{\Sigma F}{P_{y}}=\frac{1.9688}{870.8}=0.0022
$$

or

$$
F=0.0022 P_{y}
$$

2) Dimensions and value for moments.

Moment of forces $=$ Volume of forces * (lever arm)

$$
\left(\sigma_{L}\right)(d)(t) \text { (lever arm) }
$$

The moment is defined by

$$
\begin{aligned}
& \rho_{0}=\frac{\sigma_{L}}{\sigma_{y}} \times \frac{d}{r} \times \frac{t}{t} \times \frac{(1 . a)}{r} \\
& \rho_{O}=\frac{\text { Moment }}{\sigma_{y} r^{2} t} \\
& \text { Moment }=\rho_{o}\left(\sigma_{y} r^{2} t\right)
\end{aligned}
$$


with

$$
\begin{aligned}
\sigma_{y} r^{2} t & =(40.9)(11)^{2}(0.3125) \\
& =1546.5 \mathrm{kip} . \mathrm{in} .
\end{aligned}
$$

Then

$$
\text { Moment }=\rho_{0} *(1546.5) \mathrm{kip} . \text { in. }
$$

Suppose

$$
\begin{aligned}
& \rho_{0}=0.15 \\
& M=0.15 *(1546.5)=231.98 \mathrm{kip} . \text { in } .
\end{aligned}
$$

Compute Moment at first yield,

$$
M_{y}=s \cdot F_{y}
$$

As $s=\frac{\pi}{4} d^{2} t$ (approximate formula for the section modulus)

where $d=22^{\prime \prime}, t=0.3125^{\prime \prime}$

Then,

$$
\begin{aligned}
M_{y} & =(40.9)\left(\pi / 4 * 22^{2} * 0.3125\right) \\
& =4859 \mathrm{kip} . \mathrm{in} .
\end{aligned}
$$

Ratio of summation of moments to moment at first yield:

$$
\frac{\sum M}{M y}=\frac{231.98}{4859}=0.047
$$

or

$$
\Sigma M=0.047 \mathrm{M}
$$

\subsubsection{Flow chart.}

A flow diagram for the computer program is shown in Figure

4.12 .

4.1.3 Computer program.

A computer program for calculating the summation of forces and 
Eigure 4.12 Flow diagram

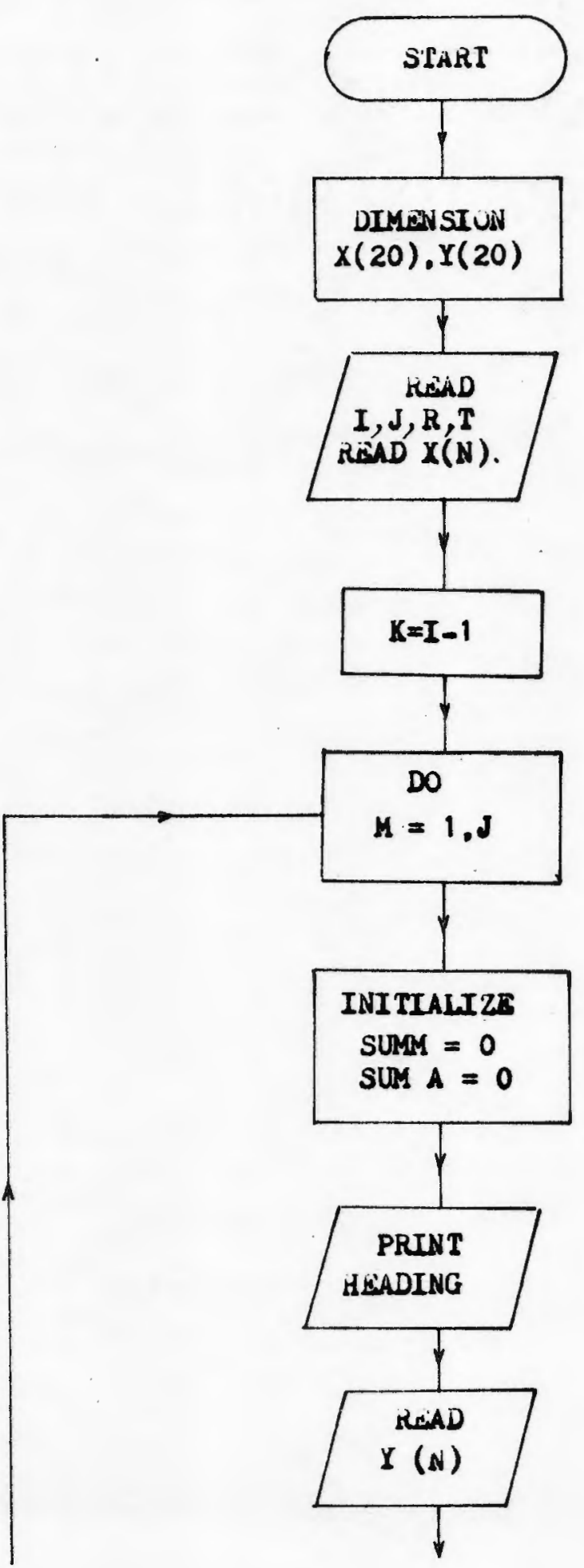




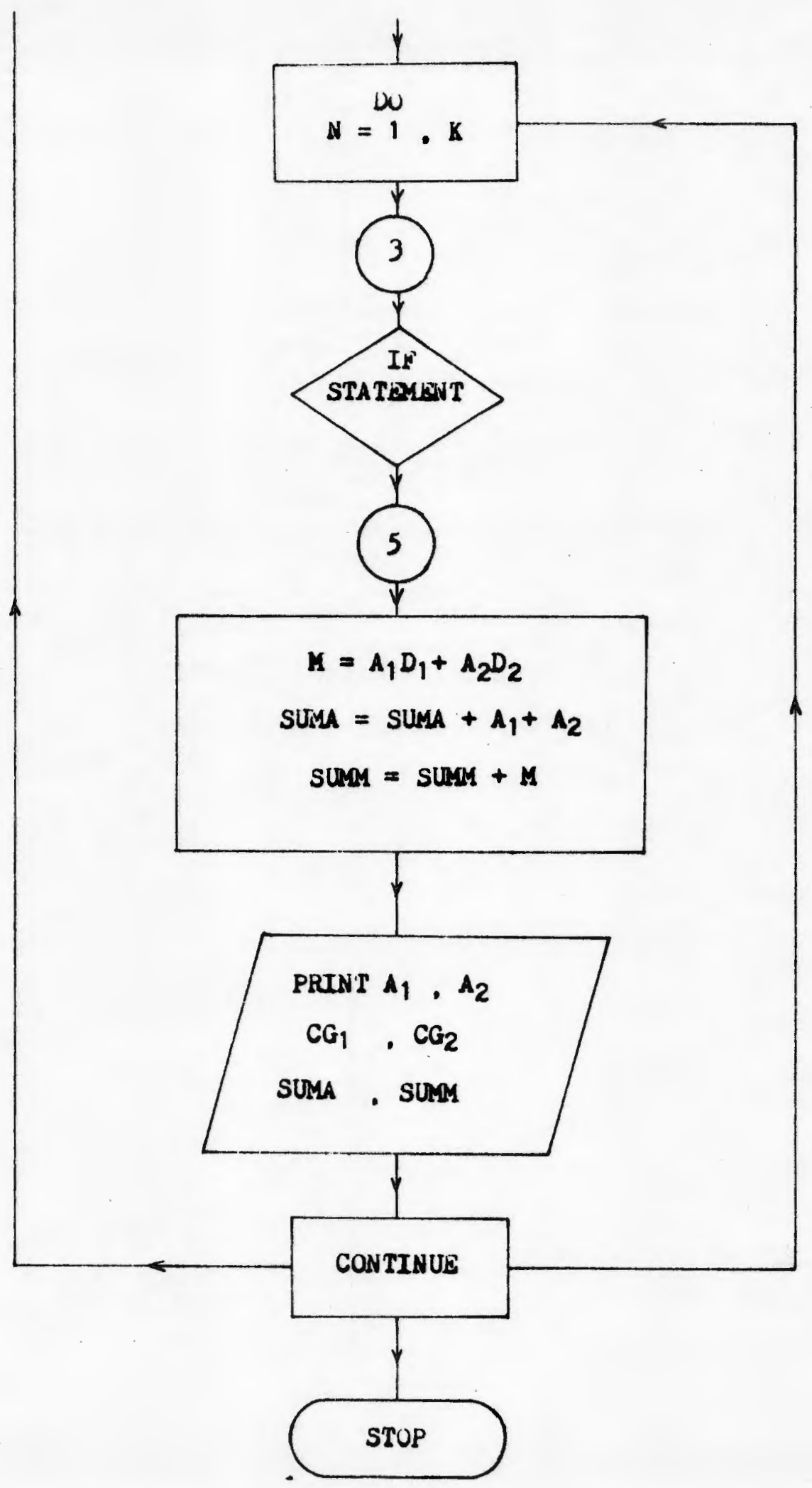


101

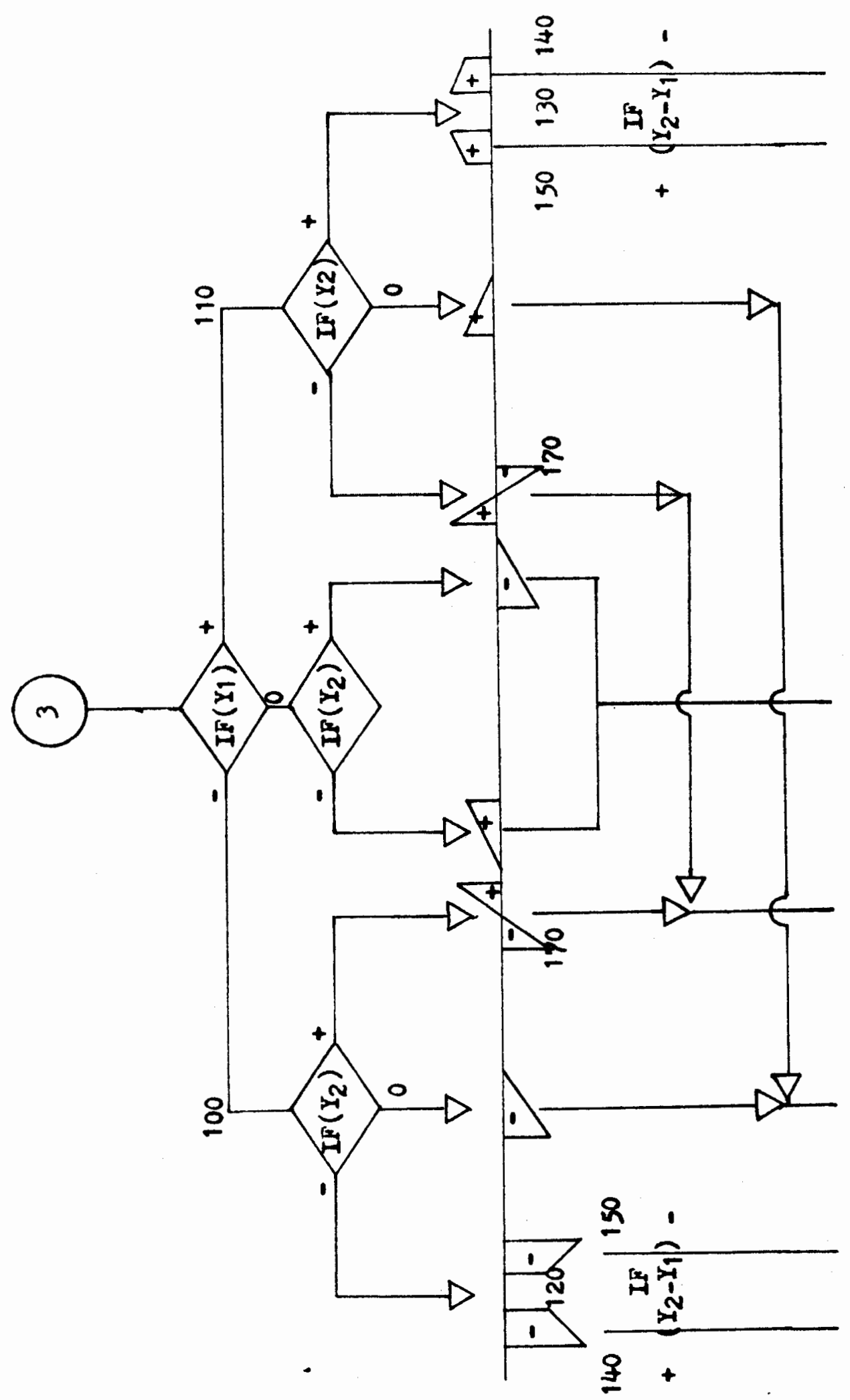




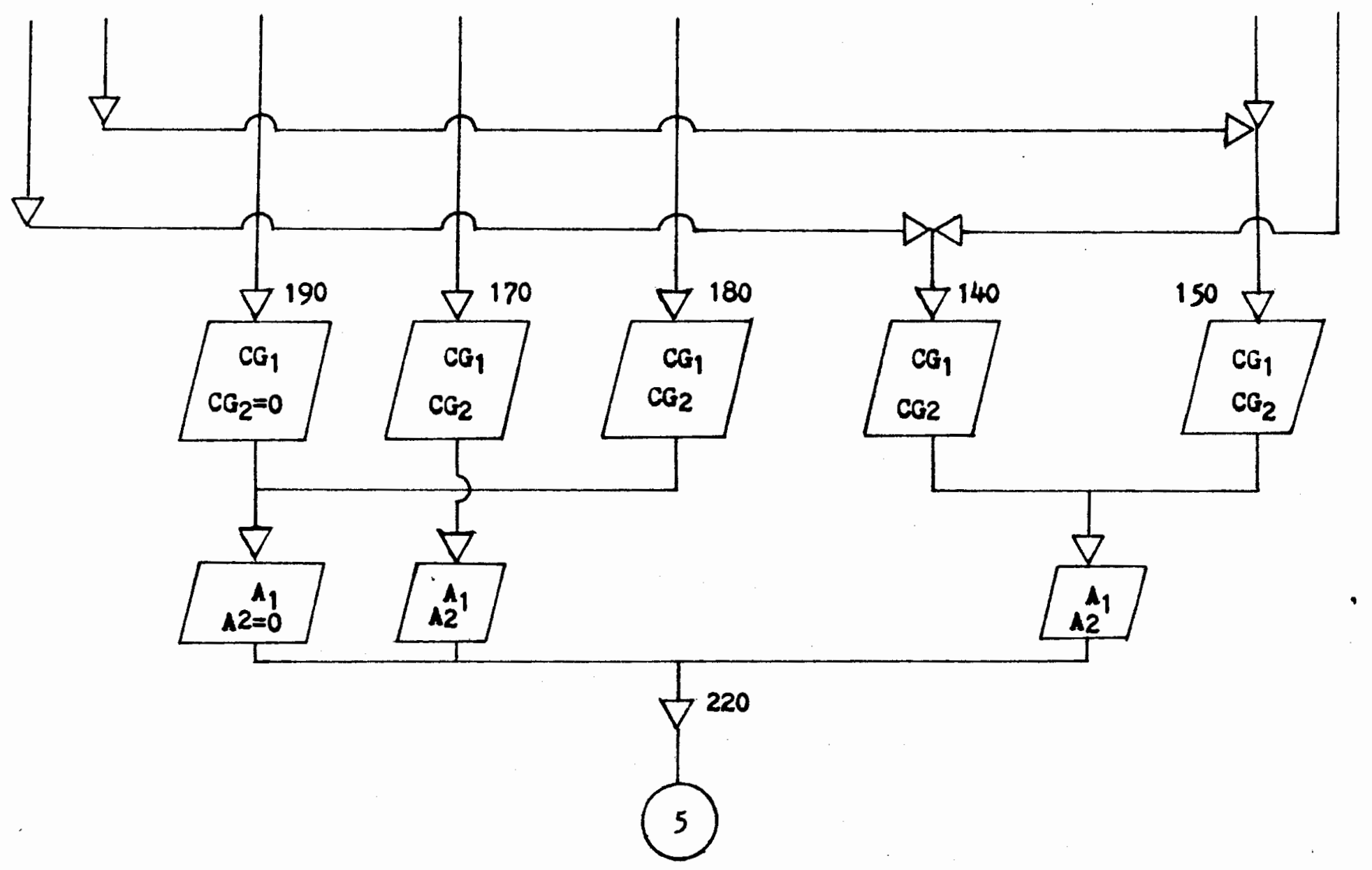


summation of moments relating to measured longitudinal residual stresses derived from measured strains is presented in Appendix IX.

It is noted that a preparation is required for converting raw data to input as the bending moment of the system of longitudinal residual stresses is taken about the $Z$ axis (see Figure 4.1). This preparation useful for a future research presented in detall for case 1 in Appendix XI with the statement and figure defining the area of forces limited by the curve and the 2 axis.

\subsubsection{Results of the computer program.}

A) Results relating to stresses obtained from measured strains with variable $4 \mathrm{~A}$ and $4 \mathrm{~B}$, Table 3.11 , case 1 .

The output obtained from the compllation of the computer program and data file shown in Appendix IX and relating to the Inftial longttudinal residual stresses derived from measured strains with varlable $4 \mathrm{~A}$ and $4 \mathrm{~B}$, case 1 , Table 3.11 , results in:

Summation of forces above the $\mathrm{Z}$ ax1s: -0.068125

Summation of forces below the $\mathrm{Z}$ axis: 0.0100453

Total summation of forces: $-0.068125+0.100453=0.032328$

This result is a dimensionless number. As described in section 4.1.1.d, it must be multiplied by $140.6 \mathrm{kfp}$ to yleld the force to find.

$$
\Sigma F=0.032328(140.6)=4.545 \mathrm{kIp}
$$

Expressed in percent of $\mathrm{P}_{y}$, the summation of forces is:

$$
4.545(100) / 870.8=0.5 \% \text { of } \mathrm{P}_{\mathrm{y}}
$$

-Summation of moments: $-0.092374-0.06026=-0.152634$ 
This summation of moments must be multiplied by $1546.5 \mathrm{kIp}$. In. to yield inch-kips, thus:

$-0.152634(1546.5) \mathrm{kip} . \mathrm{in} .=-236.05 \mathrm{kIp} . \mathrm{in}$.

Expressed in percent of $M_{y}$, the summation of moments is:

$-236.05(100) / 4859=-5 \%$ of $M_{y}$.

Computer output and data file are given in Appenxid IX.

B) Results related to stresses obtained from measured strains but computed with theoretical $4 \mathrm{~A}$ and $4 \mathrm{~B}$, Table 3.11 , case 2 .

Summation of forces above the $\mathrm{Z}$ ax1s: -0.061359

Summation of forces below the $\mathrm{Z}$ ax1s: 0.098718

Total summation of forces: $-0.061359+0.098718=0.037359$

Total summation of moments:

$$
-0.086489-0.057948=-0.144437
$$

The same approach as the above one gives the final results:

Summation of forces: $0.006 \mathrm{P}_{\mathrm{y}}$

Summation of moments: $\quad-0.046 \mathrm{M}_{\mathrm{y}}$.

Computer output and data file are given in Appendix X.

C) Results related to stresses obtained from the strain-

relaxation method with $4 \mathrm{~A}$ and $4 \mathrm{~B}$, Table 3.11 , case 3 .

Summation of forces above the $\mathrm{Z}$ axis: -0.104375

Summation of forces below the $\mathrm{Z}$ axis: 0.085563

Total summation of forces:

$$
-0.104375+0.085563=-0.018812
$$

Total summation of moments:

$$
-0.088679-0.049973=-0.13864
$$

The same approach as the above one gives the final results: 
Summation of forces $=-0.003 \mathrm{P}_{\mathrm{y}}$

Summation of moments: $-0.044 \mathrm{M}_{\mathrm{y}}$

Computer output and data file are given in Appendix X.

D) Results related to stress obtained from the strain-separation method with $4 A$ and $4 B$, Table 3.11 , case 4 .

Summation of forces above the $\mathrm{Z}$ axis: -0.043141

Summation of forces below the $\mathrm{Z}$ axis: 0.055731

Total summation of forces:

$$
-0.043141+0.055731=0.01264
$$

Total summation of moments:

$$
-0.055679-0.031260=-0.086939
$$

The same approach as the above gives the final results:

Summation of forces: $0.002 \mathrm{P}_{\mathrm{y}}$

Summation of moments: $-0.027 \mathrm{M}$

Computer output and data file are given in Appendix $x$.

These results are summarized in Table 4.1 .

\subsection{EVALUATION OF RESULTS}

In light of the data in Table 4.1 it $1 \mathrm{~s}$ seen that the results of case 1 are marginally acceptable giving an unbalance of $10 \% \mathrm{M}_{\mathrm{y}}$. Cases 2 and 3 have slightly better rotational equilibrium with the smailest unbalance being $8.8 \% \mathrm{M}_{\mathrm{y}}$. Case 4 gives the best results with $0.4 \% \mathrm{P}_{\mathrm{y}}$ translational and $5.4 \% \mathrm{M}$ rotational unbalance for the whole tube. This is to be expected since the calibration coefficients for case 4 were found using a more refined technique than any of the other cases. The unbalance present in case 4 could be attributed to 
the choice of sector division required for data generation for the computer program.

TABLE 4.1

RESULTS ON FORCE AND MOMENT BALANCE

\begin{tabular}{|c|c|c|c|c|c|}
\hline $\begin{array}{l}\text { Case } \\
\text { No. }\end{array}$ & Method & $\begin{array}{l}\text { Calibra- } \\
\text { tion } \\
\text { Coeffi- } \\
\text { clents } \\
\left(10^{-8}\right)\end{array}$ & $\Sigma \mathbf{F}$ & $\begin{array}{l}\text { Half } \\
\text { Section }\end{array}$ & $\begin{array}{l}\text { Whole } e^{----} \\
\text {Section }\end{array}$ \\
\hline 1 & Measurement & Varlable & $0.005 P_{y}$ & $-0.05 M_{y}$ & $10 \% \mathrm{M}_{\mathrm{y}}$ \\
\hline 2 & $\begin{array}{l}\text { Computation } \\
\text { of theoretical } \\
\text { calibration } \\
\text { coefficlents }\end{array}$ & $\begin{array}{l}4 A=-0.86 \\
4 B=-2.41\end{array}$ & $0.006 P_{y}$ & $-0.046 \mathrm{M}_{\mathrm{y}}$ & $9.2 \% \mathrm{M}_{\mathrm{y}}$ \\
\hline 3 & $\begin{array}{l}\text { Method of } \\
\text { strafn-relaxa- } \\
\text { tion }\end{array}$ & $\begin{array}{l}4 A=-0.93 \\
4 B=-2.08\end{array}$ & $-0.003 P_{y}$ & $-0.044 \mathrm{M}_{\mathrm{y}}$ & $8.8 \% \mathrm{M}_{\mathrm{y}}$ \\
\hline 4 & $\begin{array}{l}\text { Method of } \\
\text { strain sep- } \\
\text { aration }\end{array}$ & $\begin{array}{l}4 A=-1.30 \\
4 B=-2.23\end{array}$ & $0.002 P_{y}$ & $-0.027 \mathrm{M}_{y}$ & $5.4 \% \mathrm{M}_{\mathrm{y}}$ \\
\hline
\end{tabular}




\title{
CHAPTER V
}

\author{
SUMMARY, CONCLUSION AND RECOMMENDATIONS
}

The experiment of drilling outside and Inside holes in a welded fabricated steel tube, according to the hole-drilling technique has been carried out, as was the experiment of tensioning a steel plate specimen for callbration. Longltudinal residual stresses in the tube have been obtained from the hole drilling experiments. Calibration. coefficlents used to convert data from the hole drilling experiment to longitudinal stresses were obtained in two ways 1) Calibration coefficients were derived analytically by theory and using those recommended by published 11terature, 2) Calibration coefficients have also been computed from calibration operations performed according to the method of strain relaxation due to drilling and the method of strain separation. Calibration coefficients have been used in adjusting the data of the tube. Balance of forces and moments provides a comparison of the results of measurements and the quality of the results of refinement.

Results will be summarized, conclusion and recommendations will be presented in the following sections.

\subsection{SUMMARY OF RESULTS}

The experiments of outside and inside hole drilling on the steel tube and the calibration experiments conducted on the test plate followed by the balancing operations of forces and moments have ylelded the following results:

A) The measured strains on the tube have shown that no further 
strains were recorded after the values of the hole depth reached the hole dlameter value.

B) The strains measured for outside and inside holes and the corresponding longitudinal residual stresses computed have suggested that the stress fleld in the tube was well behaved through its thickness.

C) The field of longttudinal residual stresses in the tube assumed to be unfform through its thickness, has been substantlated by a numerical calculation using two factors of proportionality derived from the test plate in the calibration experiment and applied to the tube.

D) Four different kinds of calibration coefficlents were used, they are summarized as follows:

1. Varlable. $4 \mathrm{~A}=-0.83$ to $-1.05\left(10^{-8}\right), 4 \mathrm{~B}=-2.37$ to $-2.68\left(10^{-8}\right)$

2. $4 \mathrm{~A}=-0.86\left(10^{-8}\right), 4 \mathrm{~B}=-2.41\left(10^{-8}\right)$

3. $4 \mathrm{~A}=-0.93\left(10^{-8}\right), 4 \mathrm{~B}=-2.08\left(10^{-8}\right)$

4. $4 \mathrm{~A}=-1.30\left(10^{-8}\right), 4 \mathrm{~B}=-2.23\left(10^{-8}\right)$

As a comparison of the accuracy of the results, a statical equilibrium test in translation and rotation was performed for each of the residual stress distribution obtained using the above four kinds of calibration coefficlents. The results are summarized In Table 4.1.

E) Finally, a curve plotting the most acceptable values of residual stresses based on equilibrlum of forces and moments is repeated In Figure 5.1.

\subsection{CONCLUSION}

The results in the preceding section show the adequacy of the 


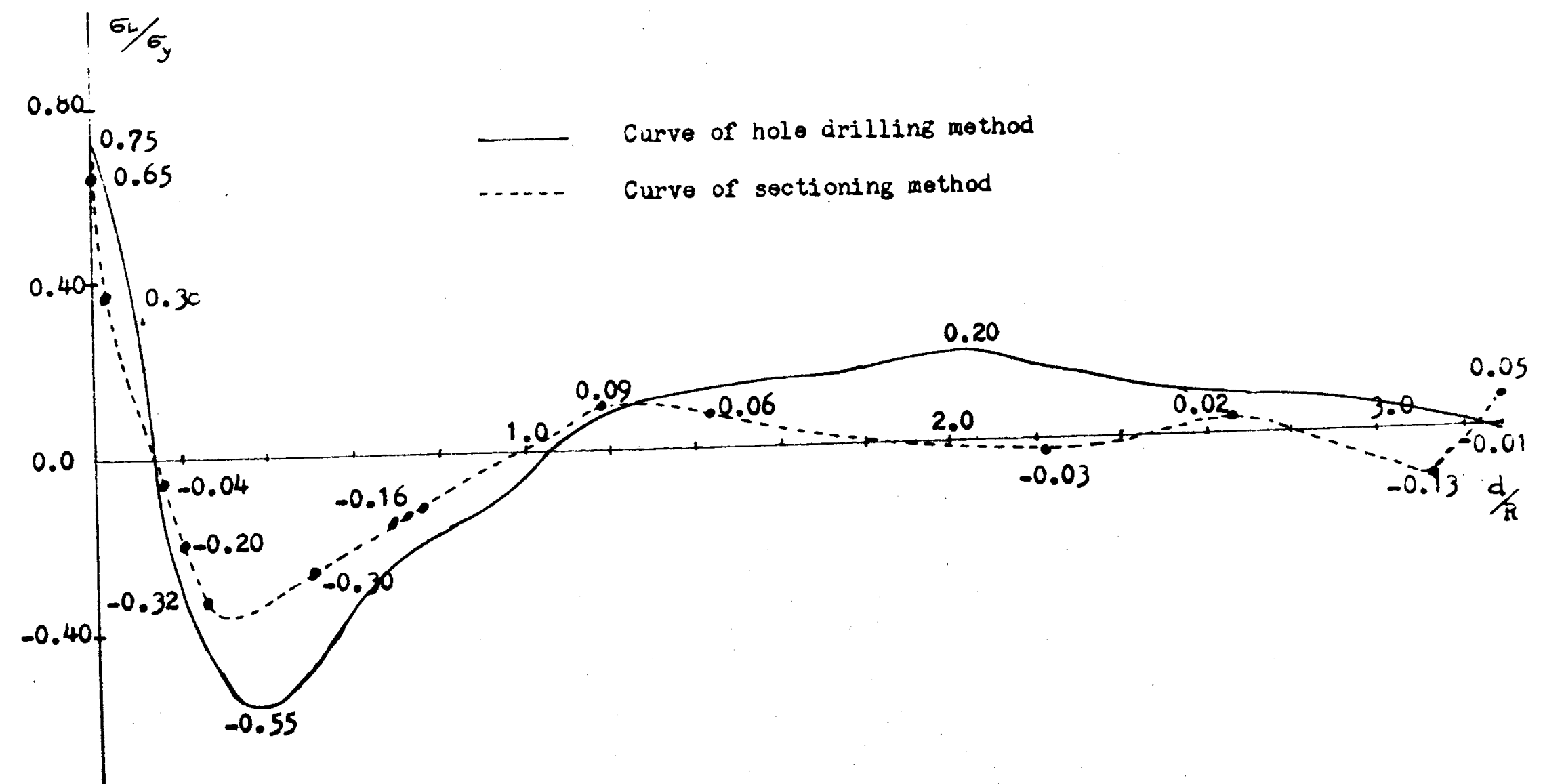

Mrure 5.1 Curve of rosidual stresses by hole drilling nothod (solid line) and curve by method of sectionsing (dished line) 
hole-drilling technique in the measurement of residual stresses, provided the hole drilling experiments are conducted in conjunction with the calibration carried out preferably according to strain separation method and using material simflar to the main experiment material.

For comparison, the curve of the longitudinal residual stresses found by the slicing method by others, is compared to the results of this investigation in Figure 5.1.

\subsection{RECOMMENDATIONS}

1) Translational and rotational equilibrium calculations confirmed the good results of the hole-drilling strain-gage experiments conducted on the steel tube. The curve of longitudinal residual stresses shown by a solid line in Figure 5.1 compared to results by others, further confirms the quality of the hole-drilling technique in measuring residual stresses. Our first recommendation is that calibration coefficients should always be used to refine the curve of stresses found and the method of strain separation would be the most efficient calibration method.

2) The solid curve shown In Figure 5.1 characterizes the distribution of residual stresses in the steel tube. For a more practical purpose, a simplified curve comprising three straight solid lines shown in Figure 5.2 is recommended. The balance of forces and moments derived from the pertinent curve is obtained with a high precision (summation of forces: $-0.0005 \mathrm{P}_{\mathrm{y}}$, summation of moments: $0.00009 \mathrm{M}_{\mathrm{y}}$ ). For comparison, a dotted straight line curve proposed by 
Ross and Chen (5) is shown in the same Figure 5.2. This curve is a simplified alternative of Ross and Chen presented in Figure 5.1. A computer program applied to this simplified curve with the same conditions as for the simplifled curve of our tube, shows that the precision obtained in balancing forces and moments was equivalent:

Summation of forces: $-0.00012 \mathrm{P}_{\mathrm{y}}$ (against $-0.0005 \mathrm{P}_{\mathrm{y}}$ for our curve) Summation of moments: $0.0026 \mathrm{M}_{\mathrm{y}}$ (against $0.00009 \mathrm{M}_{\mathrm{y}}$ for our curve) Finally, our simplified straight line approximation presented in Figure 5.2 to represent longttudinal residual stresses in the steel tube, is recommended for use in further studies of the effects of residual stresses on fallure loads. 


\section{REFERENCES}

1. Kelsey, R. A., "Measuring Non-Uniform Residual stresses by the Hole Drilling Method," Aluminum Research Laboratories, New Kensington, Pa., 1955.

2. Bush, A. J. and Kromer, F. J., "Simplification of the HoleDrilling Method of Residual Stress Measurement," Westinghouse Electric Corporation, Pittsburgh, Pa., 1972.

3. Chen, W. F. and Ross, D. A., "Residual Stress Measurements in Fabricated Tubular Steel Columns," Fritz Laboratories Report, No. 393.4, July 1975.

4. Rendler, N. J. and Vigness, I., "Hole-Drilling Strain-Gage Method of Measuring Residual Stresses," Shock and Vibration Branch, U.S. Naval Research Laboratory, Washington, D.C., May 1966.

5. Chen, W. F. and Ross, D. A., "Tests of Fabricated Tubular Columns," Journal of the Structural Division, Proceedings of ASCE, Vo1 103, No ST3, March 1977.

6. Mathar, Josef, "Determination of Initial Stresses by Measuring the Deformations Around Drilled Holes," Transactions of the American Soclety of Mechantcal Engineers, IS-56-2, pages $249-254,1933$.

7. Tebedge, N., Alpsten, G. and Tall, L., "Residual Stress Measurement by the Sectioning Method," SESA Spring Meeting held in Cleveland, Ohio, May 21-26, 1972.

8. Wagner, A. L., Mueller, W. H. and Erzurumlu, H., Portland State University, "Design Interaction Curves for Tubular Steel Beam-Columns", Eighth Annual offshore Technology Conference, Houston, Texas, May 3-6, 1976.

9. Sherman, D. R., "Circular Steel Tubes in Bending," ASCE National Water Resources and Ocean Engineering Convention, San Diego, CA, Apri1 5-8, 1976.

10. Redner, D., "Measurement of Residual Stresses by Blind Hole Drilling Method," Photoplastic, Inc., Bulletin TDG-5, Revised May, 1974.

11. Cranda11, S. H. and Dahl, N. C., "An Introduction to the Mechanics of Solids," Department of Mechanical Engineering, MIT, 1959. 
12. "RS-200 Milling Gulde, a Precision Optical Alignment and Guide Tool for Measurement of Residual Stresses by the Strain Gage Hole Drilling Method," Photolastic, Inc., Bulletin S-105, 1976.

13. Chajes, A., "Principle of Structural S.tability Theory," Department of Civil Engineering, University of Massachusetts, 1974.

14. Beedle, L. S., "Plastic Design of Steel Frames," Research Professor of Civil Engineering, Fritz Engineering Laboratory, Department of Civil Engineering, Lehigh University, 1958.

15. Wagner, A. L., "A Numerical Solution for the Ultimate Strength of Tubular Beam-Columns," Masters Thesis, Portland State Untversity, Nov. 1976.

16. Chen, W. F. and Ross, D. A., "Behavior of Fabricated Tubular Columns under Biaxial Bending," ASCE Natlonal Water Resources and Ocean Engineering Convention, San Diego, CA, April 5-8, 1976. 
APPENDIX I

DERIVATION OF EQUATIONS (3)

$$
\sigma_{1}=\frac{(A+B \cos 2 B) \varepsilon_{a}-(A-B \cos 2 B) \varepsilon_{c}}{4 A B \cos 2 \beta}
$$

(3)

$$
\begin{gathered}
\sigma_{2}=\frac{(A+B \cos 2 B) \varepsilon_{c}-(A-B \cos 2 \beta) \varepsilon_{a}}{4 A B \cos 2 \beta} \\
\tan 2 \beta=\frac{\varepsilon_{a}-2 \varepsilon_{b}+\varepsilon_{c}}{\varepsilon_{a}-\varepsilon_{c}}
\end{gathered}
$$

In section 2.2.2, the following expression has been established =

$$
\varepsilon_{\mathrm{r}}=[\mathrm{A}+\mathrm{B} \cos 2 \alpha] \sigma_{1}+[\mathrm{A}+\mathrm{B} \cos 2(\alpha+90)] \sigma_{2}
$$

Extending to directions $a$ and $c$, and replacing $\alpha$ by $\beta$, it becomes =

$$
\varepsilon_{a}=[A+B \cos 2 \beta] \sigma_{1}+[A+B \cos 2(\beta+90)] \sigma_{2}
$$

(2a)

$$
\varepsilon_{C}=[A+B \cos 2(\beta+90)] \quad \sigma_{1}+[A+B \cos 2(\beta+180)] \sigma_{2}
$$

Noting that $=$

$$
\begin{aligned}
& \cos 2(\beta+90)=\cos (2 \beta+180)=-\cos 2 \beta \\
& \cos 2(\beta+180)=\cos (2 \beta+360)=\cos 2 \beta
\end{aligned}
$$


(2a) can be rewritten $=$

$[A+B \cos 2 \beta] \sigma_{1}+[A-B \cos 2 \beta] \sigma_{2}=\varepsilon_{a}$

(2b)

$[A-B \cos 2 B] \sigma_{1}+[A+B \cos 2 B] \sigma_{2}=\varepsilon_{c}$

Dividing both members by the coefficients of $\sigma_{1}=$

$$
\begin{aligned}
& \sigma_{1}+\frac{A-B \cos 2 \beta}{A+B \cos 2 \beta} \quad \sigma_{2}=\frac{\varepsilon_{a}}{A+B \cos 2 B} \\
& \sigma_{1}+\frac{A+B \cos 2 \beta}{A-B \cos 2 \beta} \quad \sigma_{2}=\frac{\varepsilon_{c}}{A-B \cos 2 B}
\end{aligned}
$$

Using direct elimination (subtract member to member) =

$$
\left(\frac{A-B \cos 2 \beta}{A+B \cos 2 \beta}-\frac{A+B \cos 2 \beta}{A-B \cos 2 \beta}\right) \sigma_{2}=\frac{\dot{\varepsilon}_{a}}{A+B \cos 2 \beta}-\frac{\varepsilon_{c}}{A-B \cos 2 \beta}
$$

Developing and rearranging terms =

$$
\begin{aligned}
& {\left[(A-B \cos 2 B)^{2}-(A+B \cos 2 \beta)^{2} \sigma_{2}=\varepsilon_{a}(A-B \cos 2 \beta)-\varepsilon_{c}(A+B \cos 2 \beta)\right.} \\
& {[-2 A B \cos 2 B-2 A B \cos 2 B] \sigma_{2}=\varepsilon_{a}(A-B \cos 2 \beta)-\varepsilon_{c}(A+B \cos 2 \beta)}
\end{aligned}
$$

Finally:

$\sigma_{2}=\frac{(A+B \cos 2 \beta) \varepsilon_{c}-(A-B \cos 2 \beta) \varepsilon_{a}}{4 A B \cos 2 \beta}$

With the same approach =

$$
\sigma_{1}=\frac{(A+B \cos 2 \beta) \varepsilon_{a}-(A-B \cos 2 \beta) \varepsilon_{c}}{4 A B \cos 2 \beta}
$$


117

Proof of $=$

$$
\begin{aligned}
& \tan 2 \beta=\frac{\varepsilon_{a}-2 \varepsilon_{b}+\varepsilon_{c}}{\varepsilon_{a}-\varepsilon_{c}} \\
& \text { Remind }= \\
& \varepsilon_{a}=[A+B \cos 2 \beta] \sigma_{1}+[A-B \cos 2 \beta] \sigma_{2}
\end{aligned}
$$

(ab)

$$
\varepsilon_{c}=[A-B \cos 2 \beta] \sigma_{1}+[A+B \cos 2 \beta] \sigma_{2}
$$

$$
\begin{aligned}
& \text { then }=\varepsilon_{a}+\varepsilon_{c}=2 \mathrm{~A}\left(\sigma_{1}+\sigma_{2}\right) \\
& (2 c) \\
& \quad \varepsilon_{a}-\varepsilon_{c}=2 \mathrm{~B} \cos 2 \beta\left(\sigma_{1}-\sigma_{2}\right)
\end{aligned}
$$

therefore $=$

$$
\cos 2 \beta=\frac{\varepsilon_{a}-\varepsilon_{c}}{2 B\left(\sigma_{1}-\sigma_{2}\right)}
$$

Calculate $\sin 2 \beta$.

For direction $\mathrm{b}=$

$$
\begin{aligned}
& \varepsilon_{b}=\left[A+B \cos 2\left(\beta+45^{\circ}\right)\right] \sigma_{1}+\left[A+B \cos 2\left(\beta+135^{\circ}\right)\right] \sigma_{2} \\
& \varepsilon_{b}=[A-B \sin 2 \beta] \sigma_{1}+[A+B \sin 2 \beta] \sigma_{2} \\
& \varepsilon_{b}=A\left(\sigma_{1}+\sigma_{2}\right)+B\left(\sigma_{2}-\sigma_{1}\right) \sin 2 \beta
\end{aligned}
$$

Therefore $=$

$$
\sin 2 \beta=\frac{A\left(\sigma_{1}+\sigma_{2}\right)-\varepsilon_{b}}{B\left(\sigma_{2}-\sigma_{1}\right)}
$$


118

Compute $\tan 2 \beta$ :

$$
\begin{aligned}
\tan 2 \beta & =\frac{\sin 2 \beta}{\cos 2 \beta}=\frac{A\left(\sigma_{1}+\sigma_{2}\right)-\varepsilon_{b}}{B\left(\sigma_{2}-\sigma_{1}\right)} \times \frac{2 B\left(\sigma_{1}-\sigma_{2}\right)}{\epsilon_{a}-\varepsilon_{c}} \\
& =\frac{2 A\left(\sigma_{1}+\sigma_{2}\right)-2 \varepsilon_{b}}{\varepsilon_{a}-\varepsilon_{c}}
\end{aligned}
$$

As $2 \mathrm{~A}\left(\sigma_{1}+\sigma_{2}\right)=\varepsilon_{\mathrm{a}}+\varepsilon_{\mathrm{c}}$, from $(2 \mathrm{c})$

Finally:

$$
\begin{aligned}
\tan 2 \beta & =\frac{\varepsilon_{a}+\varepsilon_{c}-\varepsilon_{e b}}{\varepsilon_{a}-\varepsilon_{c}} \\
& =\frac{\varepsilon_{a}-2 \varepsilon_{b}+\varepsilon_{c}}{\varepsilon_{a}-\varepsilon_{c}}
\end{aligned}
$$


Developing and rearranging terms =

$(A-B \cos 2 \beta)(A-B \sin 2 \beta)-(A+B \sin 2 \beta)(A+B \cos 2 \beta) \sigma_{2}=$

$$
\varepsilon_{a}(A-B \sin 2 B)-\varepsilon_{b}(A+B \cos 2 B)
$$

Developing first member $=$

$A^{2}-A B \sin 2 \beta-A B \cos 2 \beta+B^{2} \sin 2 \beta \cos 2 \beta$
$-\left(A^{2}+A B \cos 2 \beta+A B \sin 2 \beta+B^{2} \sin 2 \beta \cos 2 \beta\right)=$

$-2 A B(\sin 2 \beta+\cos 2 \beta)$

Then $=$

$\sigma_{2}=\frac{(A+B \cos 2 \beta) \varepsilon_{b}-(A-B \sin 2 \beta) \varepsilon_{a}}{2 A B(\sin 2 \beta+\cos 2 \beta)}$

With the same approach =

$$
\sigma_{1}=\frac{(A+B \sin 2 \beta) \varepsilon_{a}-(A-B \cos 2 \beta) \varepsilon_{b}}{2 A B(\sin 2 \beta+\cos 2 \beta)}
$$




\section{APPENDIX III}

\section{DERIVATION OF EQUATIONS (3a)}

(3a)

$$
\sigma_{1}=\frac{S}{4 A}+\frac{D}{4 B \cos 2 B}
$$

$$
\sigma_{2}=\frac{S}{4 A}-\frac{D}{4 B \cos 2 B}
$$

with $\tan 2 \beta=\frac{S-2 \varepsilon_{b}}{D}$

$S=\varepsilon_{a}+\varepsilon_{c}$

$D=\varepsilon_{a}-\varepsilon_{c}$

Rewrite equation (3) from Appendix I

$$
\sigma_{1}=\frac{(A+B \cos 2 B) \varepsilon_{a}-(A-B \cos 2 B) \varepsilon_{c}}{4 A B \cos 2 B}
$$

(3)

$$
\sigma 2=\frac{(A+B \cos 2 B) \varepsilon_{c}-(A-B \mid \cos 2 B) \varepsilon_{a}}{4 A B \cos 2 B}
$$

Developing the second member and grouping terms =

$$
\begin{aligned}
\sigma_{1} & =\frac{A\left(\varepsilon_{a}-\varepsilon_{c}\right)+B \cos 2 B\left(\varepsilon_{a}+\varepsilon_{c}\right)}{4 A B \cos 2 B} \\
& =\frac{\varepsilon_{a}+\varepsilon_{c}}{4 A}+\frac{\varepsilon_{a}-\varepsilon_{c}}{4 B \cos 2 B}
\end{aligned}
$$


$\sigma_{1}=\frac{S}{4 A}+\frac{D}{4 B \cos 2 B}$

With the same approach =

$$
\sigma_{2}=\frac{S}{4 A}-\frac{D}{4 B \cos 2 B}
$$

Coefficients $4 \mathrm{~A}$ and $4 \mathrm{~B}$ can be computed by adding or subtracting member to member, from equations (3a)

$$
\begin{aligned}
& 4 \mathrm{~A}=\frac{2 \mathrm{~S}}{\sigma_{1}+\sigma_{2}} \\
& 4 \mathrm{~B}=\frac{2 \mathrm{D}}{\left(\sigma_{1}-\sigma_{2}\right) \cos 2 B}
\end{aligned}
$$


APPENDIX IV

COMPUTER PROGRAM FOR CALCULATING PRINCIPAL STRESSES $\sigma_{1} \& \sigma_{2}$ WHEN STRAINS

$$
\varepsilon_{A}, \varepsilon_{B}, \varepsilon_{C} \text { ARE KNOWN }
$$

En nOCK

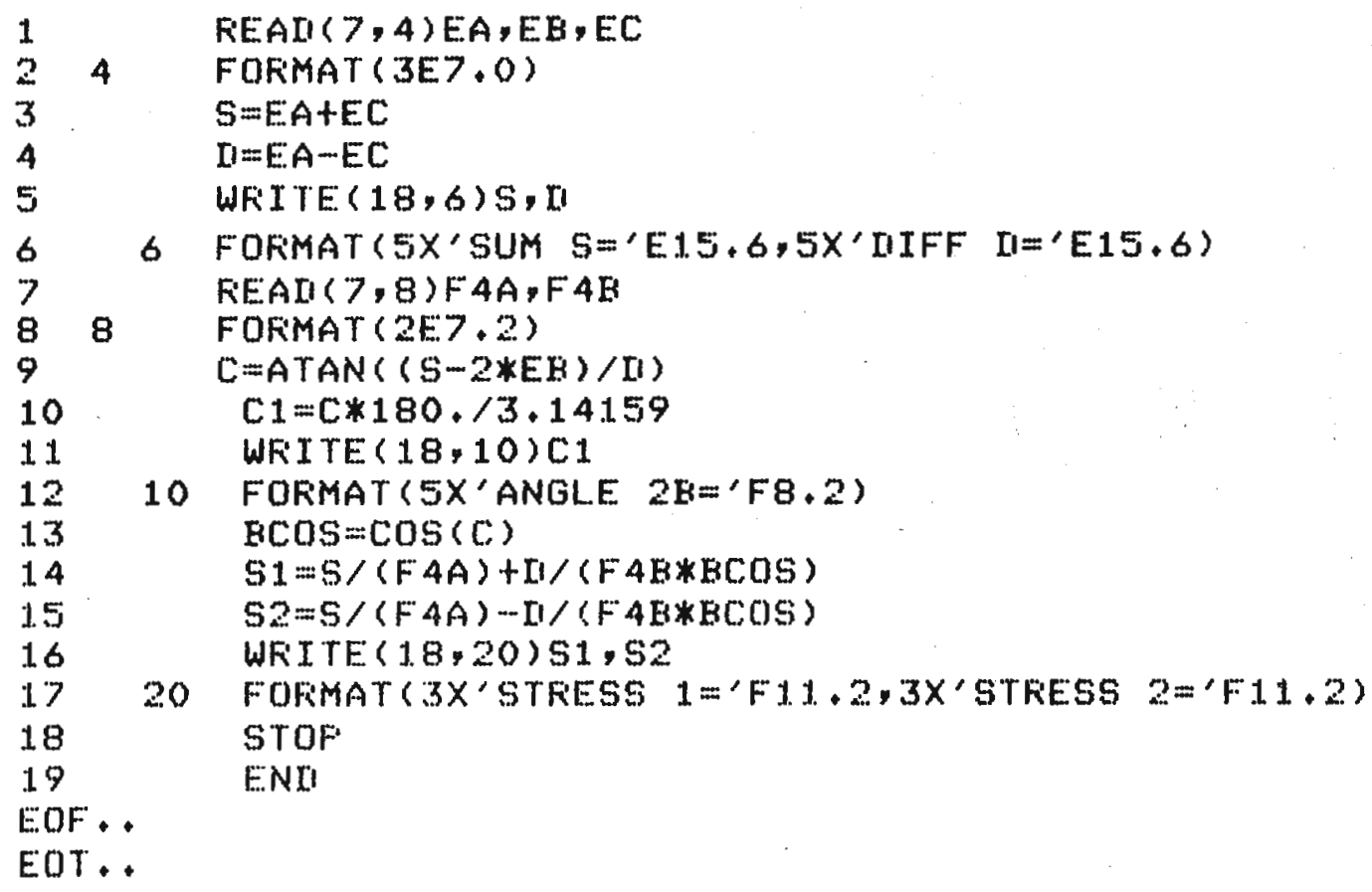


DATA FILE AND OUTPUT

En LIOC3

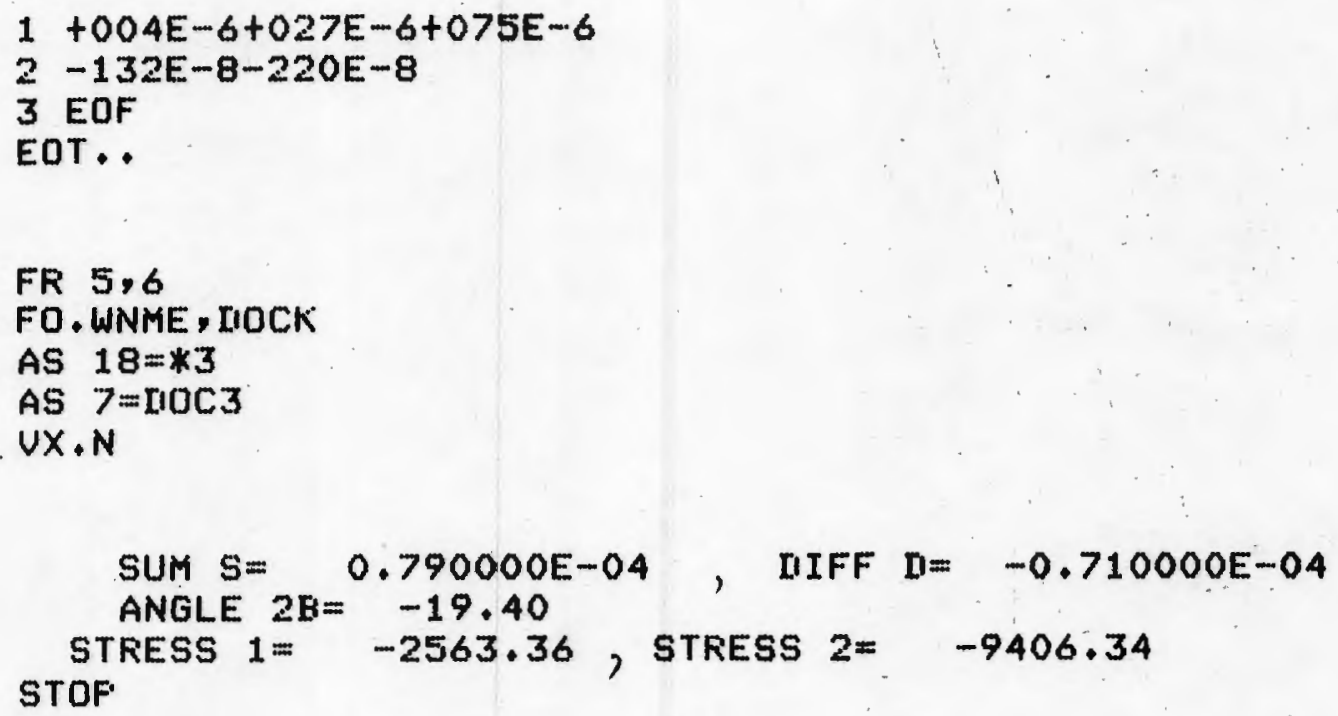


APPENDIX V

Graphical method using a stress MOHR's CIRCLE to determine longitudinal and circumferential stresses $\sigma_{\mathcal{L}} \& \sigma_{T}$ when principal stresses $\sigma_{1} \& \sigma_{2}$ are known.

Build the stress Mohr's circle with diameter $A B$, abscissa $O A=\sigma_{1}$ and abscissa $\mathrm{OB}=\sigma_{2}$.

The direction $\beta$ of gage a with respect to $\sigma_{1}$ is given by formula :

$$
\tan 2 \beta=\frac{S-2 \varepsilon_{b}}{D}
$$

If the direction $b$ coincides with the transverse axis of the pipe, and $\alpha$ is the angle of the longitudinal axis with direction $\sigma_{1}$ :

$$
\alpha=90^{\circ}-\left(45^{\circ}+\beta\right)=45^{\circ}-\beta
$$

In the Mohr's circle, the angle used for a direction is double: (see Fig. A.6.1)

$$
2 \alpha=90^{\circ}-2 \beta
$$

Knowing the direction of $\sigma_{1}$ on the Mohr's circle (radius wA), open an angle $\mathrm{AwC}=2 \alpha=90^{\circ}-2 \beta$, the abscissa of $\mathrm{M}$, intersection with the circle is the longitudinal stress $\sigma_{L}$.

The abscissa of Point $\mathrm{N}$ diametrically opposite to $\mathrm{M}$ is the transverse or circumferential stress $\sigma_{\mathrm{T}}$. 
Application. Hole 1 .

$$
\begin{aligned}
& \varepsilon_{a}=4, \varepsilon_{b}=27, \varepsilon_{c}=75 \\
& \sigma_{1}=-6070 \text { ps1, } \sigma_{2}=-12091 \text { ps } 1 \\
& 2 \beta=19^{\circ} 22 \quad \beta=9^{\circ} 41 \\
& \alpha=90^{\circ}-(45+9.41)=35^{\circ} 19 \\
& 2 \alpha=70^{\circ} 38
\end{aligned}
$$

- Build a Mohr's circle with =

$O B=-12091 \mathrm{psi}$

$\mathrm{OA}=-6070 \mathrm{psi}$

From $w A$, open an angle $\mathrm{AwC}=2 \alpha=70^{\circ} 38$; its second side cuts the clrcle in points $M \& N$.

$$
\begin{aligned}
& \text { Point } M, \sigma_{L}=-8080 \mathrm{psi} \\
& \text { Point } N, \sigma_{T}=-10090 \mathrm{psi}
\end{aligned}
$$


APPEIDIX VI

COMPUTER PROGRAM

ANALYTICAL STUDY

Determination of longltudinal stress $\sigma_{L}$ and circumferential stress $\sigma_{T}$ when principal stresses $\sigma_{1}$ and $\sigma_{2}$ are known.

\section{Part I. Longltudinal Stress $\sigma_{L}$.}

Equation of a Mohr's circle of stress, when principal stresses $\sigma_{1}$, $\sigma_{2}$ are known:

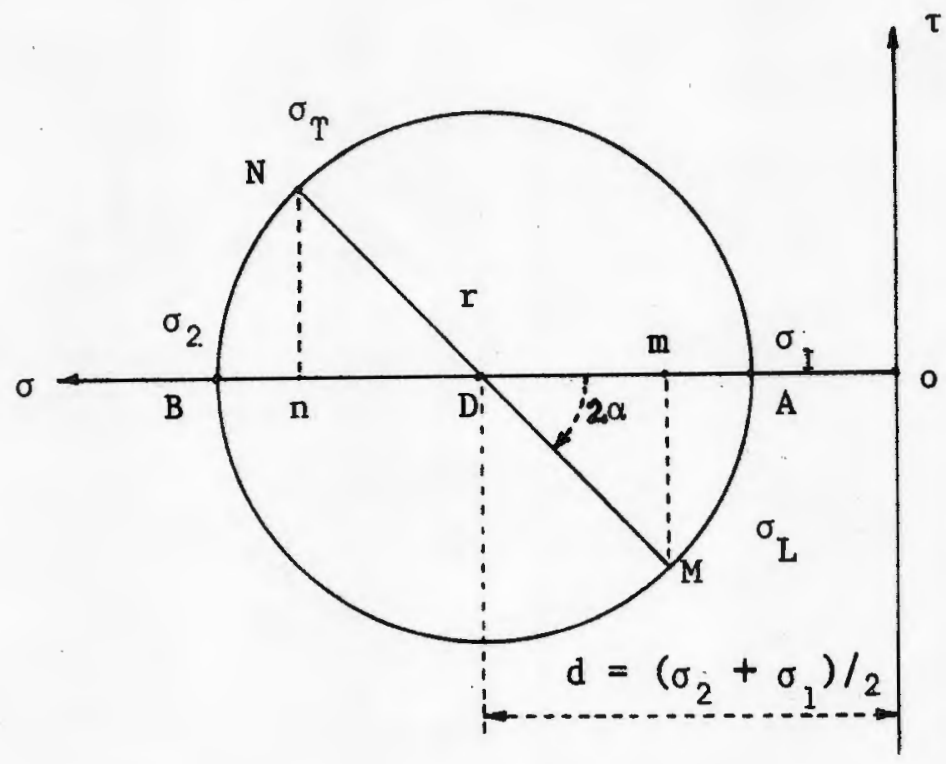

F1gure A.6.1. Stress Mohr's circle.

(1)

$$
\begin{aligned}
& (X-O D)^{2}+y^{2}=r^{2} \\
& \text { As } O D=d=\frac{\sigma_{2}-\sigma_{1}}{2}
\end{aligned}
$$




$$
r=\frac{\sigma_{2}-\sigma_{1}}{2}
$$

According to equation (2a) (Appendix 1) =

$$
\begin{aligned}
& \varepsilon_{a}+\varepsilon_{c}=2 A\left(\sigma_{1}+\sigma_{2}\right) \\
& \varepsilon_{a}-\varepsilon_{c}=2 B \cos 2 \beta\left(\sigma_{1}-\sigma_{2}\right)
\end{aligned}
$$

(2a) can be rewritten $=$

$$
\begin{aligned}
& \sigma_{1}+\sigma_{2}=\frac{\varepsilon_{a}+\varepsilon_{c}}{2 \mathrm{~A}}=\frac{\mathrm{S}}{2 \mathrm{~A}} \\
& \sigma_{1}-\sigma_{2}=\frac{\varepsilon_{\mathrm{a}}-\varepsilon_{c}}{2 \mathrm{~B} \cos 2 B}=\frac{\mathrm{D}}{2 \mathrm{~B} \cos 2 \mathrm{~B}}
\end{aligned}
$$

Therefore $=$

$$
\begin{aligned}
& \mathrm{OD}=\frac{\sigma_{2}+\sigma_{1}}{2}=\frac{\mathrm{S}}{4 \mathrm{~A}} \\
& \mathrm{R}=\frac{\sigma_{2}-\sigma_{1}}{2}=\frac{-\mathrm{D}}{2 \mathrm{~B} \cos 2 \mathrm{~B}}
\end{aligned}
$$

After substitution of terms, equation (1) becomes:

$$
\left(X-\frac{S}{4 A}\right)^{2}+Y^{2}=\frac{D^{2}}{(4 B \cos 2 B)^{2}}
$$

To find the longitudinal stress, an angle $2 \alpha$ is built from $\mathrm{DA}$, its second side cuts the Mohr's circle at point M. The abscissa of point M is the longitudinal stress.

Equation of the Straight Line DM.

a) Its slope is $\tan 2 \alpha$, ( $\alpha$ being the angle of the longitudinal stress) with direction $\sigma_{1}$. As shown in Appendix V: 


$$
\begin{aligned}
\alpha & =45^{\circ}-\beta \\
2 \alpha & =90^{\circ}-2 \beta \\
\tan 2 \alpha & =\tan \left(90^{\circ}-2 \beta\right) \\
& =\operatorname{cotan} 2 \beta \\
& =\frac{1}{\tan 2 \beta}
\end{aligned}
$$

According to equation (3), Append1x I,

$$
\begin{aligned}
& \tan 2 \beta=\frac{S-2 \varepsilon_{b}}{D} \\
& \text { Let } M=\frac{S-2 \varepsilon_{b}}{D}
\end{aligned}
$$

Then

$$
\tan 2 \alpha=\frac{1}{\tan 2 \beta}=\frac{D}{S-2^{\varepsilon} b}=\frac{1}{M}
$$

b) As the straight line passes through point D (abcissa =

$$
\begin{aligned}
\frac{\sigma_{2}+\sigma_{1}}{2}= & \left.\frac{S}{4 A}, \text { ordinate }=0\right) \\
Y & =\frac{1}{M} X+N, M=\frac{S-2 E b}{D} \\
O & =\left(\frac{D}{S-2 E b}\right) \frac{S}{4 A}+N \\
N & =\frac{-S D}{4 A(S-2 E b)} \\
Y & =\left(\frac{D}{S-2 E b}\right) X-\frac{S D}{4 A(S-2 E b)} \\
Y & =\frac{1}{M} X-\frac{S}{4 A} \times \frac{1}{M}
\end{aligned}
$$


c) Abscissa of point M. Intersection of DM and Mohr's circle $=$ Line DM $=$

$$
Y=\frac{1}{M}\left(X-\frac{S}{4 A}\right)
$$

Mohr's circle $=$

$$
\left(X-\frac{S}{4 A}\right)^{2}+Y^{2}=\left(\frac{D}{4 B \cos 2 B}\right)^{2}
$$

Let $E=\frac{S}{4 A}$,

Line $\mathrm{DM}=$

$$
\mathrm{Y}=\frac{1}{\mathrm{M}}(\mathrm{X}-\mathrm{E})
$$

Mohr's circle $=$

$$
(X-E)^{2}+Y^{2}=\left(\frac{D}{4 B \cos 2 \beta}\right)^{2}
$$

As $M$ is common to DM and and circle, its coordinates satisfy both equations (1a), (1b).

Raise (1a) to square and substitute into (1b) =

$$
\begin{aligned}
& Y^{2}=\frac{1}{M^{2}}(X-E)^{2} \\
& (X-E)^{2}+\frac{1}{M^{2}}(X-E)^{2}=\left(\frac{D}{4 B \cos 2 \beta}\right)^{2} \\
& \left(1+\frac{1}{M^{2}}\right)(X-E)^{2}-\left(\frac{D}{4 B \cos 2 \beta}\right)^{2}=0 \\
& \left(\frac{M^{2}+1}{M^{2}}\right)(X-E)^{2}-\left(\frac{D}{4 B \cos 2 B}\right)^{2}=0
\end{aligned}
$$




$$
(X-E)^{2}-\left(\frac{M^{2}}{1+M^{2}}\right)\left(\frac{D}{4 B \cos 2 B}\right)^{2}=0
$$

Developing and rearranging terms:

$\mathrm{X}^{2}-2 \mathrm{EX}+\mathrm{E}^{2}-\left(\frac{\mathrm{M}^{2}}{1+\mathrm{M}^{2}}\right)\left(\frac{\mathrm{D}}{4 \mathrm{~B} \cos 2 B}\right)^{2}=0$

Quadratic equation in $\mathrm{X}$ with $=$

$$
\begin{aligned}
& A=1 \\
& B=-2 E \\
& C=E^{2}-\left(\frac{M^{2}}{1+M^{2}}\right)\left(\frac{D}{4 B \cos 2 B}\right)^{2}
\end{aligned}
$$

\section{Existence of Roots:}

$$
\text { Discriminant } \begin{aligned}
\Delta^{\prime} & =B^{\prime 2}-A C \\
& =E^{2}-\left[E^{2}-\left(\frac{M^{2}}{1+M^{2}}\right)\left(\frac{D}{4 B \cos 2 B}\right)^{2}\right] \\
& =+\left(\frac{M^{2}}{1+M^{2}}\right)\left(\frac{D}{4 B \cos 2 B}\right)^{2}>0
\end{aligned}
$$

Therefore, the equation will always have roots.

Part II. C1rcumferential Stress $\sigma_{r}$.

$\sigma_{T}$ is obtained with point $N$ diametrically opposite to $M\left(\sigma_{L}\right)$. 
COMPUTER PROGRAM

for longitudinal and circumferentiel stresses

EOIGMAS

1

2

3

4

5

7

8

9

10

11

12

13

14

15

1. 6

17

$18 \mathrm{C}$

19

20

21.

22.

230

24

25

26

27

28

FEEAC $(7,4) E A, E B, E C$

4 FOFMAT $(3 E \%$, 0$)$

$S=E A+E C$

$X=E A-E C$

WFITE $(18,6) E A, E B, E C$

6 FOFMAT ( $\left.5 X^{\prime} E A=\prime E 15,4,5 X^{\prime} E B={ }^{\prime} E 15,4,5 X^{\prime} E C=\prime E 15,4\right)$

FEAII $(7,8) F A A, F 4 B$

8 FOFIMAT $(2 E 7,2)$

WFITE $(18,9) F 4 A, F 4 E$

9 FORMAT ( $5 X, F 4 A=\prime E 15,4,5 X, F 4 E=\prime E 15,4)$

$Q=S /(F A A)$

$X M=(5 \cdots 2, * E B) / r$

$$
X L=A T A N(X M)
$$

$X L .1=X L * 180 . / 3.14159$

WF T TE $(1.8,10) \times 1.1$

10 FOFIMAT ( $5 X^{\prime}$ ANGLE XLI $=$ 'FE.?

C COMFUTE STRESS I AND STRESS 2

$S 1=S /(F 4 A)+1 /(F 4 B * B C O S)$

$S 2=S /(F 4 A)-[1 /(F 4 B * B C O S)$

WRITE $(18,12) 51,52$

12 FOKMAT $\left(3 X^{\prime}\right.$ STRESS $1=(F 11.2,3 X$ 'STRESS $2=(F 11.2)$

COMFUTE'LONGT TULINAL STRESS'

$A=1$.

$B=-2 * * Q$

$C=Q * 22-(X M * * 2 /(1+X M * X M)) *(I /((F 4 E) * B C O S)) * 22$

TEMF $=B * * 2 \cdots 4$, *A*C

IF $(51) 30$ y 30,60 


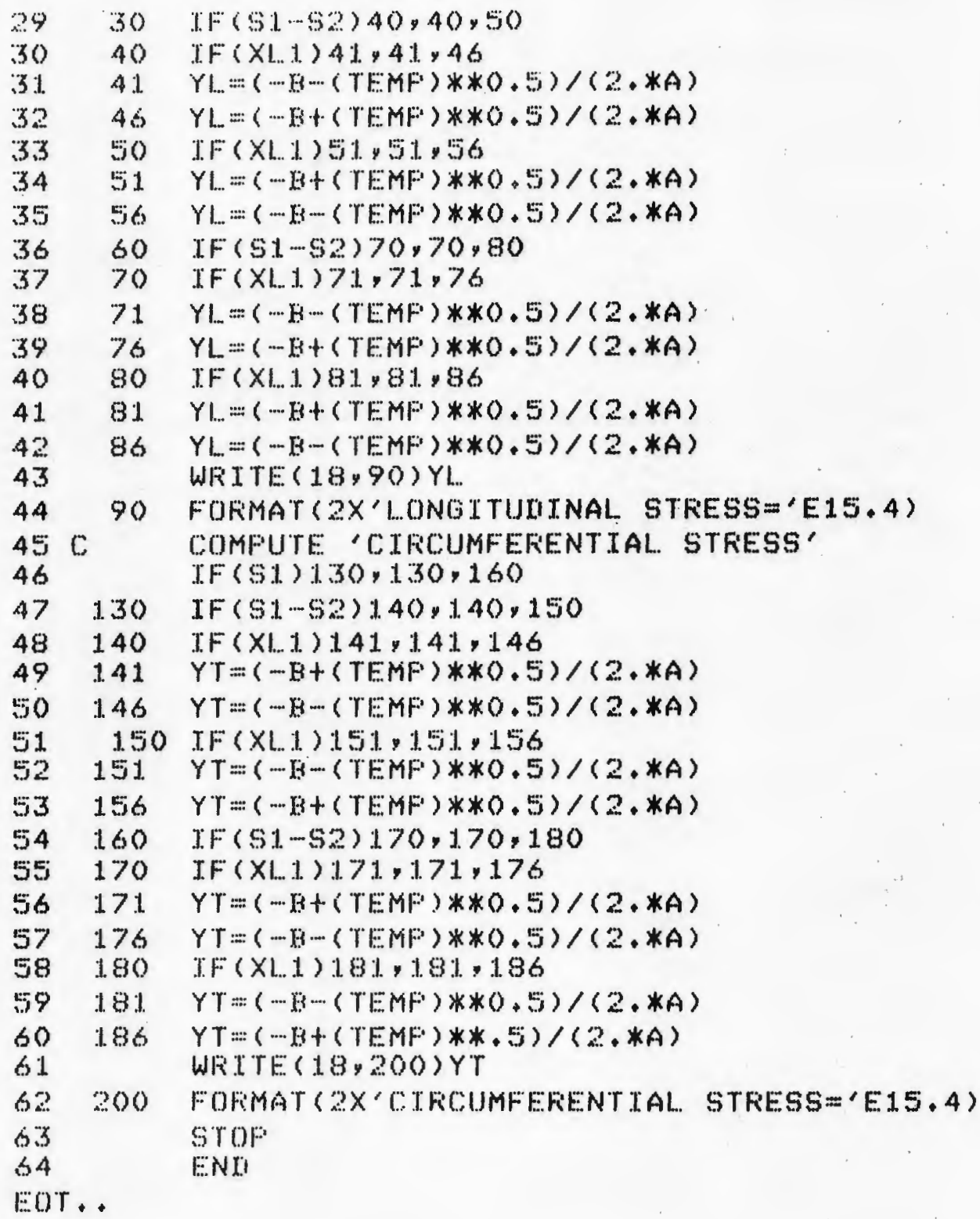




\section{DATA FILE AND OUTPUT}

for longltudinal and circumferential stresses

En nock3

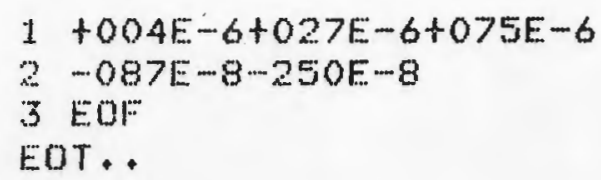


APPENDIX VII

Graphical method to determine longitudinal and circumferential strains $\varepsilon_{L} \& \varepsilon_{T}$, when strains $\varepsilon_{a}, \varepsilon_{b}, \varepsilon_{c}$ are known.

A. Construct Mohr's circle.

Build a system of orthogonal coordinates:

-vertical axis or axis of half shear-strains.

-horizontal axis or axis of strains (see Figure A7.1)

On the axis of strains, plot:

$$
\begin{aligned}
& O A=\varepsilon_{a} \\
& O B=\varepsilon_{b} \\
& O C=\varepsilon_{c}
\end{aligned}
$$

Mark point $D$ middle of $A C$. On the, verticals of $A$ and $C$, build:

$$
\mathrm{Aa}=\mathrm{BD} \quad, \quad \mathrm{Cc}=\mathrm{BD}
$$

$\mathrm{aD}$ and $\mathrm{Dc}$ are the radii of Mohr's circle.

On the vertical of $B$, build:

$$
\mathrm{Bb}=\mathrm{DA} \text {. or } \mathrm{Bb}=\mathrm{DC}
$$

$\mathrm{Db}$ is also the radius of the circle. The three right angles $\mathrm{aAD}, \mathrm{CCD}$ and bBD are equal.

Draw the Mohr's circle passing on a, b, $c$. 


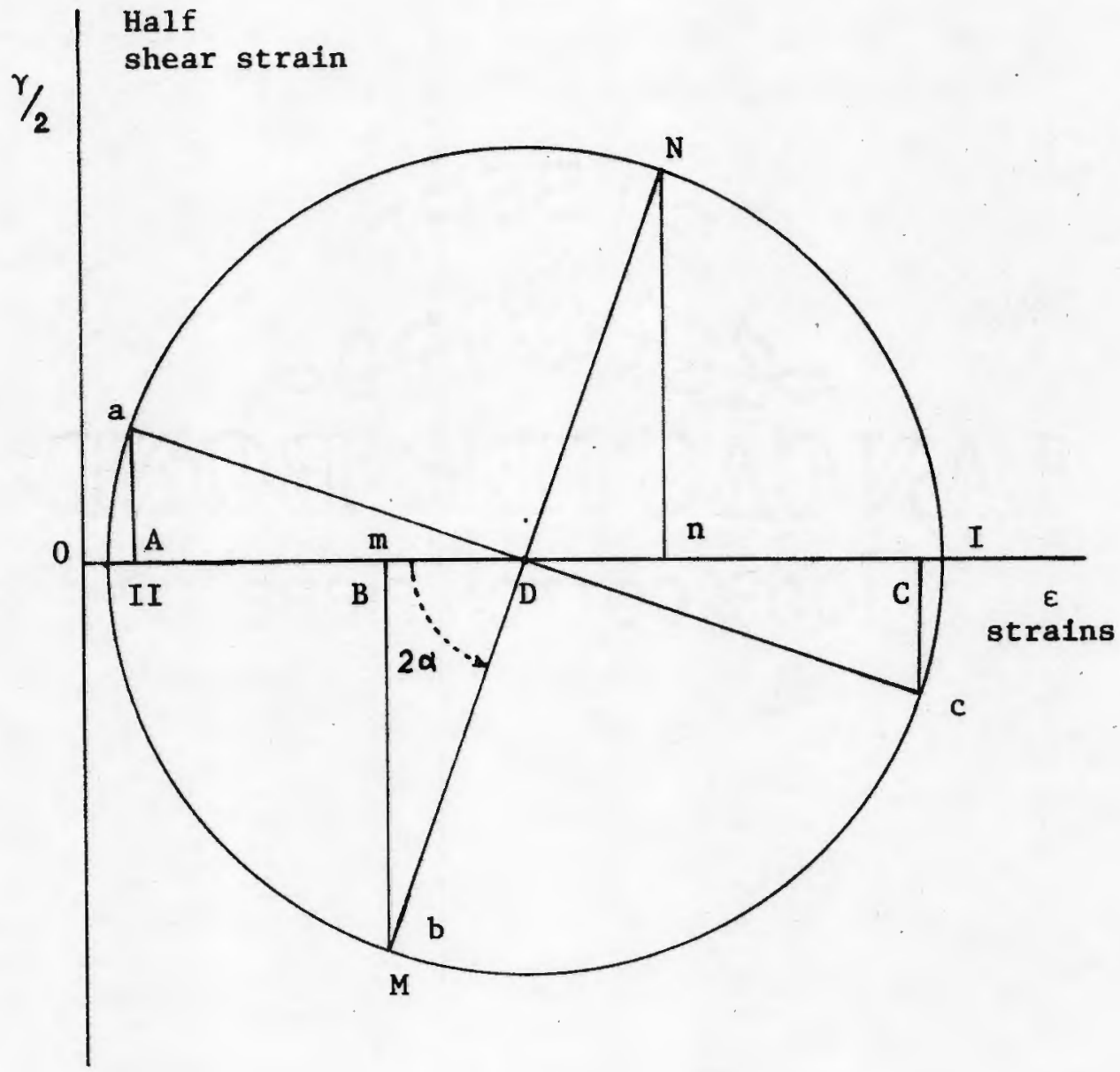

F1gure A.7.1. Straln Mohr's circle 
Note the location of points I and II giving the maximum and minimum strains $\varepsilon_{1}$ and $\varepsilon_{2}$.

B. Check location of directions (gages) a, b, c.

As the three directions $a, b, c$ are $45^{\circ}$ apart and counterclockwise, the three points a, b, c on the Mohr's circle $90^{\circ}$ apart (double angle in Mohr's circle) and counterclockwise are good ones.

C. Compute the longftudinal strain.

1.) In Appendix $\mathrm{V}=$

$$
\alpha=45^{\circ}-\beta
$$

and

$$
\tan 2 \beta=\frac{S-2 \varepsilon_{b}}{D} \quad \text { (Appendix I) }
$$

The angle of principal axis $\varepsilon_{1}$ with $\varepsilon_{L}$ is $2 \alpha$, in Mohr's circle $=$

$$
2 \alpha=90^{\circ}-2 B
$$

The second side of the angle $2 \alpha$ built from the principal strain direction cuts the Mohr's circle at point $M$, 1ts abscissa is the longitudinal strain.

2.) Numerical example.

Case of Hole 1 .

Strains $=\varepsilon_{a}=4 \times 10^{-6}, \varepsilon_{b}=27 \times 10^{-6}, \varepsilon_{c}=75 \times 10^{-6}$.

Plots points $A, B, C$ on strain axis:

$$
O A=4, \quad O B=27 \quad, \quad O C=75
$$


Mark point $D$, middle of $A C$.

Build $\mathrm{Aa}=\mathrm{Cc}=\mathrm{BD}=13$.

Draw the strain Mohr's circle from $D$ with radius $O D=37.5$.

Compute $\tan 2 \beta=\frac{4-2(27)+75}{4-75}$

$$
=-\frac{25}{71}
$$

$2 \beta=-19^{\circ} 24^{\mathrm{mi}} \quad, \quad \beta=-9^{\circ} 24^{\mathrm{mi}}$

$2 \alpha=90^{\circ}-2 \beta=70^{\circ} 18^{\text {mt }}$

From the principal axis, open an angle $2 \alpha=70^{\circ} 18^{\mathrm{mi}}$, its second side cuts the Mohr's circle, first at point $M$ then, at point $N$.

Longitudinal strain om $=27 \times 10^{-6}$.

Circumferential strain on $=52 \times 10^{-6}$. 


\section{APPENDIX VIII}

COMPUTER PROGRAM

\section{A. ANALYTICAL APPROACH}

\section{A. General Considerations}

The construction of a strain Mohr's circle has been shown in Appendix VII.

The problem consists of determining the directions and magnitudes of the longitudinal and circumferential strains when the angle $\alpha$ of the direction a with the longitudinal direction is known ( $\beta=$ angle of direction a with principal axis).

Let:

$$
\delta=\alpha-\beta
$$

In the strain Mohr's circle, double angles are considered =

$$
2 \delta=2 \alpha-2 \beta
$$

As $\tan 2 \beta$ can be determined by equation (3) and $\tan 2 \alpha$ is known, $2 \delta$ can be calculated.

$$
\begin{aligned}
\tan 2 \delta & =\tan (2 \alpha-2 \beta) \\
\text { (1) } \quad \tan 2 \delta & =\frac{\tan 2 \alpha-\tan 2 \beta}{1+\tan 2 \alpha \tan 2 \beta}
\end{aligned}
$$


B. Equation of Strain Mohr's Circle (See Fig. A7.1)

In strain Mohr's circle, are known =

$$
\begin{aligned}
& \varepsilon_{a}=O A \\
& \varepsilon_{b}=O B \\
& \varepsilon_{c}=O C
\end{aligned}
$$

For convenience's sake, let $O A=a$

$$
\begin{aligned}
& \mathrm{OB}=\mathrm{b} \\
& \mathrm{OC}=\mathrm{c}
\end{aligned}
$$

Then $O C=d=\frac{a+c}{2}$

Radius of Mohr's circle $=$

$$
\mathrm{R}^{2}=\overline{\mathrm{BD}}^{2}+\overline{\mathrm{Bb}}^{2}
$$

As

$$
\begin{aligned}
\mathrm{Bb}=\mathrm{DC} & =\mathrm{c}-\mathrm{d} \\
& =\mathrm{c}-\frac{\mathrm{a}+\mathrm{c}}{2} \\
\mathrm{Bb} & =\frac{\mathrm{c}-\mathrm{a}}{2} \\
\mathrm{BD} & =\mathrm{d}-\mathrm{b}=\frac{a+c}{2}-\mathrm{b}=\frac{a+c-2 b}{2}
\end{aligned}
$$

Let

$$
\mathrm{S}=\mathrm{a}+\mathrm{c}
$$

$$
D=a-c
$$

$\mathrm{R}^{2}=\left(\frac{c-\mathrm{a}}{2}\right)^{2}+\left(\frac{\mathrm{a}+\mathrm{c}-2 \mathrm{~b}}{2}\right)^{2}$

$$
=\left(\frac{D}{2}\right)^{2}+\left(\frac{S-2 b}{2}\right)^{2}
$$

Equation of the strain Mohr's circle =

$$
\left(x-\frac{a+c}{2}\right)^{2}+y^{2}=\frac{1}{4}\left[D^{2}+(S-2 b)^{2}\right]
$$


Let $Q=S-2 b$

$$
\left(X-\frac{S}{2}\right)^{2}+Y^{2}=\frac{1}{4}\left(D^{2}+Q^{2}\right)
$$

C. Equation of the Straight Line DM.

$$
\mathrm{Y}=\mathrm{MX}+\mathrm{N}
$$

If $2 \delta$ is the angle of the principal direction and the longitudinal direction, its second side cuts Mohr's circle at point M, its abscissa is the value of the longitudinal strain.

The slope of DM is $\tan 2 \delta$ which can be computed by the equation (1)

$$
Y=\tan 2 \delta x+N
$$

As the line DM passes through point $D\left(\frac{a+c}{2}, 0\right)$, the coordinates of D satisfy this equation: (See Figure A.7.1)

$$
\begin{aligned}
& \mathrm{O}=\tan 2 \delta\left(\frac{\mathrm{S}}{2}\right)+\mathrm{N} \\
& \mathrm{N}=-\frac{\mathrm{S}}{2} \tan 2 \delta
\end{aligned}
$$

Then:

$$
Y=\tan 2 \delta\left(X-\frac{S}{2}\right)
$$

\section{Magnitude of Longitudinal Strain}

As $M$ is common to the 1 ine and the circle, its coordinates satisfy both equations.:

$$
\text { Line: } Y=\tan 2 \delta\left(X-\frac{S}{2}\right)
$$

$$
\text { Circle: }\left(X-\frac{S}{2}\right)^{2}+Y^{2}=\frac{1}{4}\left(D^{2}+Q^{2}\right)
$$


Raise (1a) to square and substitute into (1b):

$$
\begin{aligned}
& Y^{2}=\tan 2 \delta\left(X-\frac{S}{2}\right) \\
& \left(X-\frac{S}{2}\right)^{2}+\tan ^{2} 2 \delta\left(X-\frac{S}{2}\right)^{2}=\frac{1}{4}\left(D^{2}+Q^{2}\right)
\end{aligned}
$$

or

$$
\left(1+\tan ^{2} 2 \delta\right)\left(X-\frac{S}{2}\right)^{2}-\frac{1}{4}\left(D^{2}+Q^{2}\right)=0
$$

or

$$
\left(x-\frac{S}{2}\right)^{2}-\frac{\left(D^{2}+Q^{2}\right)}{4\left(1+\tan ^{2} 2 \delta\right)}=0
$$

Developing and rearranging terms =

$$
x^{2}-s x+\frac{s^{2}}{4}-\frac{\left(D^{2}+Q^{2}\right)}{4\left(1+\tan ^{2} 2 \delta\right)}=0
$$

Quadratic equation in $\mathrm{X}$ where $=$

$$
\begin{aligned}
& A=1 \\
& B=-S \\
& C=\frac{S^{2}}{4}-\frac{\left(D^{2}+Q^{2}\right)}{4\left(1+\tan ^{2} 2 \delta\right)}
\end{aligned}
$$

\section{Discussion}

a) Condition of root existence:

$$
\Delta=B^{2}-4 A C \geq 0
$$

b) When angle $2 \delta<90^{\circ}$, the longitudinal strain equals:

$$
\varepsilon_{L}=X_{1}=\frac{-B-\sqrt{B^{2}-4 A C}}{2 A}
$$


and the circumferential strain equals:

$$
\varepsilon_{T}=x_{2}=\frac{-B+\sqrt{B^{2}-4 A C}}{2 A}
$$


COMPUTER PROGRAM

for longitudinal and circumferential strains.

EII EFSIL3

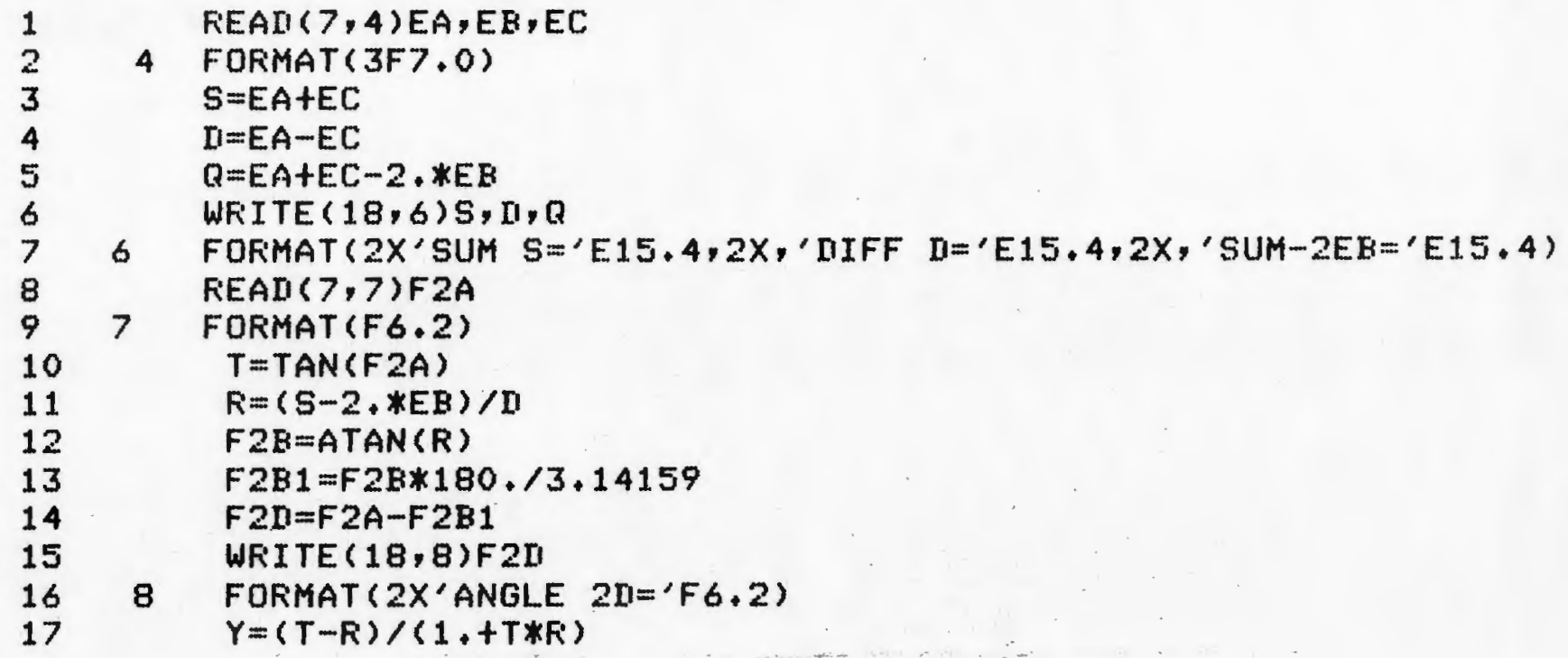




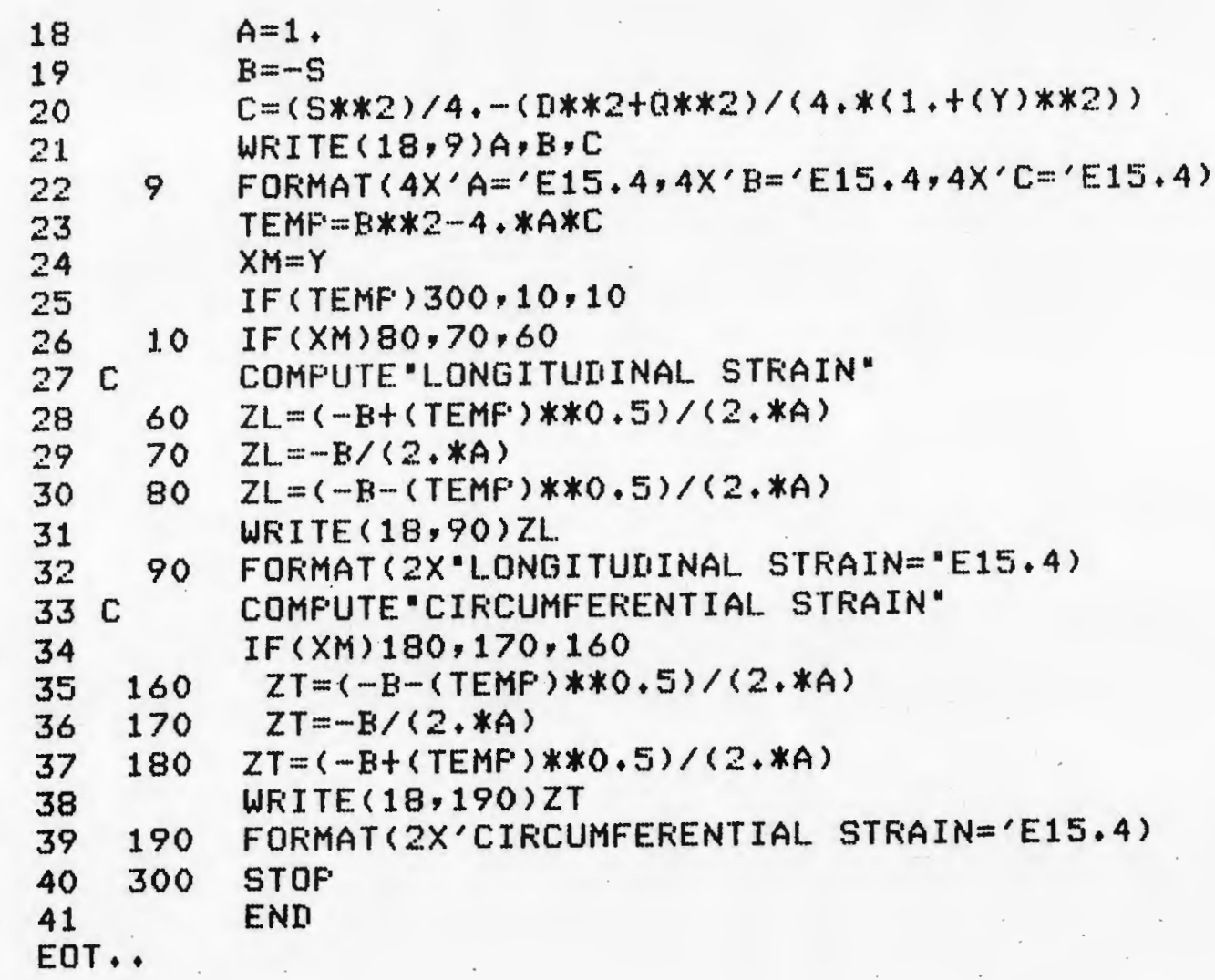




\section{VIII $\mathrm{C}$}

\section{DATA FILE AND OUTPUT}

for longitudinal and circumferential strains.

EII AFEI

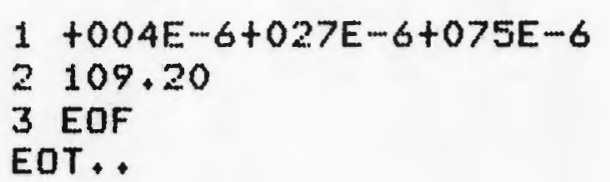




\section{APPENDIX IX}

IX A. COMPUTER PROGRAM

for force and moment balance.

\section{EII FIETFI}

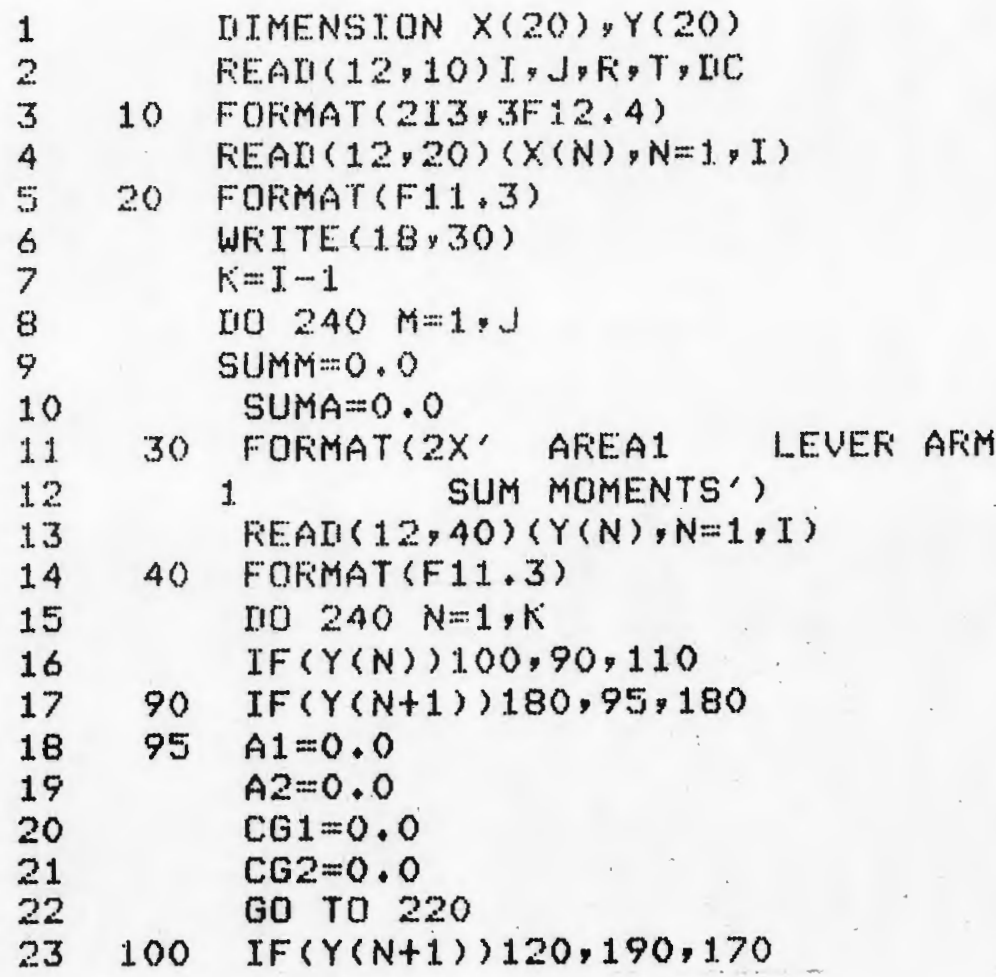




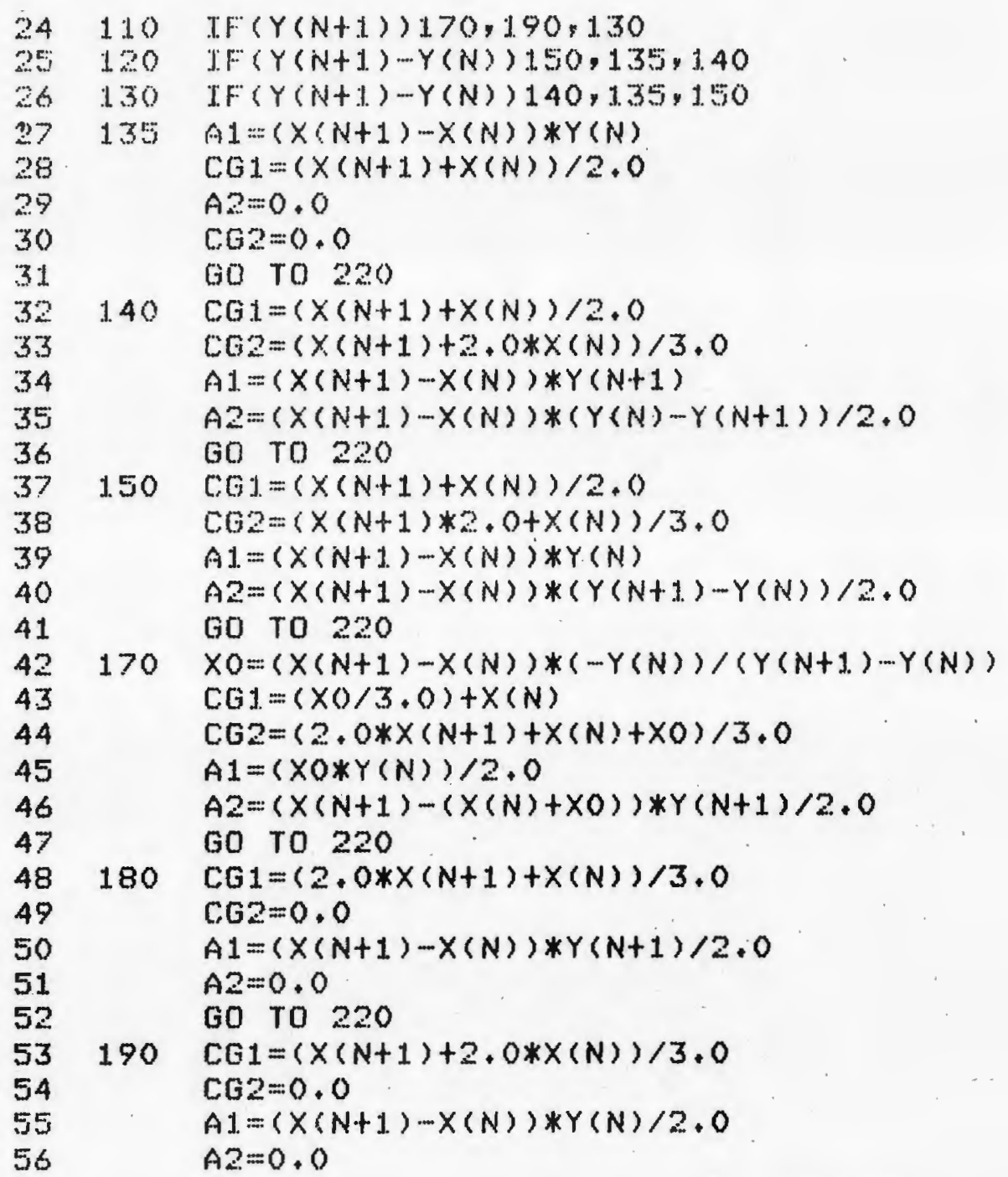




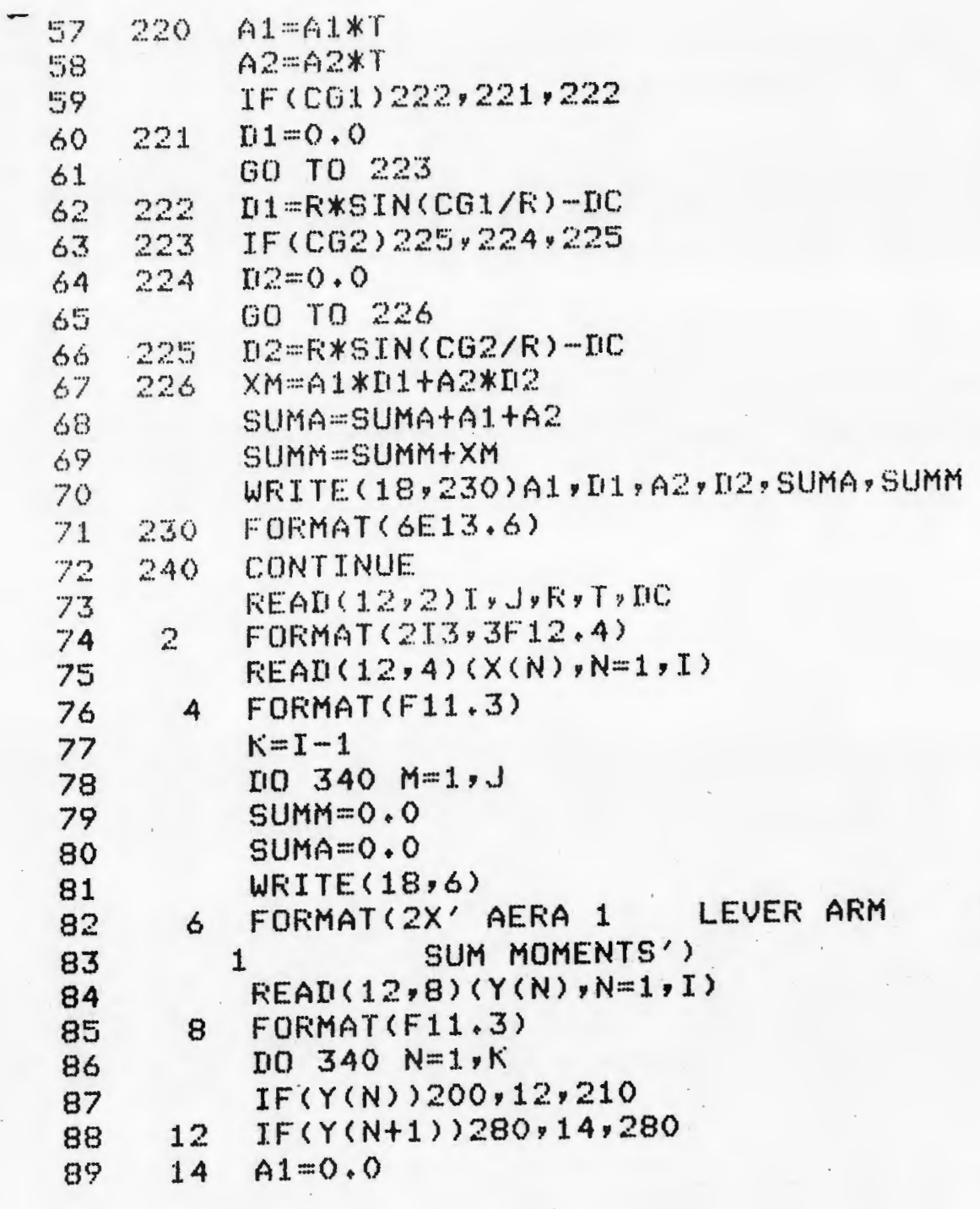




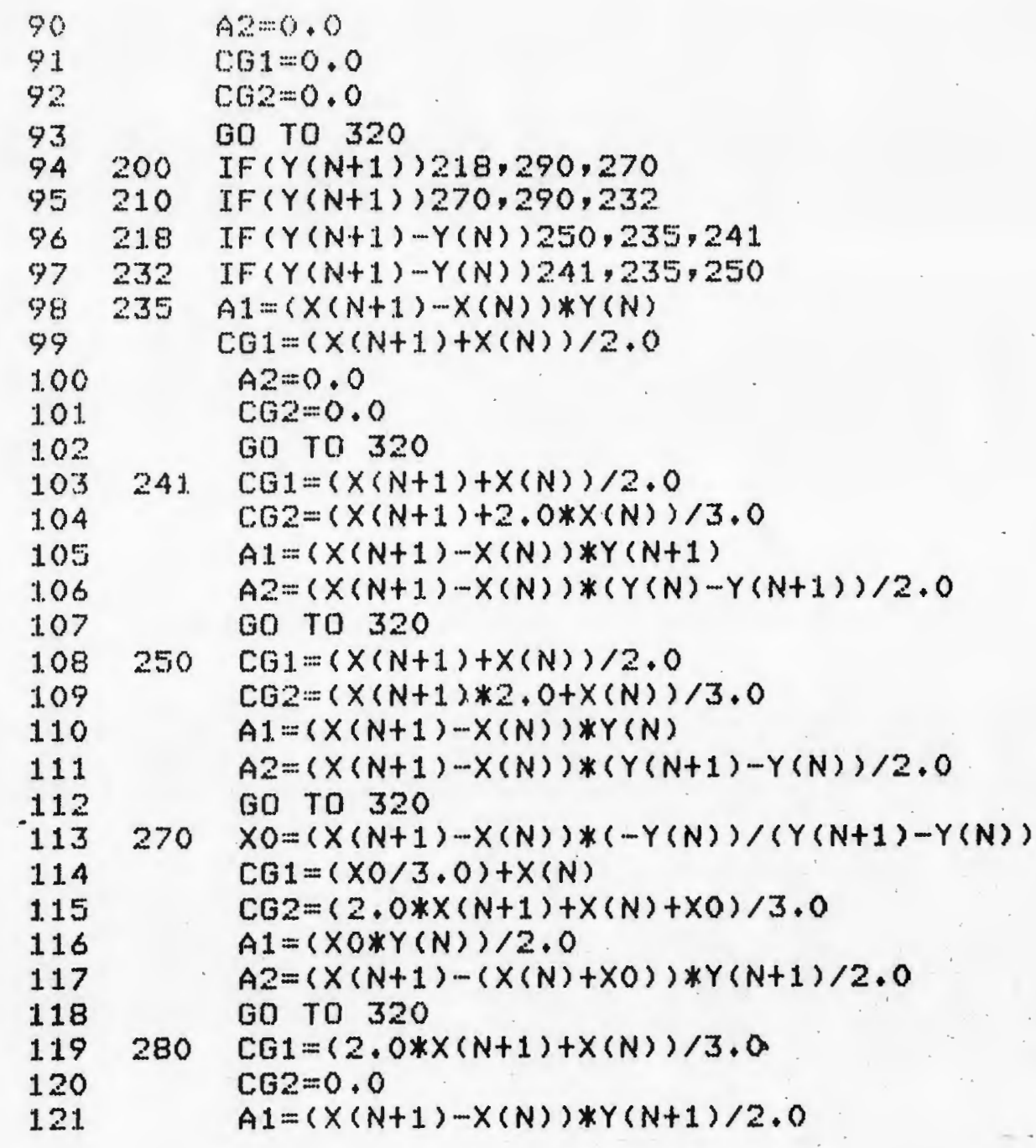




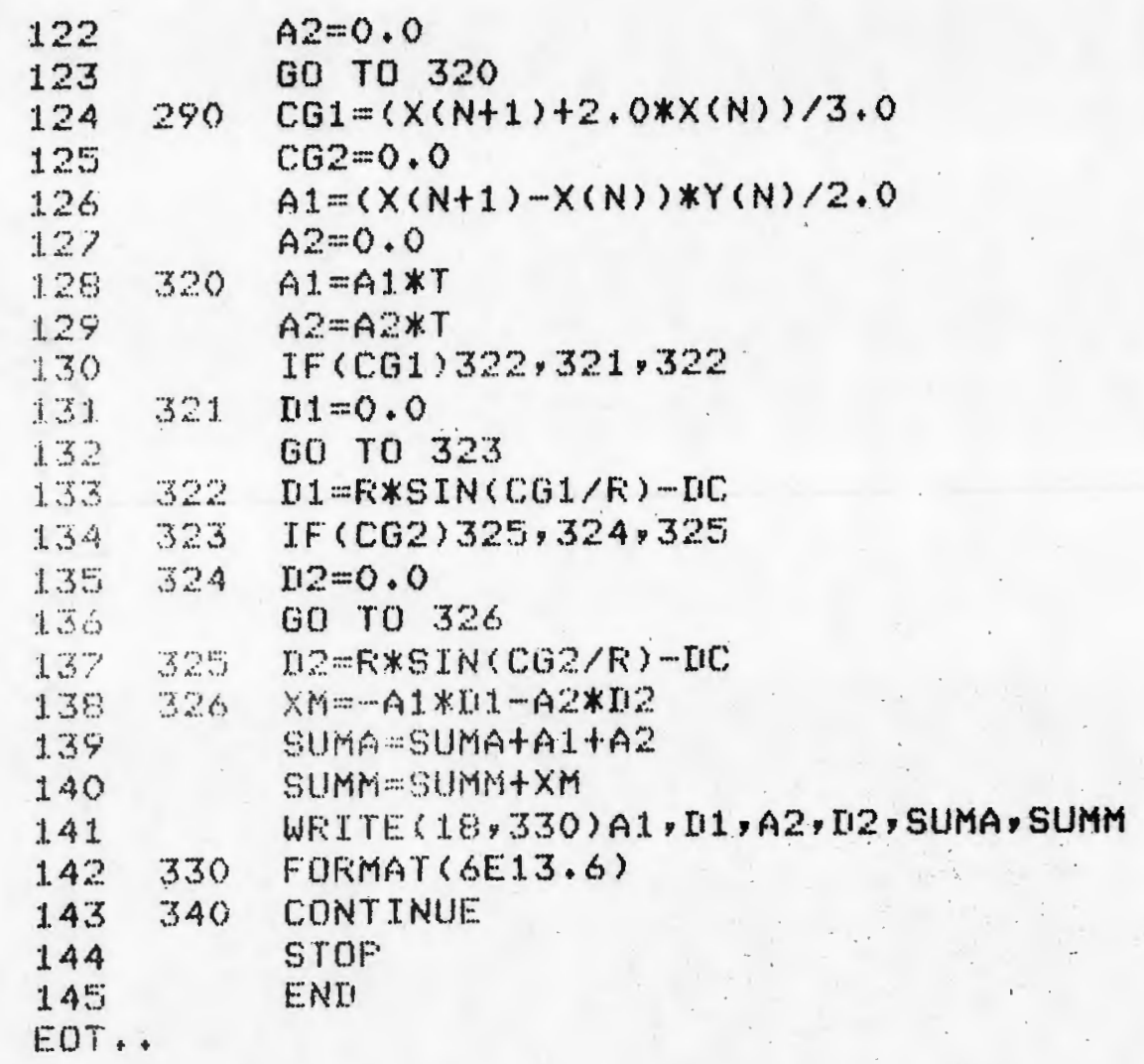


IX B. DATA FILE AND OUTPUT

EI FEFTLEA3

$$
\begin{aligned}
& \begin{array}{lllll}
1.18 & 1 & 11.0 & 0.3125
\end{array} \\
& 3 \quad 0.27 \\
& 40.4 \\
& 50.51 \\
& 60.56 \\
& 70.67 \\
& 8 \quad 0.785 \\
& 90.89 \\
& 10 \quad 0.98 \\
& 11.09 \\
& 12 \quad 1+18 \\
& 13 \quad 1.29 \\
& 14 \quad 1.38 \\
& 15 \quad 1.41 \\
& 161.45 \\
& 1.7 \quad 1.47 \\
& 18 \quad 1.51 \\
& 19 \quad 1.57 \\
& 20 \quad 0.26 \\
& 210.18 \\
& 220.13 \\
& 230.03 \\
& 240.0 \\
& 25 \quad-0,16 \\
& 26-0.24 \\
& 27 \quad-0.32 \\
& 28 \quad-0.42 \\
& 29-0.66 \\
& 30 \quad-.0 .75 \\
& 31-0.66 \\
& 32 \quad-0.45 \\
& \begin{array}{ll}
33 & \cdots 0.3
\end{array} \\
& 340.0 \\
& 30 \quad 0.2 \\
& 36 \quad 0.5 \\
& 370.8
\end{aligned}
$$

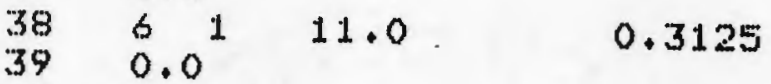

$$
\begin{aligned}
& 40 \quad 0.39 \\
& \text { 41. } 0.78 \\
& 42.1 .18 \\
& 43 \quad 1.31 \\
& 44 \quad 1.57 \\
& 45 \quad 0.26 \\
& 46 \quad 0.34 \\
& 47 \quad 0.19 \\
& 48 \quad 0.14 \\
& 490.12 \\
& 50 \quad 0.02
\end{aligned}
$$


FO. WNME , FERR1.

AS $18=* 3$

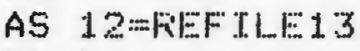

$U X+N$

AFEEAL IEVEF AFIM AFEA 2 LEVEF AFIM SUM FOF SUM MOMENTS $0.151875 E-01.0 .134997 E+00 \quad 0.337500 E-02 \quad 0.899990 E-010.185625 E-010.235401 E-02$

$0.528125 E-02 \quad 0.334948 E+00 \quad 0.101563 E-02 \quad 0.313291 E+00 \quad 0.248594 E-01 \quad 0+444114 E-02$

0.103 1.25E-02 $0.454870 E+00 \quad 0.171875 E-02 \quad 0.436552 E+00 \quad 0.276094 E-01 \quad 0.566055 E-02$ $0.234375 E-0.3 \quad 0.526465 E+00 \quad 0.000000 E+01 \quad 0.000000 E+01 \quad 0.278437 E-01 \quad 0.578394 E-03$ $0.275000 E-02 \quad 0.632983 E+00 \quad 0.000000 E+01 \quad 0.000000 E+01 \quad 0.250937 E-01 \quad 0.404323 E-02$ $0.575000 E-02 \quad 0.726970 E+00-0.143750 E-02 \quad 0.746093 E+00 \quad 0.179062 E-01-0.120935 E-02$ $0.787500 E-02 \quad 0.836691 E+00-0.131250 E-02 \quad 0.854139 E+00 \quad 0.871875 E-02 \cdots 0.691935 E-02$ $0.900000 E-02 \quad 0.933875 E+00 \cdots 0.140625 E-02 \quad 0.948819 E+00 \cdots 0.168750 E-02-0.186565 E-01$. $0.144375 E-01 \quad 0.103347 E+0.1-0.412500 \mathrm{E}-02 \quad 0.105172 E+01-0.202500 E-01-0.3791 .6 E-01$ $0.185625 E-01 \quad 0.113299 E+01-0.126562 E-02 \quad 0.114791 E+01-0.400781 E-01 \cdots 0.604015 E-01$ $0.226875 E-01 \quad 0.123241 E+01-0.154688 E-02 \quad 0.121419 E+01-0.643125 E-01 \cdots 0.902400 E \cdots 01$ $0.126563 E-01 \quad 0.133173 E+01-0.295313 E-02 \quad 0.131683 E+01-0.799219 E-01-0.110983 E+00$ $0.281250 E-02 \quad 0.139126 E+01-0.703125 E-03 \quad 0.138630 E+01-0.834375 E-01-0.115871 E+00$ $0.187500 E-02 \quad 0.141936 E+01 \quad 0.000000 E+01 \quad 0.000000 E+01-0.853125 E-01 \cdots 0+118532 E+00$ $0.625000 E-03 \quad 0.145902 E+01 \quad 0.000000 E+01 \quad 0.000000 E+01-0.846875 E-01-0.117620 E+00$ $0.250000 E-02 \quad 0.148545 E+01 \quad 0.187500 E-02 \quad 0.149205 E+01-0.803125 E-01 \cdots 0.1111 .09 E+00$ $0.937500 E-02 \quad 0.153497 E+01 \quad 0.281250 E-02 \quad 0.154488 E+01-0.681250 E-01 \cdots 0.923739 E-01$
AEFiA 1
LEVEF AFIM
AFEA 2
LEVEF AFM
SUM FOF:
SUM MOMENTS

$0.316875 E-010.194990 E+00 \quad 0.487500 E-02 \quad 0.259976 E+000.365625 E-01-0.74461 .2 E-02$ $0.231562 E-01 \quad 0.584724 E+00 \quad 0.914062 E-02 \quad 0.519806 E+00 \quad 0.688594 E-01-0.257375 E-01$ $0.175000 E-01 \quad 0.978704 E+00 \quad 0.312500 E-02 \quad 0.912284 E+00 \quad 0.894844 E-01-0.457157 E-01$ $0.487500 E-02 \quad 0.124234 E+01 \quad 0.406250 E-03 \quad 0.122081 E+010.947656 E-01-0.522681 E-01$ $0.162500 E-02 \quad 0.143589 E+01 \quad 0.406250 E-02 \quad 0.139292 E+01 \quad 0.100453 E+00 \cdots 0.602601 E-01$ STOF 
APPENDIX $\mathrm{X}$

DATA FILE AND OUTPUT

FO. WNME , FETFI

AS $18=* 3$

(Force and moment balance)

AS $12=\mathrm{K}=\mathrm{K}=\mathrm{ILIN} 14$

$U X, N$

AFEA 1

1...EVEF AFM

AFEA 2

LEEVEF AFM SUM FOF

SUM MOMENTS $0.890625 E-02 \quad 0.304961 E+00 \quad 0.237500 E-02$ $0.225000 E-02 \quad 0.444879 E+00 \quad 0.984375 E-03$ $0.699995 E-010.164062 E-010.1676691-02$ $0.273305 E+00 \quad 0.276875 E-01 \quad 0.504185 E \cdots 0 \%$ $0.875000 E-03 \quad 0.513147 E+00 \quad 0.000000 E+01$ $0.250000 E-02 \quad 0.626328 E+00 \quad 0.000000 E+01$ $0.429890 E+00 \quad 0.309219 E-01.0 .646600 E \cdots 02$ $0.000000 E+010.317969 E-01.0 .691501 E-02$ $0.000000 E+01 \quad 0.292969 E-010.53491 .9 E-02$ $0.625000 E-02 \quad 0.721981 \mathrm{E}+00-0.175781 \mathrm{E}-02$ $0.820312 E-02 \quad 0.836691 E+00-0.820312 E-03$ $0.843750 E-02 \quad 0.933875 E+00 \cdots 0.154688 E-02$ $0.742768 E+00 \quad 0.212891 E-01-0.468838 E-0.3$ $0.854139 E+00 \quad 0.122656 E-01-0.803298 E-02$ $0.948819 E+00 \quad 0.228125 E-02 \cdots 0.1 \% 3803 E \cdots 1$ $0.140937 E-01 \quad 0.103347 E+01-0.464062 E \cdots 02$ $0.191250 E-01 \quad 0.113299 E+01-0.984375 E-03$ $0.233750 E-01 \quad 0.123241 E+01-0.120313 E-02$ $0.135000 E-01 \quad 0.133173 E+01-0.281250 E-02$ $0.105172 \mathrm{E}+01-0.164531 \mathrm{E}-01 \cdots 0.368264 \mathrm{E}-01$ $0.114791 E+01-0.365625 E-01-0.596248 E-01$ $0.337500 \mathrm{E}-02 \quad 0.139622 E+01-0.131250 \mathrm{E}-02$ $0.121419 E+01-0.611 .406 E-01-0.898931 E-01$ $0.131683 E+01-0.774531 E-01-0.11 .1575 E+00$ $0.138961 E+01-0.821406 E-01-0.118111 .1+00$ $\begin{array}{lll}0.843750 E-03 & 0.142267 E+01 & 0.000000 E+01 \\ 0.150000 E-02 & 0.145572 E+01 & 0.000000 E+01\end{array}$ $0.150000 E-02 \quad 0.145572 E+010.000000 E+01$ $0.000000 E+01-0.829844 E-01 \cdots 0.119311 \mathrm{E}+00$ $0.400000 \mathrm{E}-02$ $0.153497 E+010.262500 E-02$ $0.000000 E+01-0.814844 E-01-0.1171 .28 E+00$ $0.116250 E-01$ AERIA 1 LEVEF AFI AREA 2 $0.149205 E+01-0.756094 E-01-0.108399 E+00$ $0.320625 E-010.189991 E+00 \quad 0.356250 E-02$ $0.183750 E-010.484843 E+000.164063 E-02$ $0.118750 E-01 \quad 0.684557 E+00 \quad 0.237500 E-02$ $0.690625 E-02 \quad 0.864109 E+00 \quad 0.185937 E-02$ $0.934375 E-02 \quad 0.106334 E+010.359375 E-03$ $0.365625 E-02 \quad 0.137142 E+01 \quad 0.670313 E-02$ $0.154488 E+01-0.613594 E-01-0.864892 E-01$ LEVER AFIM SUM FOF SUM MOMENTS STOF 


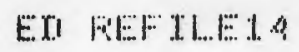

$$
\begin{array}{lll}
1 & 18 & 1 \\
2 & 0.0 & 1.0 \\
3 & 0.21 \\
4 & 0.4 \\
5 & 0.49 \\
6 & 0.56 \\
7 & 0.66 \\
8 & 0.785 \\
9 & 0.89 \\
10 & 0.98 \\
11 & 1.09 \\
12 & 1.18 \\
13 & 1.29 \\
14 & 1.38 \\
15 & 1.42 \\
16 & 1.44 \\
17 & 1.47 \\
18 & 1.51 \\
19 & 1.57 \\
20 & 0.27 \\
21 & 0.23 \\
22 & 0.15 \\
23 & 0.08 \\
24 & 0.0 \\
25 & -0.16 \\
26 & -0.25 \\
27 & -0.3 \\
28 & -0.41 \\
29 & -0.68 \\
30 & -0.75 \\
31 & -0.68 \\
32 & -0.48 \\
33 & -0.27 \\
34 & 0.0 \\
35 & 0.32 \\
36 & 0.62 \\
37 & 0.9 \\
38 & 7 \\
39 & 0.0 \\
40 & 0.38 \\
41 & 0.59 \\
42 & 0.78 \\
43 & 0.95 \\
44 & 1.18 \\
45 & 1.57 \\
46 & 0.27 \\
47 & 0.33 \\
48 & 0.28 \\
49 & 0.20 \\
50 & 0.13 \\
51 & 0.14 \\
52 & 0.03 \\
&
\end{array}
$$


EU REFIIENO

$$
\begin{aligned}
& 1171.11 .0 \quad 0.31 .25 \\
& ? 0+0 \\
& 30.23 \\
& 40.34 \\
& \text { 5) } 0.51 \text {. } \\
& 60.56 \\
& 7 \quad \cdots .6 \% \\
& 80.785 \\
& 90.89 \\
& 10 \quad 0.98 \\
& 111.07 \\
& 121.18 \\
& 131.29 \\
& 141.38 \\
& 151.43 \\
& 16 \quad 1.45 \\
& 17 \quad 1.52 \\
& 18 \quad 1.57 \\
& 190.23 \\
& 20 \quad 0.20 \\
& 210.13 \\
& 220.11 \\
& 23 \quad 0.0 \\
& 24-0.12 \\
& 25 \quad-0.24 \\
& \text { 26 }-0.28 \\
& 27-0.40 \\
& 28-0.56 \\
& 29-0.72 \\
& 30-0.60 \\
& 31-0.40 \\
& 32-0.22 \\
& 330.0 \\
& 34 \quad 0.7 \\
& 350.94 \\
& \begin{array}{lll}
36 & 7 & 1
\end{array} \\
& 370.0 \\
& \begin{array}{ll}
38 & 0.39
\end{array} \\
& 390.59 \\
& 40 \quad 0.78 \\
& 41 \quad 1.17 \\
& 42 \quad 1.33 \\
& 431.57 \\
& 44 \quad 0.23 \\
& 45 \quad 0.29 \\
& 46 \quad 0.24 \\
& 47 \quad 0.16 \\
& 48 \quad 0.12 \\
& 49 \quad 0.08 \\
& 50 \quad 0.01
\end{aligned}
$$


FO. WNME, FETR1.

AS $18=* 3$

AS 12FFEF ILE 10

$U X \cdot N$

AFEA1. LEUEF ARM AREA 2 LEVER ARM SUM FOF

$0.1437: 0 E-01.0 .114998 E+00 \quad 0.107812 E-02 \quad 0.756660 E-010.154531 E-0110.173575 E-02$

$0.650000 E-020.309959 E+00 \quad 0.175000 E \cdots 02 \quad 0.283302 E+00 \quad 0.237031 E-01 \quad 0.424626 E \cdots 02$

$0.41 .2500 E-02 \quad 0.449874 E+00 \quad 0.375000 E-03 \quad 0.429890 E+00 \quad 0.282031 E-01 \quad 0.626320 E \cdots . \cdots 2$

$0.859375 E-03 \quad 0.526465 E+00 \quad 0.000000 E+01 \quad 0.000000 E+010.290625 E-01.0 .671563 E \cdots 02$

$0.226875 E-01-0.246646 E+00 \quad 0.000000 E+01 \quad 0.000000 E+010.517500 E-01 \quad 0.111 .985 E-02$

$0.538125 E-01 \quad 0.674996 E-01-0.269062 E-01 \quad 0.306627 E+00-0.289688 E-01-0.107626 E-01$

$0.787500 E-02 \quad 0.836691 E+00 \cdots 0.656250 E-03 \quad 0.854139 E+00-0.375000 E-01-0.179121 E-01$

$0.737500 E-02 \quad 0.933875 E+00-0.168750 E-02 \quad 0.948819 E+00-0.470625 E-01-0.268675 E \cdots-01$

$0.112500 E-01 \quad 0.102352 E+01-0.225000 E-02 \quad 0.103845 E+01-0.605625 E-01-0.407186 E-01$

$0.192500 E-010.112304 E+01-0.275000 E-02 \quad 0.114128 E+01-0.825625 E-01-0.654756 E-01$

$0.206250 E-010.123241 E+01-0.206250 E-02 \quad 0.121419 E+01-0.105250 E+00-0.933583 E-01$.

$0.112500 E-01 \quad 0.133173 E+01-0.281250 E-02 \quad 0.131683 E+01-0.119313 E+00-0.112084 E+00$

$0.343750 E-02 \quad 0.140118 E+01-0.140625 E-02 \quad 0.139292 E+01-0.124156 E+00-0.118959 E+00$

$0.687500 E-03 \quad 0.143259 E+01 \quad 0.000000 E+01 \quad 0.000000 E+01-0.124844 E+00-0.119844 E+00$

$0.765625 E-02 \quad 0.149205 E+01 \quad 0.000000 E+010.000000 E+01-0.117188 E+00-0.108421 E+00$

$0.109375 E-01 \quad 0.153993 E+01 \quad 0.187500 E-02 \quad 0.154818 E+01-0.104375 E+00-0.886748 E-01$
AERAA 1
LEVEF AFIM
AREA 2
LEVER AFM SUM FOF SUM MOMENTS

$0.280312 E-01 \quad 0.194990 E+00 \quad 0.365625 E-02 \quad 0.259976 E+00 \quad 0.316875 E-01-0.641634 E-02$

$0.150000 E-01 \quad 0.489838 E+00 \quad 0.156250 E-02 \quad 0.456535 E+00 \quad 0.482500 E-01-0.1 .44773 E-01$

$0.950000 E-02 \quad 0.684557 E+00 \quad 0.237500 E-02 \quad 0.652949 E+00.0 .601250 E-01-0.225313 E-01$

$0.146250 E-01.0 .973724 E+00 \quad 0.243750 E-02 \quad 0.908962 E+00 \quad 0.771875 E-01-0.389876 E-01$

$0.400000 E-02 \quad 0.124731 E+01 \quad 0.100000 E-02 \quad 0.122081 E+01 \quad 0.821875 E-01-0.451977 E-01$

$0.750000 E-03 \quad 0.144580 E+01 \quad 0.262500 E-02 \quad 0.140614 E+01 \quad 0.855625 E-01-0.499731 E-01$ STOF 
ED FEFILE12

$$
\begin{aligned}
& 1.17 \quad 11.0 \quad 0.3125 \\
& 2 \quad 0.00 \\
& 30.21 \\
& 40.4 \\
& 5 \quad 0.49 \\
& 60.55 \\
& 70.67 \\
& 80.795 \\
& 9 \quad 0.89 \\
& 10 \quad 0.981 \\
& 111.09 \\
& 12 \quad 1.177 \\
& 131.29 \\
& 14 \quad 1.374 \\
& 151.43 \\
& 16 \quad 1.45 \\
& 17 \quad 1.52 \\
& 18 \quad 1.57 \\
& 190.15 \\
& 20 \quad 0.14 \\
& 210.09 \\
& 220.06 \\
& 23 \quad 0.0 \\
& 24-0.12 \\
& 25-0.17 \\
& \begin{array}{lll}
26 & -0.22
\end{array} \\
& 27-0.31 \\
& 28 \quad-0.48 \\
& 29-0.55 \\
& \begin{array}{ll}
30 & -0.5
\end{array} \\
& \begin{array}{ll}
31 & -0.32
\end{array} \\
& 320.0 \\
& 33 \quad 0.12 \\
& \begin{array}{ll}
34 & 0.6
\end{array} \\
& \begin{array}{ll}
35 & 0.75
\end{array} \\
& 36 \text { 6 } 11.11 .0 \\
& 37 \quad 0.0 \\
& 38 \quad 0.38 \\
& 39 \quad 0.78 \\
& 40 \quad 1.18 \\
& 41.1 .49 \\
& 42 \quad 1.57 \\
& 43 \quad 0.15 \\
& 44 \quad 0.2 \\
& 450.11 \\
& 46, \quad 0.08 \\
& 47 \quad 0.0 \\
& 48 \quad-0.01
\end{aligned}
$$


FO. WNME, FEETFI

AS $18=* 3$

AS 12:FEFILE12

$U X \cdot N$

AFEA1 LEVEF AFM AREA 2 LEVEF ARM SUM FOF SUM MOMENTS

$0.918750 E-02 \quad 0.104998 E+00 \quad 0.328125 E-03 \quad 0.699995 E-01 \quad 0.951562 E-02 \quad 0.987641 E-0.3$

$0.534375 E-02.0 .304961 E+00 \quad 0.148437 E-02 \quad 0.273305 E+00 \quad 0.163437 E-01 \quad 0.302296 E-02$

$0.168750 E-02 \quad 0.444879 E+00 \quad 0.421875 E-03 \quad 0.429890 E+00 \quad 0.184531 E-01 \quad 0.395506 E-02$

$0.562500 E-03 \quad 0.509817 E+00 \quad 0.000000 E+01 \quad 0.000000 E+01 \quad 0.190156 E-01 \quad 0.424183 E-02$

$0.225000 E-02 \quad 0.629656 E+00 \quad 0.000000 E+01 \quad 0.000000 E+01 \quad 0.167656 E-01 \quad 0.282510 E-02$

$0.431250 E-02 \quad 0.726970 E+00-0.898437 E-03 \quad 0.746093 E+00 \quad 0.115547 E-01-0.980272 E-03$

$0.557812 E-02 \quad 0.836691 E+00-0.820312 E-03 \quad 0.854139 E+00 \quad 0.515625 E-02-0.634810 E-02$

$0.625625 E-02 \quad 0.934373 E+00-0.127969 E-02 \quad 0.949484 E+00-0.237969 E-02-0.134088 E-01$

$0.105594 E-01 \quad 0.103397 E+01-0.289531 E-02 \quad 0.105206 E+01-0.158344 E-01-0.273729 E-01$

$0.130500 E-010.113150 E+01-0.951562 E-030.114592 E+01-0.298359 E-01-0.432294 E-01$

$0.176562 E-010.123092 E+01-0.882812 E-03 \quad 0.121220 E+01-0.483750 E-01-0.660329 E-01$

$0.840000 E-02 \quad 0.132875 E+01-0.236250 E-02 \quad 0.131485 E+01-0.591375 E-01-0.803007 E-01$

$0.280000 E-02 \quad 0.138895 E+01 \quad 0.000000 E+01 \quad 0.000000 E+01-0.619375 E-01-0.841897 E-01$

$0.375000 E-03 \quad 0.143920 E+01$ 0.000000E+01. $0.000000 E+01-0.615625 E-01-0.836500 E-01$

$0.262500 \mathrm{E}-02 \quad 0.148049 \mathrm{E}+01 \quad 0.525000 \mathrm{E}-02 \quad 0.149205 \mathrm{E}+01-0.536875 \mathrm{E}-01-0.719305 \mathrm{E}-01$

$0.937500 E-02 \quad 0.153993 E+01 \quad 0.117188 E-02 \quad 0.154818 E+01-0.431406 E-01-0.556794 E-01$

AERA 1 LEUEF ARM AFEA 2 LEVER ARM SUM FOF SUM MOMENTS

$0.178125 E-01 \quad 0.189991 E+00 \quad 0.296875 E-02.0 .253311 E+000.207812 E-01-0.413622 E-02$

$0.137500 E-01 \quad 0.579731 E+00 \quad 0.562500 E-02 \quad 0.513147 E+00 \quad 0.401562 E-01-0.149940 E-01$

$0.100000 E-010.978704 E+00 \quad 0.187500 E-02 \quad 0.912284 E+00.0 .520312 E-01-0.264916 E-01$

$0.387500 E-02 \quad 0.128042 E+01 \quad 0.000000 E+01 \quad 0.000000 E+010.559062 E-01-0.314532 E-01$

$0.125000 E-03 \quad 0.153827 E+010.000000 E+010.000000 E+010.557812 E-01-0.312609 E-01$ STOF 
APPENDIX XI

CONVERSION OF RAW DATA TO INPUT FOR COMPUTER PROGRAM

This conversion deals with data preparation pertalning to the curve of Inttial residual stresses in the tube shown in Figure 3.28 .

I) Definition of areas of forces 1imited by the curve and the $X$ axis.

a) The curve of Inttlal residual stresses obtained from measured strains in the tube with variable $4 \mathrm{~A}$ and $4 \mathrm{~B}$, In Figure 3.28 , has been drawn as follows:

-The longltudinal residual stresses computed from measured strains for 11 holes with hole depth of $0.125^{\prime \prime}$, shown In Table 3.3 (column 4) divided by ylald atress, give ratios of $\sigma_{L} / \sigma_{y}(\operatorname{colum} 6)$. -The position of each hole is located by the ratio $d / r, r$ being the radius of the steel tube $\left(r=11^{\prime \prime}\right)$ and $d$, the distance in inch of the hole to the longltudinal weld, measured by cutting the tube with a plane passing by the weld and the tube center and flattening the cylinder on a plane parallel to the XY plane in Figure 4.8 . -On a system of perpendlcular axes, plot $d / r$ on the absclssa, $\sigma_{L} / \sigma_{y}$ on the ordinate. A polygonal line (see Figure A.11.1) forms the curve which represents the pattern of distribution of longltudinal residual stresses at each of the 11 holes drilled in the tube. -For obtalning a better curve whlch may reflect the continulty of the stresses present In the tube and give a closer value of the stress at any hole drilled on the semf-ctrcular section of the 11 holes, a continuous smooth curved line was drawn, passing through the points of the above polygonal 1Ine (see Figure A.11.1). 


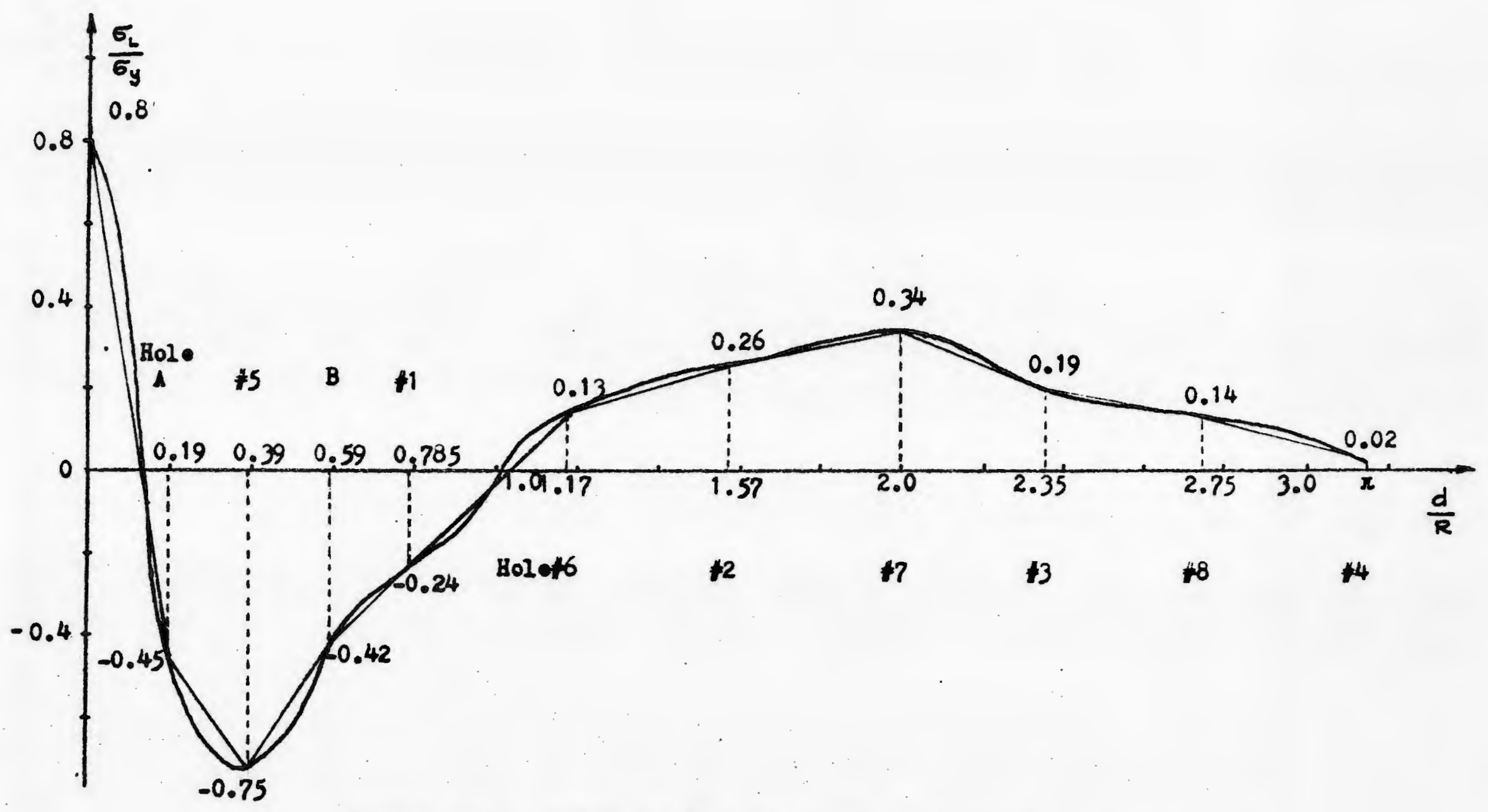

Firure A.11.1 Poljgonal Iine and mooth centinuous ourre representing restdual stresses. Table 3.11 , case 1 . 
b) Taking the moment of an area of forces about an axis, is to compute the product of the area limited by the curve and the axis of abscissa and the lever arm, distance of the center of gravity of the area to the axis. As the above curve is not defined by an algebraic equation, the area limited by the curve and the axis of abscissa is calculated by a graphical method by approximation. The curve is approximated by a polygonal line (different from the above) which follows the curve as closely as possible, that is, when curvature is high, the Inscribed line comprises short stralght 11nes. The areas limited by the inscribed polygonal line is thus divided into trapezolds and triangles of which the evaluation of area is simple.

This principle is applied to the curve of residual stresses In Figure 3.28, and the polygonal line inscribed in the curve defines elementary areas of forces, shown in Figure A.11.2. As the points forming the trapezolds or triangles of forces are known by thelr coordinates, it is simple to calculate the areas of forces.

II) Conversion of tube data to input for the computer program.

a) Summation of forces.

Tensions are represented by positive areas and compressions, by negative areas.

The computer program defines the summation of forces by adding algebraically positive and negative areas.

b) Summation of moments.

It has been pointed out in paragraph 4.1 .1 that the 81 gn of moments taken about the $\mathrm{Z}$ axis depends on the position of forces above or below the $\mathrm{Z}$ axis, therefore, the moment of forces 18 computed 


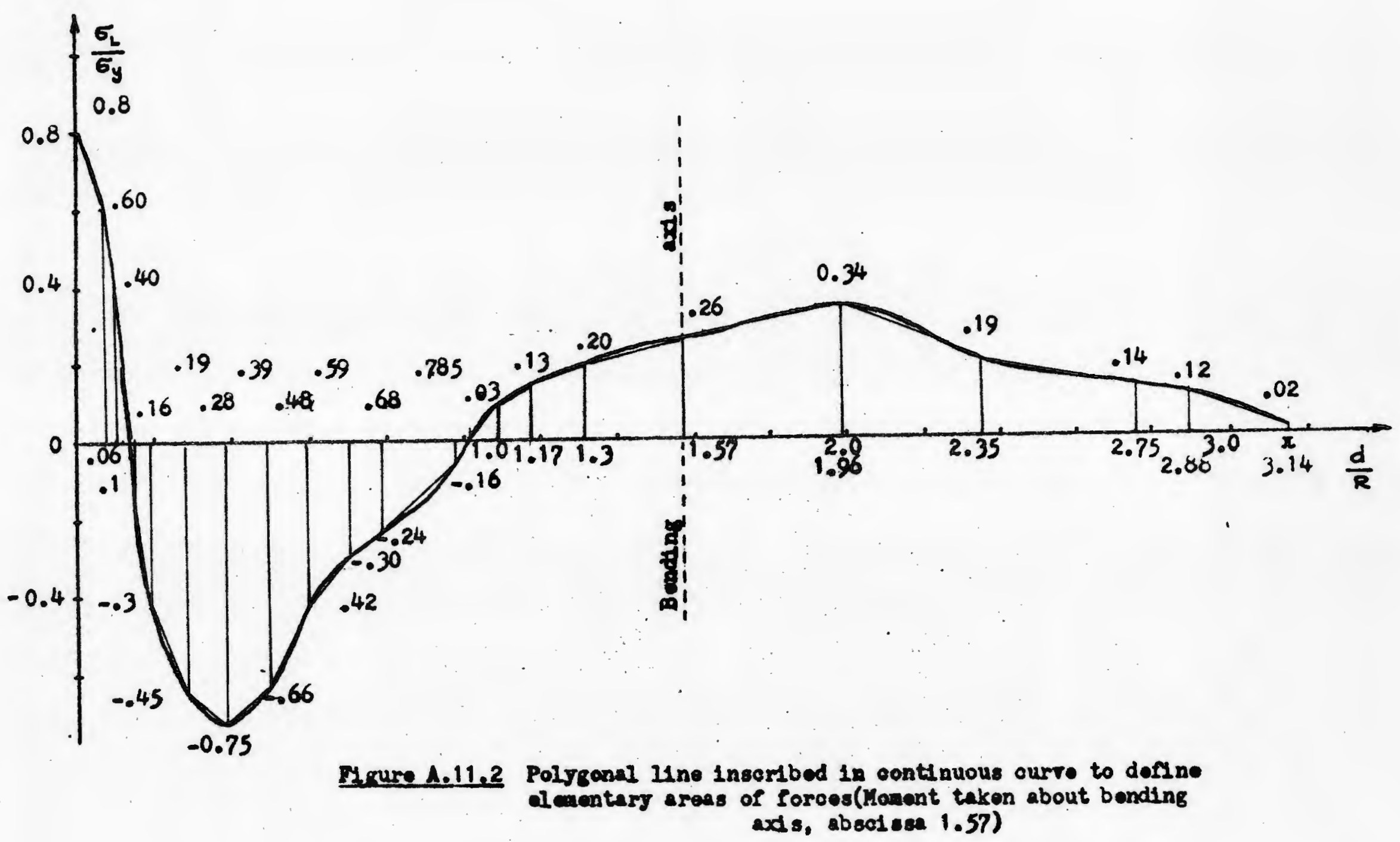


separately for forces above the $\mathrm{Z}$ axis and for forces below this axis. Sample calculation. (See Figure A.11.3)

A) For areas of forces below the $Z$ axis, abscissa 1.57 .

First trapezoid. (at right hand side of the bending axis)

Abscissa of first side, $x_{1}$ (new axis) $=0.0$

Abscissa of second side $X_{2}=1.96-1.57=0.39$

Length of first side $Y_{1}=0.26$

Length of second side $\mathrm{Y}_{2}=0.34$

Second trapezold.

Abscissa of first side, $X_{2}=0.39$

Absctssa of second side $X_{3}=2.35-1.57=0.78$

Length of first side, $\mathrm{Y}_{2}=0.34$

Length of second side $\mathrm{Y}_{3}=0.19$

Third trapezold.

Abscissa of first side, $x_{3}=0.78$

Abscissa of second side, $x_{4}=2.75-1.57=1.18$

Length of first side, $\mathrm{Y}_{3}=0.19$

Length of second side, $\mathrm{Y}_{4}=0.14$

Fourth trapezoid.

Abscissa of first side, $x_{4}=1.18$

Abscissa of second side $x_{5}=2.88-1.57=1.31$

Length of first side, $\mathrm{Y}_{4}=0.14$

Length of second side, $x_{5}=0.12$

Fifth trapezold.

Abscissa of first side, $x_{5}=1.31$

Abscissa of second side, $x_{6}=3.14-1.57=1.57$ 
Length of first side, $\mathrm{Y}_{5}=0.12$

Length of second side, $Y_{6}=0.02$

In Appendix IX, the input will be read as follows:

First reading. (Format statement $\# 10$ )

$I$ - number of data $=6$ for this case.

$\mathrm{J}=$ number of set of data $=1$

$R=$ radius of the tube $=11.0$ (inches)

$T=$ thickness of the tube $=0.3125$ (inches)

(see Appendix IX B, line 38)

Second reading. (Format statement $\# 20$ )

$\mathrm{X}(\mathrm{N})$, by turns, equals

$\mathrm{x}_{1}=0.0, \mathrm{x}_{1}=0.34, \mathrm{x}_{3}=0.78, \mathrm{x}_{4}=1.18, \mathrm{x}_{5}=1.31, \mathrm{x}_{6}=1.57$

(see Appendix IX B. lines 38 to 44)

Third reading. (Format statement $\$ 40$ )

$Y(N)$, by turns, equals

$\mathrm{Y}_{1}=0.26, \mathrm{Y}_{2}=0.34, \mathrm{Y}_{3}=0.19, \mathrm{Y}_{4}=0.14, \mathrm{Y}_{5}=0.12, \mathrm{Y}_{6}=0.02$

(see Appendix IX b, lines 45 to 50)

B) For areas of forces above the $\mathrm{Z}$ axis.

The same approach will lead to the input presented in Appendix IX $B$, line 1 to line 37 . 